\title{
The Impact of Diffuse Large B-Cell Lymphoma on Primary Care and Costs of Chronic Conditions in Elderly Medicare Beneficiaries
}

Rahul Garg

Follow this and additional works at: https://researchrepository.wvu.edu/etd

\section{Recommended Citation}

Garg, Rahul, "The Impact of Diffuse Large B-Cell Lymphoma on Primary Care and Costs of Chronic Conditions in Elderly Medicare Beneficiaries" (2017). Graduate Theses, Dissertations, and Problem Reports. 5649.

https://researchrepository.wvu.edu/etd/5649

This Dissertation is protected by copyright and/or related rights. It has been brought to you by the The Research Repository @ WVU with permission from the rights-holder(s). You are free to use this Dissertation in any way that is permitted by the copyright and related rights legislation that applies to your use. For other uses you must obtain permission from the rights-holder(s) directly, unless additional rights are indicated by a Creative Commons license in the record and/ or on the work itself. This Dissertation has been accepted for inclusion in WVU Graduate Theses, Dissertations, and Problem Reports collection by an authorized administrator of The Research Repository @ WVU.

For more information, please contact researchrepository@mail.wvu.edu. 


\title{
The Impact of Diffuse Large B-Cell Lymphoma on Primary Care and Costs of Chronic Conditions in Elderly Medicare Beneficiaries
}

\author{
Rahul Garg \\ Dissertation submitted to the \\ School of Pharmacy \\ at West Virginia University
}

in partial fulfillment of the requirements for the degree of

Doctor of Philosophy in

Health Services and Outcomes Research

Kimberly M. Kelly, Ph.D., Chair

Usha Sambamoorthi, Ph.D.

Xi Tan, Ph.D.

Soumit K. Basu, MD, Ph.D.

Treah Haggerty, MD

Department of Pharmaceutical Systems and Policy

Morgantown, West Virginia 2017

Keywords: Non-Hodgkin's Lymphoma, Diffuse Large B Cell Lymphoma, primary care physician visits, mammography, bone density testing, cost of chronic conditions

Copyright 2017 Rahul Garg 


\section{ABSTRACT \\ The Impact of Diffuse Large B-Cell Lymphoma on Primary Care and Costs of Chronic Conditions in Elderly Medicare Beneficiaries}

\section{Rahul Garg}

Diffuse Large B-Cell Lymphoma (DLBCL) is an aggressive form of Non-Hodgkin's lymphoma with a median age of diagnosis of 67 years. The intensive treatment of DLBCL can negatively influence elderly patients' preventive and chronic care, which can increase the costs of different chronic conditions. DLBCL diagnosis and treatment can affect patients' visits to their primary care providers (PCPs) and other specialists, which are important for patients' preventive screenings and chronic care. Further, having DLBCL increases the risk for breast cancer, and DLBCL treatment is associated with cardiotoxicity and increases the risk of osteoporosis and fractures. Thus, mammography and bone mineral density testing (BDT) are critical areas of screening for individuals with DLBCL, and a change in visits to PCPs can affect preventive and chronic care. Along with these challenges to care quality in DLBCL patients, the costs of different chronic conditions may increase. Currently, there is a dearth of studies that have examined visits to PCPs and specialists, preventive screenings, and costs of chronic conditions among DLBCL patients as compared to individuals with no cancer. We conducted this study to reduce this knowledge gap and to provide actionable strategies to improve the preventive care and reduce the costs of DLBCL patients. The three specific aims of this study were to: 1) analyze the impact of DLBCL on visits to PCPs and specialists over a three-year period of DLBCL diagnosis, treatment, and follow-up; 2) examine the receipt of mammography and BDT by female DLBCL patients during two years after DLBCL diagnosis; and 3) examine the costs of common chronic conditions and total cost over a three-year period of DLBCL diagnosis, treatment, and follow-up among fee-for-service elderly Medicare beneficiaries with 
newly diagnosed DLBCL as compared to Medicare beneficiaries without cancer. We used a retrospective longitudinal study design for aim 1 and aim 3; and a cross-sectional design for aim 2 of this study. We used Surveillance, Epidemiology and End Results (SEER) program (20022013) data linked with Medicare administrative claims and the Area Health Resource Files. In the first aim, DLBCL patients $(n=5,455)$ were more likely to visit PCPs (AOR [95\%CI]: 1.25 $[1.18,1.31])$ and had a greater number of visits to PCPs $(\beta$, SE: $0.384,-0.014)$ than non-cancer patients $(n=14,770)$. Further, DLBCL patients were more likely to have any visit to a cardiologist (AOR [95\%CI]: $1.40[1.32,1.47])$, endocrinologist $(1.43,[1.21,1.70])$, and pulmonologist $(1.51[1.36,1.67])$ than non-cancer patients. Among DLBCL patients, the number of PCP visits markedly increased during the treatment period compared to the baseline period ( $\beta$, SE: $0.491,-0.028)$ and then decreased to baseline levels $(-0.464,-0.022)$. In the second aim, although DLBCL and its treatment increase the risk of breast cancer and bone density loss, mammography and BDT did not differ between women with DLBCL (mammography: 59.8\%, BDT: $18.5 \%$ ) and no cancer (mammography: 60.2\%, BDT: 19.6\%; $>$ > .05). After adjusting for PCP visits, DLBCL patients were less likely to have mammography (AOR [95\%CI]: 0.82 [0.71, 0.94]) and BDT $(0.80[0.71,0.90])$ than non-cancer patients. Further, those with more primary care physician visits were more likely to have mammography $(1.62[1.48,1.77])$ and BDT $(1.60$ $[1.50,1.71])$. In the third aim, the net total cost of DLBCL patients increased substantially during the treatment period $(\$ 60,746.1)$. DLBCL patients had significantly higher cost of heart conditions but lower costs of hypertension, asthma/chronic obstructive pulmonary disease, any mental illness, and diabetes than non-cancer patients (all $\mathrm{p}<.001)$. To summarize, our study found that the visits to PCPs and specialists were much higher for DLBCL than non-cancer patients, which drastically increased during the DLBCL treatment period for chronic care. 
Treatment adverse effects and more frequent contact with healthcare system may have increased the visits to PCPs and specialists. Female DLBCL patients received lower preventive care, which may be due to prioritization of DLBCL treatment. There is a need to increase the recommendations for mammography and $\mathrm{BDT}$ to reduce the morbidity and mortality from breast cancer and fractures. DLBCL treatment cardiotoxicity may have increased the cost of heart conditions, while suboptimal care may have reduced the short term costs of other common chronic conditions. Interventions are needed to increase the preventive and chronic care among elderly DLBCL patients. 


\section{Acknowledgement}

I thank Dr. Kimberly Kelly for not only serving as my dissertation committee chair, but also being an excellent mentor throughout the PhD program. I thank her for helping me improve my research and writing skills and giving me the freedom to pursue my research interests. I am also highly thankful to Dr. Usha Sambamoorthi for teaching me database analysis, advanced statistical techniques, and being a very helpful teacher. I was very fortunate to have worked on numerous projects with her which highly advanced my skills as health outcomes researcher. I want to thank my other committee members, Drs Xi Tan, Soumit K. Basu, and Treah Haggerty for their kind support and wise advice during the dissertation process. I want to thank Dr. Suresh Madhavan for being a supportive department chair and always being there when I needed help. I would also like to thank the WVU family: Dr. Ginger Scott, Dr. Nilanjana Dwibedi, Angie Frame, and all of my friends and colleagues for their support and making my time spent at WVU very memorable. Finally, although words are not enough to thank one's family and friends, I want to thank my mom for her sacrifices she made to make me what I am today. I also want to acknowledge love and support of my dad, sister, brother, and fiancé during high and low of my graduate studies. 


\section{Table of Contents}

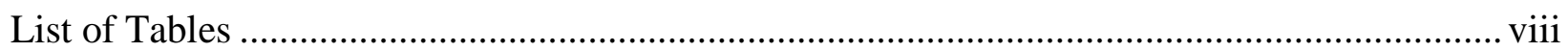

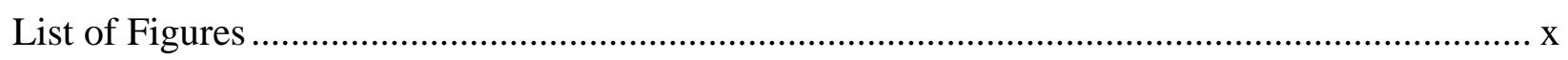

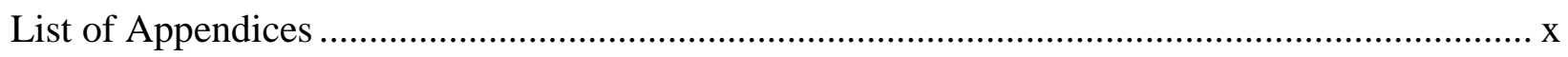

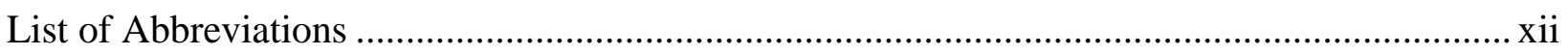

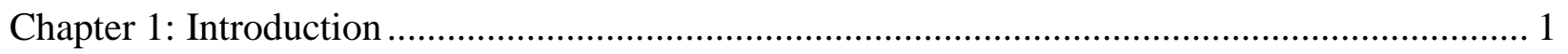

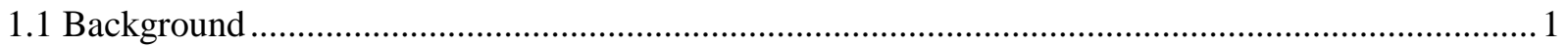

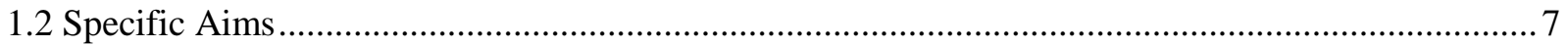

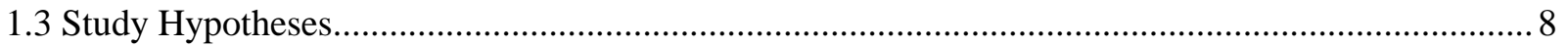

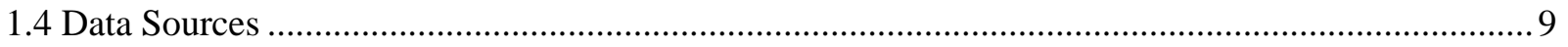

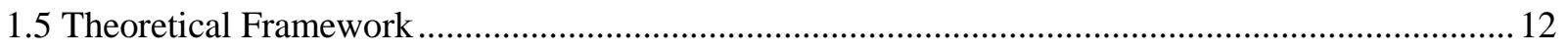

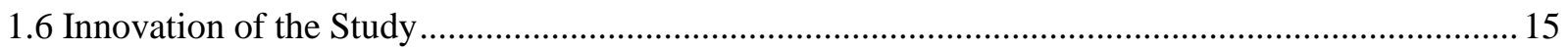

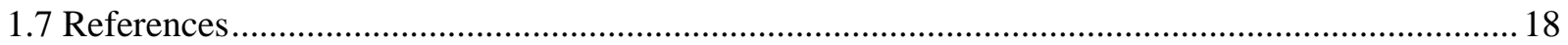

Chapter 2: Impact of Diffuse Large B-Cell Lymphoma on Visits to Different Provider Specialties among Elderly Medicare Beneficiaries: Challenges for Care Coordination ................................. 26

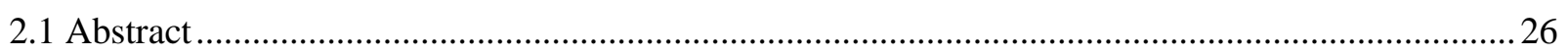

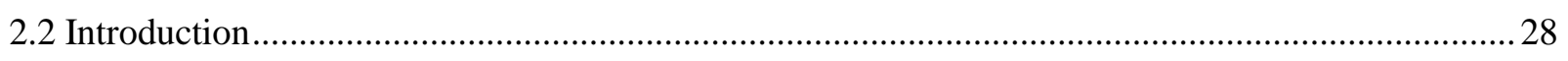

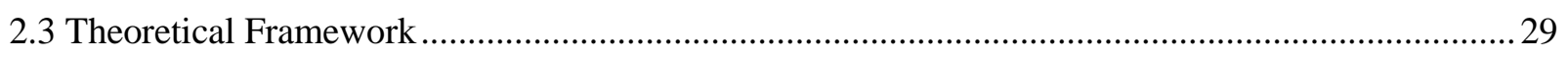

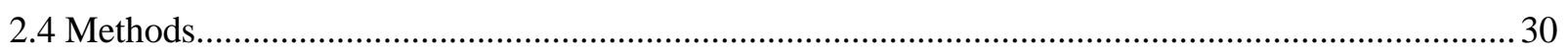

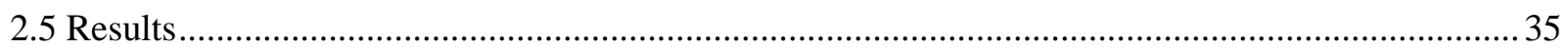

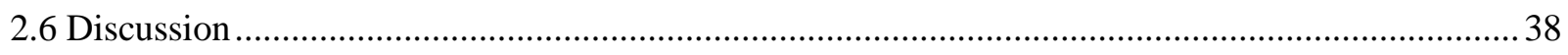

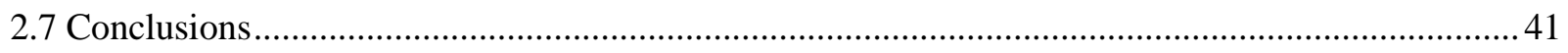

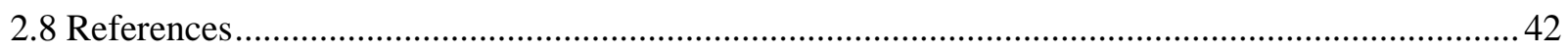

Chapter 3: Receipt of Mammography and Bone Density Testing by Women with Diffuse Large

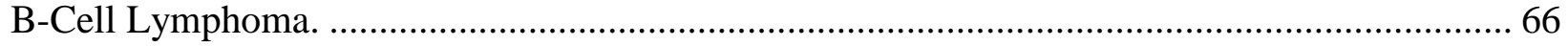

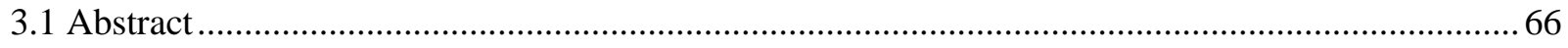

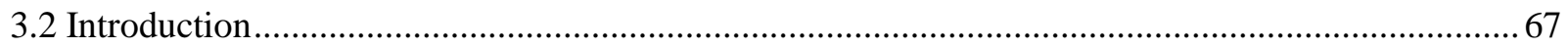

3.3 Theoretical Framework ……………………………………………………………..... 69

3.4 Methods

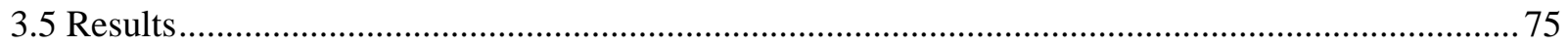

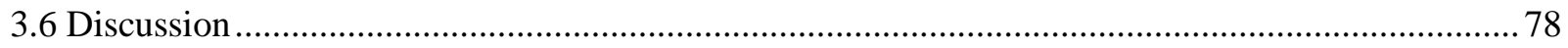

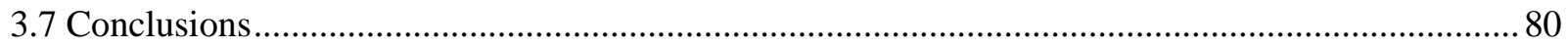

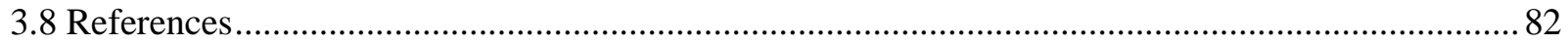


Chapter 4: Impact of Diffuse Large B-Cell Lymphoma on the Costs of Chronic Conditions in

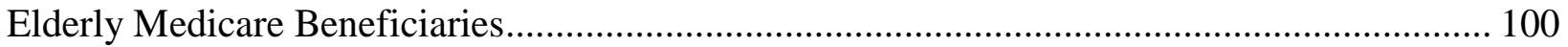

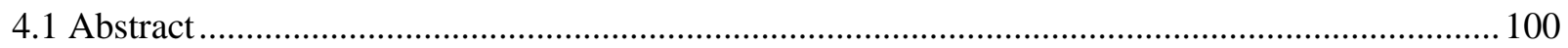

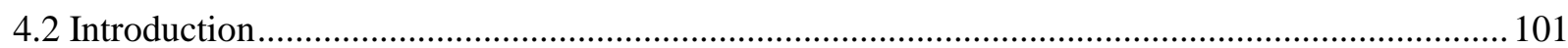

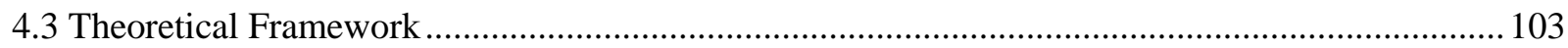

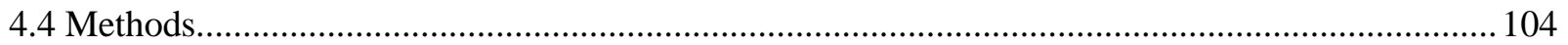

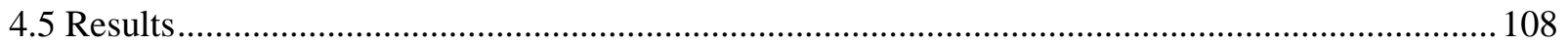

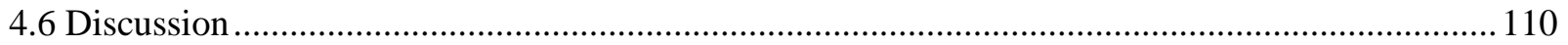

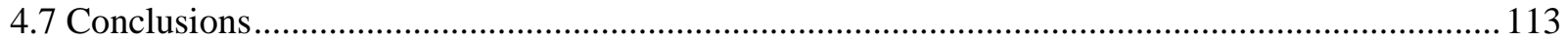

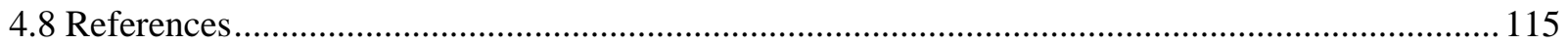

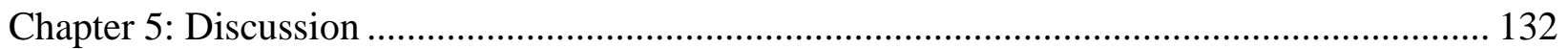

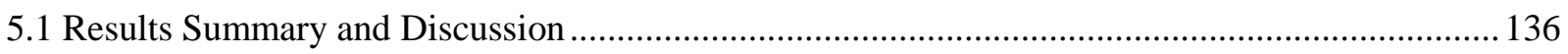

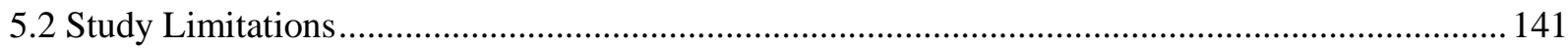

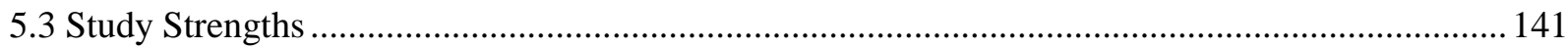

5.4 Conclusions and Research Implications ............................................................................... 142

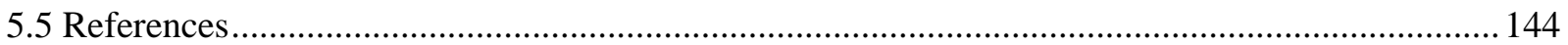




\section{List of Tables}

Table 1.1 Selected Preventive Care Services for Adults over 65 years of Age 5

Table 2.1 Description of Selected Characteristics of Elderly Medicare Beneficiaries with Diffuse Large B-Cell Lymphoma (DLBCL) and Non-Cancer Patients before and after Inverse Probability Treatment Weights. Surveillance Epidemiology and End Results Program (SEER) Medicare 2003-2011.

Table 2.2 Unadjusted and Adjusted Parameter Estimates of DLBCL vs No Cancer from Hurdle Models on Any Visit to PCP and Number of PCP Visits with Inverse Probability Treatment Weights. Surveillance Epidemiology and End Results Program (SEER)-Medicare 2003-2011.. 51

Table 2.3 Unadjusted and Adjusted Estimates from Logistic Regression with Generalized Estimating Equation on Any Visit to Other Medical Specialists with Inverse Probability Treatment Weights. Surveillance Epidemiology and End Results Program (SEER)-Medicare 2003-2011.

Table 2.4 Unadjusted and Adjusted Estimates from Negative Binomial Regressions with Generalized Estimating Equation on Number of Visits to Primary Care Physicians (PCPs) among elderly with Diffuse Large B-Cell Lymphoma (DLBCL). Surveillance Epidemiology and End Results Program (SEER)-Medicare 2003-2011.

Table 3.1 Description of Selected Characteristics of Female Medicare Beneficiaries above 65 Years of Age with Diffuse Large B-Cell Lymphoma (DLBCL) and No Cancer before and after Inverse Probability Treatment Weights. Surveillance Epidemiology and End Results Program (SEER) - Medicare 2003-2011.

Table 3.2 Unadjusted Differences and Adjusted Odds Ratios for Screening Mammography by Selected Characteristics of Female Medicare Beneficiaries between 66-74 years of age after Inverse Probability Treatment Weights. Surveillance Epidemiology and End Results Program (SEER) - Medicare 2003-2011.

Table 3.3 Unadjusted Differences and Adjusted Odds Ratios for Bone Density Testing by Selected Characteristics of Female Medicare Beneficiaries above 65 years of Age after Inverse Probability Treatment Weights. Surveillance Epidemiology and End Results Program (SEER) -

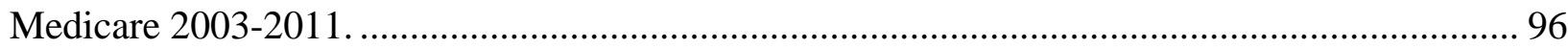

Table 4.1 Description of Mean Total Cost and Cost of Chronic Conditions among Medicare Beneficiaries with Diffuse Large B-Cell Lymphoma (DLBCL) during 12 Months after Cancer

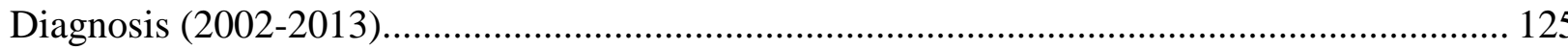

Table 4.2 Differences in Total Cost and Cost of Chronic Conditions between Medicare Beneficiaries with Diffuse Large B-Cell Lymphoma (DLBCL) and Beneficiaries without Cancer (2002-2013)......

Table 4.3 Description of Cost of Common Chronic Conditions among Medicare Beneficiaries with Diffuse Large B-Cell Lymphoma (DLBCL) and Beneficiaries without Cancer (2002-2013). 
Table 4.4 Parameter Estimates from Generalized Estimating Equations on Cost of Chronic Conditions among Medicare Beneficiaries with Diffuse Large B-Cell Lymphoma (DLBCL) as compared to Beneficiaries without Cancer (2002-2013)............................................................ 130 


\section{List of Figures}

Figure 1.1 Social-Ecological Model of Health Behavior. 14

Figure 2.1 Differences in Any Visit to Primary Care Physician and Other Medical Specialists between Elderly Medicare Beneficiaries with Diffuse Large B-Cell Lymphoma and No Cancer. SEER Medicare 2003-2011.

Figure 2.2 Unadjusted and Adjusted Differences in Average Number of Visits to Primary Care Physicians between Elderly Medicare Beneficiaries with Diffuse Large B-Cell Lymphoma and No Cancer. SEER Medicare 2003-2011.

Figure 4.1 Change in Cost of Heart Conditions and Cost of All Chronic Conditions among Medicare Beneficiaries with Diffuse Large B-Cell Lymphoma (DLBCL) and Beneficiaries without Cancer (2002-2013).

\section{List of Appendices}

Appendix 2.1 Flowchart of Sample Selection for Elderly Medicare Beneficiaries with Diffuse Large B-Cell Lymphoma.

Appendix 2.2 Flowchart of Sample Selection for Elderly Medicare Beneficiaries with No

Cancer.

Appendix 2.3 Adjusted Estimates from Logistic Regressions on Diffuse Large B-Cell Lymphoma vs. No Cancer by Selected Characteristics of Elderly Medicare Beneficiaries. Surveillance Epidemiology and End Results Program (SEER)-Medicare 2003-2011. 58

Appendix 2.4 Adjusted Parameter Estimates from Hurdle Models on Any Visit to PCP and Number of PCP Visits with Inverse Probability Treatment Weights. Surveillance Epidemiology and End Results Program (SEER) Medicare 2003-2011.

Appendix 2.5 Adjusted Parameter Estimates from Logistic Regression with Generalized Estimating Equations on Any Visit to Other Medical Specialists with Inverse Probability Treatment Weights. Surveillance Epidemiology and End Results Program (SEER) Medicare 2003-2011.

Appendix 2.6 Adjusted Estimates from Negative Binomial Regression with Generalized Estimating Equation on Number of PCP Visits with Inverse Probability Treatment Weights among Elderly with Diffuse Large B-Cell Lymphoma. Surveillance Epidemiology and End Results Program (SEER) Medicare 2003-2011.

Appendix 3.1 Flowchart of Sample Selection for Female Medicare Beneficiaries with Diffuse Large B-Cell Lymphoma. .... 98

Appendix 3.2 Flowchart of Sample Selection for Female Medicare Beneficiaries with No Cancer. 
Appendix 4.1 Description of One-Year Total Cost and Cost of Chronic Conditions among Medicare Beneficiaries $\geq 66$ Years of Age without Cancer (2002-2013). ............................. 132

Appendix 4.2 Parameter Estimates from Generalized Estimating Equations on Cost of Chronic Conditions among Medicare Beneficiaries with Diffuse Large B-Cell Lymphoma $\geq 66$ Years of Age (2002-2013). 


\section{List of Abbreviations}

\begin{tabular}{|c|c|}
\hline AHRF & Area Health Resource File \\
\hline BDT & Bone Mineral Density Testing \\
\hline CMS & Center for Medicare and Medicaid \\
\hline COPD & Chronic Obstructive Pulmonary Disease \\
\hline DLBCL & Diffuse Large B-Cell Lymphoma \\
\hline DME & Durable Medical Equipment \\
\hline ESRD & End Stage Renal Disease \\
\hline FIPS & Federal Information Processing Standard \\
\hline FQHC & Federal Qualified Health Centers \\
\hline GEE & Generalized Estimating Equations \\
\hline HCFA & Health Care Financing Administration \\
\hline $\mathrm{HCPCS}$ & Healthcare Common Procedure Coding System \\
\hline HHA & Home Health Agencies \\
\hline HMO & Health Maintenance Organizations \\
\hline ICD-9-CM & $\begin{array}{l}\text { International Classification of Diseases, Ninth Revision, Clinical } \\
\text { Modification }\end{array}$ \\
\hline ICD-O-3 & $\begin{array}{l}\text { International Classification of Diseases for Oncology - Third } \\
\text { Revision }\end{array}$ \\
\hline IOM & Institute of Medicine \\
\hline IPTW & Inverse Treatment Probability Treatment Weights \\
\hline MEDPAR & Medicare Provider Analysis and Review \\
\hline $\mathrm{NCH}$ & National Claims History \\
\hline $\mathrm{NCI}$ & National Cancer Institute \\
\hline NHL & Non-Hodgkin's Lymphoma \\
\hline PCP & Primary Care Physicians \\
\hline PDE & Part D Event \\
\hline PEDSF & Patient Entitlement and Diagnosis Summary File \\
\hline PET-CT & Positron Emission Tomography/Computed Tomography \\
\hline $\mathrm{R}-\mathrm{CHOP}$ & $\begin{array}{l}\text { Rituximab plus Cyclophosphamide, Doxorubicin, Vincristine, and } \\
\text { Prednisone }\end{array}$ \\
\hline SEER & Surveillance Epidemiology and End-Results Program \\
\hline SEM & Social Ecological Model \\
\hline US & United States \\
\hline USPSTF & US Preventive Services Task Force \\
\hline
\end{tabular}




\section{Chapter 1: Introduction}

\subsection{Background}

Diffuse Large B-Cell Lymphoma (DLBCL) is an aggressive and the most common subtype of Non-Hodgkin's Lymphoma, accounting for about 30-40\% of all newly diagnosed cases. ${ }^{1}$ Newly diagnosed DLBCL requires intensive treatment with chemo-immunotherapy, radiotherapy, or stem cell transplant. ${ }^{2,3}$ Due to these treatments, many DLBCL cases $(\sim 60 \%)$ are cured and DLBCL patients have a 5-year survival rate of $60.5 \% .^{1,4}$ However, aggressive treatment of DLBCL can lead to many adverse consequences ${ }^{5}$ such as secondary cancers, ${ }^{6}$ posttraumatic stress, ${ }^{7}$ and poor quality of life. ${ }^{8}$ Further, most DLBCL patients are above 65 years of age,${ }^{910}$ who have at least one $(82.0 \%)$ or two or more $(67.3 \%)$ chronic physical and mental conditions (multimorbidity). ${ }^{11,12}$ The National Cancer Institute (NCI) comorbidity score, which measures the number and severity of 15 non-cancer comorbidities, ranged from 1-3 for a majority of DLBCL patients. ${ }^{3}$

The treatment side effects and presence of multiple chronic conditions require regular visits to multiple providers for chronic and preventive care. The role of multiple provider specialties in providing care to cancer patients has been emphasized by the Institute of Medicine (IOM) in its report on delivering high-quality cancer care. ${ }^{13}$ These different providers include oncologists (e.g., hematology, medical oncology, surgical oncology, and radiation oncology), primary care physicians (PCPs, e.g., general internal medicine, family medicine), other physician specialties (e.g., endocrinology, pulmonology, and ophthalmology - hereafter referred to as “other medical specialists"), nurses, and caregivers. ${ }^{13}$ A diagnosis of DLBCL can affect patients' 
visits to different provider specialties, thereby negatively affecting their chronic and preventive care. $^{14}$

Less chronic and preventive care can decrease the short term costs but increase the long term costs of chronic conditions, which has not been previously investigated. Elderly individuals with multiple chronic conditions bear a significant cost burden due to these multiple illnesses, which can be disproportionately affected by a diagnosis of cancer. DLBCL treatment increases the risk of breast cancer ${ }^{6,15}$ and osteoporosis ${ }^{16}$ and can increase the severity of other chronic conditions leading to higher costs. Conversely, prioritization of DLBCL treatment can eclipse patients' chronic care and can reduce the short term costs of certain chronic conditions. There is a lack of research on how DLBCL diagnosis affects patients' visits to different provider specialties, their preventive care, and the resulting costs of chronic conditions among elderly Medicare beneficiaries with DLBCL. Therefore, the overall goal of this dissertation is to analyze the impact of newly diagnosed DLBCL on visits to PCPs and specialists, preventive care, and costs of chronic conditions among Medicare beneficiaries with DLBCL as compared to beneficiaries without cancer.

The dissertation is organized in five chapters. Chapter 1 briefly describes the epidemiology and treatment of DLBCL, need for this study, data sources, and the theoretical framework used for this study. Chapter 2 focuses on the change in visits to PCPs and other medical specialists over a 3-year period of DLBCL diagnosis, treatment, and follow-up among DLBCL patients as compared to those without cancer. Chapter 3 describes the receipt of mammography and bone mineral density testing (BDT) among women with DLBCL as compared to women without cancer. Chapter 4 highlights the impact of DLBCL on the costs of common chronic conditions and total cost before DLBCL diagnosis, during DLBCL treatment, 
and at follow-up periods among DLBCL patients as compared to those without cancer. Finally, chapter 5 summarizes the findings from chapter 2, 3, and 4 and includes the implications and recommendations for future research. Chapter 5 also consists of the limitations and strengths of this study.

\subsubsection{Epidemiology of DLBCL}

Non-Hodgkin's Lymphoma (NHL) is the most prevalent hematologic cancer in the US with 72,240 new cases diagnosed in $2017 .{ }^{17}$ DLBCL is the most common subtype of NHL, accounting for about one-third of NHL cases. ${ }^{1}$ The incidence of DLBCL is approximately 7 cases per 100,000 individuals in the United States (US). ${ }^{18}$ Similar to most other subtypes of NHL, DLBCL is more prevalent in males (55\%) than females. The incidence of DLBCL increases with age, with the median age of diagnosis being 67 years. ${ }^{9}$ However, African Americans are more likely to be diagnosed at $\leq 60$ years of age (65\%) than Whites $(37 \%) .{ }^{19}$ Most DLBCL cases with localized disease and approximately half of those with advanced stage disease are cured by treatment, which leads to a moderate five-year survival rate of $60.5 \% .^{3}$ The survival rates have been found to be better for women (61\%) than men (58\%) and for Whites $(60 \%)$ than African Americans (50\%). ${ }^{19}$ Age at diagnosis $>60$ years, African American race, male sex, and advanced stage are associated with worse survival among DLBCL patients. ${ }^{19}$

\subsubsection{Treatment of DLBCL}

The overall treatment period of DLBCL among elderly patients lasts for approximately six months from the date of DLBCL diagnosis. ${ }^{3}$ The treatment pattern for elderly patients with

DLBCL includes chemo-immunotherapy (49\%), chemotherapy only (23\%), immunotherapy only (5\%), or no treatment (23\%) depending upon the stage of cancer and patient's age. ${ }^{3}$ About 30$40 \%$ of DLBCL patients present with limited stage (Ann Arbor stage I or II) disease. ${ }^{19}$ These 
patients are usually treated with chemo-immunotherapy (3-6 cycles) using R-CHOP (cyclophosphamide, doxorubicin, vincristine, and prednisone plus rituximab) with or without radiotherapy. ${ }^{3,20}$ Advanced stage DLBCL (60-70\% cases) are given six cycles of R-CHOP or are recommended to be enrolled in a clinical trial. Radiotherapy to treat initially bulky disease (neoadjuvant chemotherapy) may also be employed for advanced DLBCL. If responsive, the patients are observed for disease progression with positron emission tomography/computed tomography (PET-CT) scan. All refractory or relapsed cases are considered for high dose chemotherapy with either autologous (patient's) or allogeneic (someone else's) stem cell transplant. ${ }^{20}$

\subsubsection{Visits to PCPs and Other Medical Specialists by DLBCL Patients}

The adverse sequelae of DLBCL treatments and presence of multimorbidity in elderly DLBCL patients call for regular visits to PCPs and other medical specialists during and after the DLBCL treatment period. The patient's PCP or other medical specialist might have a better knowledge of patient's pre-existing chronic conditions, and they may be more effective in providing care for his/her chronic conditions. Other important roles of PCPs and other medical specialists for cancer patients include helping with treatment decisions, providing psychosocial support, and continuing preventive and chronic care. ${ }^{21}$ The IOM has emphasized the role of multiple providers and caregivers in providing high-quality cancer care during and after the cancer treatment period. ${ }^{13}$

Although physicians trained in family medicine or general internal medicine typically serve as PCPs, other medical specialists such as cardiologists, pulmonologists, or endocrinologists, assume an important role in providing health care to elderly individuals, due to the variety of chronic diseases that may be present (e.g., heart disease, chronic obstructive pulmonary disease, diabetes). Regular visits to PCPs and other medical specialists are 
recommended for elderly individuals with chronic physical and mental conditions, which should not be interrupted during the DLBCL treatment and follow-up periods. ${ }^{22,23}$ However, there is a lack of studies on the impact of DLBCL diagnosis and treatment on the visits to PCPs and other medical specialists.

\subsubsection{Preventive Care of DLBCL Patients}

As outlined by the US Preventive Services Task Force (USPSTF), clinical preventive services for elderly individuals include a wide range of screenings for chronic diseases and immunizations $^{24}$ (Table 1.1). Despite being covered by Medicare, less than half of elderly above 65 years of age have been found to be up-to-date with recommended clinical preventive services. ${ }^{25}$ Receipt of preventive services, specifically mammography and BDT, is critical for women with DLBCL because of their heightened risk of breast cancer and osteoporosis. $5,6,15,16$ Timely mammography screening and BDT can lead to early diagnosis of breast cancer and can reduce the risk of fractures in female DLBCL patients. ${ }^{26,27}$ Hence, it is important to assess the receipt of mammography and BDT among elderly women with newly diagnosed DLBCL as compared to women without cancer.

Table 1.1 Selected Preventive Care Services for Adults over 65 years of Age

\begin{tabular}{|l|}
\hline \multicolumn{1}{|c|}{ U.S. Preventive Services Task Force Screening Recommendations } \\
\hline 1. Screening for Breast Cancer: Using Film Mammography \\
Individualize decision to begin biennial screening according to the patient's circumstances and \\
values - Women aged 40-49 years. \\
Biennial screening for women aged 50-74 years. \\
Women aged $\geq 75$ years - Evidence of benefit is lacking. \\
\hline$\underline{\text { 2. Screening for Prostate Cancer }}$ \\
Adult males - Do not use prostate-specific antigen (PSA)-based screening for prostate cancer \\
(2012). \\
In 2008, the USPSTF had recommended against PSA-based screening for men 75 years and \\
older in 2008. \\
\hline$\underline{\text { 3. Screening for Osteoporosis using dual-energy X-ray absorptiometry of the hip and lumbar }}$ \\
$\underline{\text { spine. }}$
\end{tabular}


Evidence is lacking about optimal intervals for repeated screening.

Women age $\geq 65$ years without previous known fractures or secondary causes of osteoporosis. Men without previous known fractures or secondary causes of osteoporosis - No recommendation.

Advisory Committee on Immunization Practices-Recommended Immunizations

4. Annual vaccination for Influenza - All adults

The receipt of screening and preventive health services has been found to vary by the type of provider seen. Breast cancer patients with outpatient visits to a gynecologist or a PCP were found more likely to undergo mammograms. ${ }^{28}$ A study by Earle et al. found that the breast cancer patients who visited oncologists were more likely to receive mammography while those who visited a PCP were more likely to receive non-cancer related preventive services such as flu vaccine, lipid testing, and bone densitometry. ${ }^{29}$ Similarly, colorectal cancer patients who visited both PCP and oncologist were more likely to receive appropriate follow-up care for heart failure, diabetes care, and other preventive services. ${ }^{30-33}$ Although existing studies have examined the receipt of preventive care services in patients with breast and colorectal cancer, there is a lack of research on the association of PCP visits with preventive care of patients with DLBCL.

\subsubsection{Costs of Chronic Conditions for DLBCL Patients}

Medicare beneficiaries with multiple chronic conditions bear a disproportionate burden of costs of care. ${ }^{11}$ For example, $36 \%$ of Medicare Part A enrollees have $\geq 2$ chronic conditions; however these enrollees account for $86 \%$ of total Part A expenditures. ${ }^{34}$ Similarly, $41 \%$ of Medicare Part B enrollees have $\geq 2$ chronic conditions; but these enrollees account for approximately $70 \%$ of Part B payments. ${ }^{34}$ The cost burden of chronic conditions can be significantly increased by the diagnosis of DLBCL, which increases the risk and severity of certain chronic conditions. DLBCL patients are more likely to have osteoporosis and fractures due to chemotherapy and stem cell transplant. ${ }^{16,35,36}$ Also, the cardiotoxicity of chemotherapy 
can worsen heart conditions, leading to an increase in costs of these conditions. ${ }^{37}$ However, the prioritization of cancer care can reduce the care provided for chronic conditions. For example, patients with colorectal cancer received lower care for heart conditions, diabetes, and Chronic Obstructive Pulmonary Disease (COPD), ${ }^{38,39}$ which can decrease the short term cost of these conditions. There is a paucity of studies that have investigated the cost of chronic conditions among cancer survivors as compared to those without cancer. Also, evidence is lacking on the change in cost of chronic conditions before cancer diagnosis, during cancer treatment, and at follow-up periods.

Cost estimates of chronic conditions at different phases of cancer care are critical for resource allocation and setting benchmarks for cost reduction, as supported by the 'Oncology Care Model, a new payment and delivery model from the Center for Medicare \& Medicaid Innovation, which aims to increase the quality while reducing the cost of cancer care. ${ }^{40}$ Our study will examine the cost of specific chronic conditions and total costs of care, which will assist in implementing these innovative models of cancer care.

\subsection{Specific Aims}

The specific aims of this dissertation are as follows:

Specific Aim 1. To examine the impact of DLBCL diagnosis on the visits to PCPs and, among those with chronic conditions, visits to other medical specialists among Medicare beneficiaries with DLBCL as compared to beneficiaries without cancer.

- Objective 1.1: To examine the impact of DLBCL diagnosis on the visits to PCPs and other medical specialists among elderly Medicare beneficiaries $\geq 66$ years of age with DLBCL as compared to beneficiaries without cancer.

- Objective 1.2: To examine the change in visits to PCPs and other medical specialists before cancer diagnosis, during cancer treatment, and at follow-up periods among elderly Medicare beneficiaries $\geq 66$ years of age with DLBCL as compared to beneficiaries without cancer. 
Specific Aim 2. To examine the receipt of mammography and BDT by female Medicare beneficiaries with DLBCL as compared to female beneficiaries without cancer.

- Objective 2.1: To investigate the receipt of mammography and the association of PCP visits with mammography rates among female Medicare beneficiaries with DLBCL between 66 and 74 years of age as compared to those without cancer.

- Objective 2.2: To investigate the receipt of BDT and the association of PCP visits with BDT rates among female Medicare beneficiaries with DLBCL $\geq 66$ years of age as compared to those without cancer.

Specific Aim 3. To evaluate the impact of DLBCL on the costs of common chronic conditions and total costs among elderly Medicare beneficiaries with DLBCL as compared to those without cancer.

- Objective 3.1: To evaluate the change in costs of specific chronic conditions before cancer diagnosis, during cancer treatment, and at follow-up periods among Medicare beneficiaries with DLBCL as compared to those without cancer.

- Objective 3.2: To evaluate the change in total costs before cancer diagnosis, during cancer treatment, and at follow-up periods among Medicare beneficiaries with DLBCL as compared to those without cancer.

\subsection{Study Hypotheses}

Aim 1 A previous study among breast cancer patients found that face-to-face visits with PCPs increased during the active treatment phase as compared to the period before cancer diagnosis. ${ }^{41}$ Further, visits to PCPs by colorectal patients have been found to increase during the follow-up period after the cancer treatment is over, as compared to the pre-treatment period. ${ }^{42,43}$ Based on the results of these studies, we hypothesized that visits to PCPs and other medical specialists will increase during both the cancer treatment and follow-up periods as compared to the baseline period because cancer patients may have higher healthcare needs during the treatment period. Aim 2 Cancer patients have been found to be more likely to have preventive screenings than non-cancer patients. For example, breast cancer patients were more likely to receive mammography (74.0\%) and BDT (8.3\%) than patients without cancer $(41.0 \%$ and $6.8 \%$, 
respectively). ${ }^{29}$ Similarly, colorectal cancer patients were more likely to receive a mammogram $(49.8 \%)$ than non-cancer patients $(47.4 \%) .{ }^{33}$ Hence, we hypothesized that women with DLBCL will be more likely to receive mammography and BDT than women without cancer.

Women cancer patients with higher visits to PCPs have been found to receive more preventive screenings. ${ }^{28,29,32}$ For example, breast cancer patients with more visits to PCPs were twice as likely to receive mammography ${ }^{28}$ and colorectal patients with more PCP visits were twice as likely to receive BDT. ${ }^{31}$ Hence, we hypothesized that patients with higher visits to PCPs will be more likely to receive mammography and BDT.

$\underline{\text { Aim } 3}$ Chemotherapy can worsen heart conditions in DLBCL patients. ${ }^{37}$ Also, stem cell transplant and chemotherapy can cause osteoporosis and fractures in DLBCL patients. ${ }^{16}$ Hence, for aim 3 we hypothesized that the cost of heart conditions, osteoporosis, and arthritis will increase during cancer treatment and short follow-up among DLBCL patients. According to previous studies, colorectal patients received lower care for diabetes and asthma/COPD. ${ }^{38} \mathrm{We}$ hypothesized that due to lower quality of care, the short term costs of other common chronic conditions such as diabetes, hypertension, and Asthma/COPD will decrease among DLBCL patients as compared to those without cancer.

\subsection{Data Sources}

We linked data from the following data sources for this study: 1) Surveillance Epidemiology and End-Results Program (SEER) cancer registries; 2) 5\% Medicare sample for patients without any cancer; 3) Medicare claims of SEER and non-cancer patients; and 4) the Area Health Resource File (AHRF).

\subsubsection{Surveillance Epidemiology and End-Results Program (SEER)}


The SEER is an epidemiologic surveillance system representing about $28 \%$ of the US population residing in 20 population-based tumor registries (Alaska Native Tumor Registry, Arizona Indians, Cherokee Nation-Oklahoma, Connecticut, Detroit, Atlanta-Georgia, Greater Georgia, Rural Georgia, San Francisco-Oakland, San Jose-Monterey, Greater California, Hawaii, Iowa, Kentucky, Los Angeles, Louisiana, New Jersey, New Mexico, Seattle-Puget Sound, and Utah). ${ }^{44}$ The SEER cancer registries collect information for all the newly diagnosed cancer cases such as patient's demographic characteristics, cancer site, date of cancer diagnosis, and cancer pathology (e.g., stage and grade). This information is included in the Patient Entitlement and Diagnosis Summary File (PEDSF).

\subsubsection{Medicare Sample of Non-Cancer Patients}

We also utilized a 5\% random sample of Medicare beneficiaries who did not have any cancer (except basal cell carcinoma) as the comparison group in this study. This sample of noncancer patients was derived from Medicare beneficiaries who resided in the SEER areas. The individuals in this sample who also appeared in the SEER data are removed.

\subsubsection{Medicare Claims}

As majority of cancer cases are diagnosed among the elderly population aged 65 years and above, SEER patients' Medicare claims can be utilized to obtain detailed information on medical treatment, chronic conditions, healthcare utilization, and expenditures. Medicare is the US government mandated insurance program for about $97 \%$ of the US population aged 65 years and above. ${ }^{45,46}$ The National Cancer institute (NCI) links SEER cases with Medicare enrolled patients using an individual's last name, first name, social security number, and date of birth. More than $95 \%$ of the Medicare beneficiaries are enrolled in Medicare Part A and Part B coverage. Medicare Part A reimburses the use of inpatient care in hospitals and skilled nursing 
facilities, home health care, and hospice care. Part B covers the use of physician and outpatient services. The Medicare beneficiaries enrolled in Health Maintenance Organizations (HMO) do not have all the information in their medical claims because these organizations are not mandated to submit all their service claims to the Center for Medicare and Medicaid (CMS). Hence, we excluded those Medicare beneficiaries who were enrolled in HMO at any time during the study period.

An encrypted identification number was provided for each Medicare beneficiary to link the PEDSF file from SEER with the Medicare files. The Medicare data consisted of Medicare Provider Analysis and Review (MEDPAR) files, the Carrier Claims (old name Physician/Supplier National Claims History (NCH)), Outpatient, Home Health Agencies (HHA), Hospice, Durable Medical Equipment (DME), and Part D Event (PDE). The MEDPAR file includes Medicare Part A claims records and the NCH and outpatient files consist of Part B claims for outpatient visits and physician services. Each claim record represents an episode of health service use and includes up to 12 diagnoses according to the International Classification of Diseases, Ninth Revision, Clinical Modification (ICD-9-CM), service dates, and payments made by the CMS. The carrier claims file includes the physician specialty associated with the service provided. The carrier claims and outpatient claims files also include procedure codes according to the Healthcare Common Procedure Coding System (HCPCS).

\subsubsection{Area Health Resources File (AHRF)}

The AHRF is a publicly available data file provided by the Department of Health and Human Services which contains information on more than 6,000 variables for each of the US counties. ${ }^{47}$ The AHRF contains data on the availability of health professionals, healthcare facilities, and socioeconomic and environmental characteristics of each county. We used the state 
and county Federal Information Processing Standard (FIPS) codes to link the AHRF files with the SEER-Medicare dataset to measure the county level inter-personal, healthcare system, and community factors.

\subsection{Theoretical Framework}

We utilized the Social Ecological Model (SEM) as the theoretical framework for this study (Figure 1.1). We chose this model because patients' visits to different provider specialties and use of mammography and BDT are influenced by both their personal characteristics as well as the surrounding social and organizational environments. Further, healthcare costs have been found to be a result of expenditure decisions made at micro (age, sex, health status) and macro (availability of hospitals, area poverty, area health insurance, travel time) levels. ${ }^{48}$ Hence, we utilized a multilevel SEM to examine the costs of chronic conditions among Medicare beneficiaries with DLBCL as compared to those without cancer.

The SEM is an overarching framework to investigate the interactions between diverse personal and socio-physical factors that impact health behavior. The SEM provides a framework to integrate multiple individual and contextual theories of health behavior and presents a more comprehensive approach to study and modify particular behaviors. ${ }^{49}$ This theoretical perspective will help us in examining the key personal and environmental factors that are significant predictors of patients' visits to a provider specialty and the receipt of preventive services.

According to the SEM, the following multiple levels influence a health behavior: (1) intra-personal factors: personal characteristics such as socio-demographics, chronic conditions, stage of cancer, and cancer treatments; (2) inter-personal factors: formal and informal social support systems and networks made of family, friends, and colleagues (e.g., racial isolation index and social or cultural cohesion); (3) Healthcare system factors: characteristics of healthcare 
system such as density of healthcare facilities and physicians; (4) community factors:

relationships among organizations within a larger political or geographical area, which can be understood by SEER region, urban/rural region, area poverty and education, and; (5) public policy: local, state, or federal policies and laws that support or inhibit certain health practices such as policies and recommendations of IOM and USPSTF regarding the role of different provider specialties in cancer care and recommendations for preventive services. ${ }^{50-52}$

There are five principles of $\left.\mathrm{SEM}^{49}: 1\right)$ Factors at multiple levels including intra-personal, inter-personal, healthcare system, community, and policy factors influence health behaviors. The relative effects of different factors vary with the particular behavior and context; 2) Contextual factors including physical and social environments of the individual are important determinants of health behavior; 3) Factors interact across multiple levels in modifying the health behavior. Various individual and contextual factors work together in promoting or inhibiting a health behavior; 4) Ecological models should be specific to the targeted behavior; and 5) Multilevel interventions implement changes at individual, organizational, environmental, and policy levels and hence, should be more effective than single level interventions. 


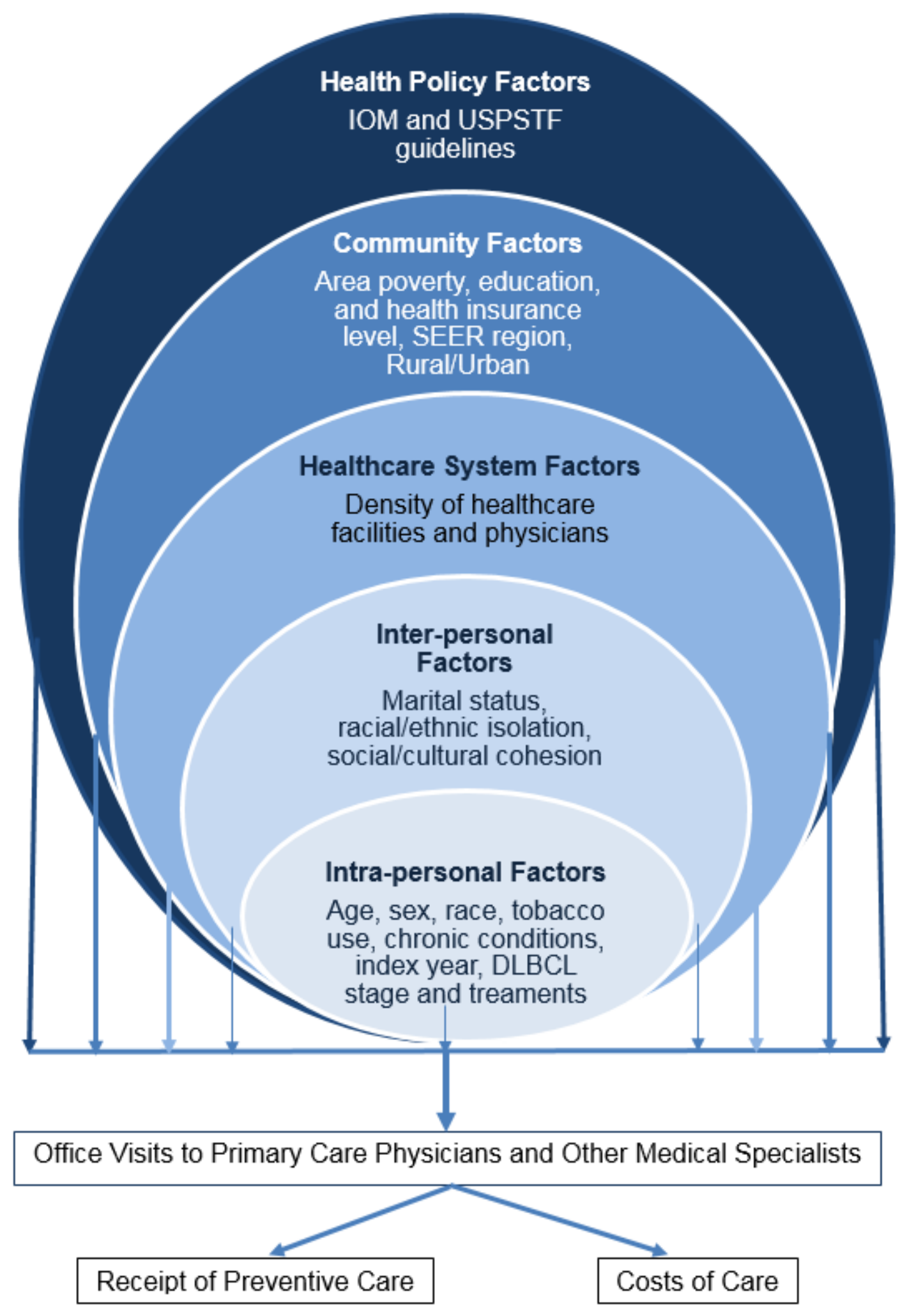

Figure 1.1 Social-Ecological Model of Health Behavior. 


\subsection{Innovation of the Study}

The visits to different provider specialties, receipt of preventive care, and the costs of care for DLBCL patients is largely unknown. Most previous studies examining the visits to different providers and preventive care have been conducted among patients with breast, colorectal, or prostate cancer during the follow-up period. There is a lack of research on the visits to PCPs, oncologists, and other medical specialists before cancer diagnosis, during cancer treatment, and at follow-up periods among patients with DLBCL. Specifically, our study will make the following novel contributions to literature:

1. Lack of evidence among patients with DLBCL. Most existing studies have evaluated visits to different providers and receipt of mammography and BDT among patients with common malignancies such as breast, colorectal, and prostate cancers. ${ }^{53-57}$ Forsythe and colleagues conducted a survey among NHL patients after 2-5 years of cancer diagnosis. ${ }^{58}$ Many NHL patients were found to visit oncologists, PCPs, and other medical specialists (46.6\%), while others saw only oncologists (12.9\%), oncologists plus PCPs (24.6\%), and oncologists plus other medical specialists $(15.9 \%)$ for cancer follow-up care in last one year. ${ }^{58}$ However, the study was conducted in a small patient population $(\mathrm{N}=363)$ in Los Angeles county. Further, the study by Forsythe et al. utilized self-reports of visits to providers which may be affected by recall bias. The study did not distinguish between the subtypes of NHL which have widely different prognosis and require different treatments. ${ }^{1}$ Our study examined the provider visits and receipt of preventive care by DLBCL patients, which is the most common subtype of NHL, by utilizing a national claims database of elderly Medicare beneficiaries with cancer. DLBCL is an aggressive form of cancer with unique treatments such as stem cell transplant. DLBCL can have a 
significant effect on the preventive care and costs, which is different from the effect of other malignancies.

2. Investigation of visits to specialists other than PCPs. Most past studies have focused on the roles of PCPs and oncologists only. A large proportion of cancer patients visit physicians of other medical specialties such as cardiologists, pulmonologists, and endocrinologists. ${ }^{59}$ Our study analyzed the visits to providers of all medical specialties at all the stages of cancer treatment and follow-up.

3. Impact of cancer diagnosis on costs of chronic conditions. We could not find a study that examined the change in costs of common chronic conditions during cancer diagnosis, treatment, and follow-up periods. Our study examined the costs of chronic conditions and total costs of DLBCL patients before diagnosis, during treatment, and at follow-up period to fill this gap in literature.

4. Visits to provider specialties during cancer treatment period. Most extant studies have examined the contact with physicians of different specialties and its effect on the outcomes of care after the cancer treatment period is over. There is limited evidence on the involvement of providers during the cancer treatment period. One study did not evaluate visits to physicians during cancer treatment period with an assumption that visits to PCPs will decrease. ${ }^{42}$ However, the IOM in its report on high quality cancer care, has emphasized the role of PCPs during the cancer treatment period. In order to better understand the role of different provider specialties during and after cancer treatment period, we examined the change in visits to physicians of different specialties before, during, and after the cancer treatment period. 
5. Use of Social Ecological Model of health behavior. Visits to different provider specialties, preventive services, and costs of care are affected by both the individual and environmental factors. The factors at higher societal and community level such as the racial/ethnic composition, availability of providers, and community education level have a significant effect on access to care and healthcare utilization. A contextualized investigation of visits to and care received from different provider specialties has been lacking in existing studies. We utilized the Social Ecological Model of Health Behavior as the multilevel model to take into account the multiple levels of factors in a systematic way. ${ }^{60}$ 


\subsection{References}

1. Shankland KR, Armitage JO, Hancock BW. Non-hodgkin lymphoma. The Lancet. 2012;380(9844):848-857.

2. Armitage JO. My treatment approach to patients with diffuse large B-cell lymphoma. . 2012;87(2):161-171.

3. Hamlin PA, Satram-Hoang S, Reyes C, Hoang KQ, Guduru SR, Skettino S. Treatment patterns and comparative effectiveness in elderly diffuse large B-cell lymphoma patients: A surveillance, epidemiology, and end results-medicare analysis. Oncologist. 2014;19(12):12491257. doi: 10.1634/theoncologist.2014-0113 [doi].

4. Vaidya R, Witzig TE. Prognostic factors for diffuse large B-cell lymphoma in the R(X)CHOP era. Ann Oncol. 2014;25(11):2124-2133. doi: 10.1093/annonc/mdu109 [doi].

5. Ng AK, LaCasce A, Travis LB. Long-term complications of lymphoma and its treatment. $J$ Clin Oncol. 2011;29(14):1885-1892. doi: 10.1200/JCO.2010.32.8427 [doi].

6. Pirani M, Marcheselli R, Marcheselli L, Bari A, Federico M, Sacchi S. Risk for second malignancies in non-hodgkin's lymphoma survivors: A meta-analysis. Ann Oncol. 2011;22(8):1845-1858. doi: 10.1093/annonc/mdq697 [doi].

7. Smith SK, Zimmerman S, Williams CS, Preisser JS, Clipp EC. Post-traumatic stress outcomes in non-hodgkin's lymphoma survivors. J Clin Oncol. 2008;26(6):934-941. doi: 10.1200/JCO.2007.12.3414 [doi]. 
8. Smith SK, Crespi CM, Petersen L, Zimmerman S, Ganz PA. The impact of cancer and quality of life for post-treatment non-Hodgkin lymphoma survivors. Psycho-Oncology. 2010;19(12):1259-1267.

9. Ries L, Melbert D, Krapcho M. SEER Cancer Statistics Review, 1975-2005.SEER website. 2015.

10. Shenoy PJ, Malik N, Nooka A, et al. Racial differences in the presentation and outcomes of diffuse large B-cell lymphoma in the united states. Cancer. 2011;117(11):2530-2540.

11. Lochner KA, Goodman RA, Posner S, Parekh A. Multiple chronic conditions among medicare beneficiaries: State-level variations in prevalence, utilization, and cost, 2011. Medicare \& medicaid research review. 2013;3(3).

12. Wolff JL, Starfield B, Anderson G. Prevalence, expenditures, and complications of multiple chronic conditions in the elderly. Arch Intern Med. 2002;162(20):2269-2276.

13. Levit L, Balogh E, Nass S, Ganz PA. Delivering high-quality cancer care:: Charting a new course for a system in crisis. National Academies Press; 2013.

14. Austin S, Martin MY, Kim Y, Funkhouser EM, Partridge EE, Pisu M. Disparities in use of gynecologic oncologists for women with ovarian cancer in the united states. Health Serv Res. 2013;48(3):1135-1153.

15. Sanna G, Lorizzo K, Rotmensz N, et al. Breast cancer in hodgkin's disease and non-hodgkin's lymphoma survivors. Ann Oncol. 2007;18(2):288-292. doi: mdl399 [pii]. 
16. Cabanillas ME, Lu H, Fang S, Du XL. Elderly patients with non-hodgkin lymphoma who receive chemotherapy are at higher risk for osteoporosis and fractures. Leuk Lymphoma. 2007;48(8):1514-1521.

17. American cancer society. What are the key statistics about non-hodgkin lymphoma? https://www.cancer.org/cancer/non-hodgkin-lymphoma/about/key-statistics.html. Accessed 02/24, 2017 .

18. Morton LM, Wang SS, Devesa SS, Hartge P, Weisenburger DD, Linet MS. Lymphoma incidence patterns by WHO subtype in the united states, 1992-2001. Blood. 2006;107(1):265276. doi: 2005-06-2508 [pii].

19. Shenoy PJ, Malik N, Nooka A, et al. Racial differences in the presentation and outcomes of diffuse large B-cell lymphoma in the united states. Cancer. 2011;117(11):2530-2540.

20. Zelenetz AD, Abramson JS, Advani RH, et al. NCCN clinical practice guidelines in oncology: Non-hodgkin's lymphomas. J Natl Compr Canc Netw. 2010;8(3):288-334.

21. Smith GF, Toonen TR. Primary care of the patient with cancer. Am Fam Physician. $2007 ; 75(8)$.

22. Javorsky E, Robinson A, Boer Kimball A. Evidence-based guidelines to determine follow-up intervals: A call for action. Am J Manag Care. 2014;20(1):17-19. doi: 85339 [pii].

23. Ostbye T, Yarnall KS, Krause KM, Pollak KI, Gradison M, Michener JL. Is there time for management of patients with chronic diseases in primary care? Ann Fam Med. 2005;3(3):209214. doi: 3/3/209 [pii]. 
24. US preventive services task force. https://www.uspreventiveservicestaskforce.org/. Updated 2016. Accessed 02/13, 2017.

25. HHS 2010: Department of health and human services. healthy people 2020, older adult section. www.healthypeople.gov/2020/topicsobjectives2020/overview.aspx?topicid=31. Updated 2016. Accessed 02/13, 2017.

26. Ratcliffe MA, Lanham SA, Reid DM, Dawson AA. Bone mineral density (BMD) in patients with lymphoma: The effects of chemotherapy, intermittent corticosteroids and premature menopause. Hematol Oncol. 1992;10(3-4):181-187.

27. Ng AK, Garber JE, Diller LR, et al. Prospective study of the efficacy of breast magnetic resonance imaging and mammographic screening in survivors of hodgkin lymphoma. J Clin Oncol. 2013;31(18):2282-2288. doi: 10.1200/JCO.2012.46.5732 [doi].

28. Doubeni CA, Field TS, Ulcickas Yood M, et al. Patterns and predictors of mammography utilization among breast cancer survivors. Cancer. 2006;106(11):2482-2488.

29. Earle CC, Burstein HJ, Winer EP, Weeks JC. Quality of non-breast cancer health maintenance among elderly breast cancer survivors. J Clin Oncol. 2003;21(8):1447-1451. doi: 10.1200/JCO.2003.03.060 [doi].

30. Earle CC, Neville BA. Under use of necessary care among cancer survivors. Cancer. 2004;101(8):1712-1719. 
31. Snyder CF, Earle CC, Herbert RJ, Neville BA, Blackford AL, Frick KD. Preventive care for colorectal cancer survivors: A 5-year longitudinal study. J Clin Oncol. 2008;26(7):1073-1079. doi: 10.1200/JCO.2007.11.9859 [doi].

32. Snyder CF, Earle CC, Herbert RJ, Neville BA, Blackford AL, Frick KD. Trends in follow-up and preventive care for colorectal cancer survivors. Journal of general internal medicine. 2008;23(3):254-259.

33. Yu X, McBean AM, Virnig BA. Physician visits, patient comorbidities, and mammography use among elderly colorectal cancer survivors. Journal of Cancer Survivorship. 2007;1(4):275282.

34. Erdem E, Prada SI, Haffer SC. Medicare payments: How much do chronic conditions matter. Medicare Medicaid Res Rev. 2013;3(2):E1-15.

35. Majhail NS, Ness KK, Burns LJ, et al. Late effects in survivors of hodgkin and non-hodgkin lymphoma treated with autologous hematopoietic cell transplantation: A report from the bone marrow transplant survivor study. Biology of Blood and Marrow Transplantation. 2007;13(10):1153-1159.

36. Majhail NS, Rizzo JD, Lee SJ, et al. Recommended screening and preventive practices for long-term survivors after hematopoietic cell transplantation. Hematology/oncology and stem cell therapy. 2012;5(1):1-30.

37. Hershman DL, McBride RB, Eisenberger A, Tsai WY, Grann VR, Jacobson JS. Doxorubicin, cardiac risk factors, and cardiac toxicity in elderly patients with diffuse B-cell non- 
hodgkin's lymphoma. J Clin Oncol. 2008;26(19):3159-3165. doi: 10.1200/JCO.2007.14.1242

[doi].

38. Snyder CF, Frick KD, Herbert RJ, et al. Quality of care for comorbid conditions during the transition to survivorship: Differences between cancer survivors and noncancer controls. J Clin Oncol. 2013;31(9):1140-1148. doi: 10.1200/JCO.2012.43.0272 [doi].

39. Earle CC, Neville BA. Under use of necessary care among cancer survivors. Cancer. 2004;101(8):1712-1719.

40. Mortimer L, Strawbridge L, Lukens E, et al. CMS'oncology care model: Delivering higher value cancer care. Clinical Pharmacology \& Therapeutics. 2017.

41. Roorda C, de Bock GH, van der Veen, Willem Jan, Lindeman A, Jansen L, van der Meer K. Role of the general practitioner during the active breast cancer treatment phase: An analysis of health care use. Supportive Care in Cancer. 2012;20(4):705-714.

42. Dobie S, Saver BG, Wang CY, Green PK, Baldwin LM. Do primary care physicians lose contact with their colorectal cancer patients? J Am Board Fam Med. 2011;24(6):704-709. doi: 10.3122/jabfm.2011.06.100192 [doi].

43. Snyder CF, Frick KD, Herbert RJ, et al. Comorbid condition care quality in cancer survivors: Role of primary care and specialty providers and care coordination. Journal of Cancer Survivorship. 2015;9(4):641-649.

44. SEER-medicare linked database. https://healthcaredelivery.cancer.gov/seermedicare/. Accessed 11/09, 2016. 
45. Ash AS, Virnig B. Medicare data. Wiley StatsRef: Statistics Reference Online. 2005.

46. PASHOS CL, ESCARCE JJ. Using medicare claims for outcomes research. .

47. US Department of Health and Human Services. Area health resource file (AHRF). Rockville, MD: Health Resources and Services Administration. .

http://ahrf.hrsa.gov/ALLVARs_search.asp.

48. Getzen TE. Health care is an individual necessity and a national luxury: Applying multilevel decision models to the analysis of health care expenditures. J Health Econ. 2000;19(2):259-270.

49. Glanz K, Rimer BK, Viswanath K. Health behavior: Theory, research, and practice. John Wiley \& Sons; 2015.

50. McLeroy KR, Bibeau D, Steckler A, Glanz K. An ecological perspective on health promotion programs. Health Education \& Behavior. 1988;15(4):351-377.

51. Mobley L, Kuo T, Urato M, Boos J, Lozano-Gracia N, Anselin L. Predictors of endoscopic colorectal cancer screening over time in 11 states. Cancer Causes \& Control. 2010;21(3):445461.

52. Mobley LR, Clayton LJ, Evans WD. Mammography facilities are accessible, so why is utilization so low? Cancer Causes \& Control. 2009;20(6):1017-1028.

53. Klabunde CN, Han PK, Earle CC, et al. Physician roles in the cancer-related follow-up care of cancer survivors. Fam Med. 2013;45(7):463-474. 
54. Klabunde CN, Ambs A, Keating NL, et al. The role of primary care physicians in cancer care. Journal of general internal medicine. 2009;24(9):1029-1036.

55. Nadel MR, Shapiro JA, Klabunde CN, et al. A national survey of primary care physicians' methods for screening for fecal occult blood. Ann Intern Med. 2005;142(2):86-94.

56. Haggstrom DA, Arora NK, Helft P, Clayman ML, Oakley-Girvan I. Follow-up care delivery among colorectal cancer survivors most often seen by primary and subspecialty care physicians. Journal of general internal medicine. 2009;24(2):472.

57. Jiang L, Lofters A, Moineddin R, et al. Primary care physician use across the breast cancer care continuum: CanIMPACT study using canadian administrative data. Can Fam Physician. 2016;62(10):e589-e598. doi: 62/10/e589 [pii].

58. Forsythe LP, Arora NK, Alfano CM, et al. Role of oncologists and primary care physicians in providing follow-up care to non-hodgkin lymphoma survivors within 5 years of diagnosis: A population-based study. Supportive Care in Cancer. 2014;22(6):1509-1517.

59. Craig BM, Bell BA, Quinn GP, Vadaparampil ST. Prevalence of cancer visits by physician specialty, 1997-2006. Journal of Cancer Education. 2010;25(4):548-555.

60. Stokols D. Translating social ecological theory into guidelines for community health promotion. American journal of health promotion. 1996;10(4):282-298. 


\section{Chapter 2: Impact of Diffuse Large B-Cell Lymphoma on Visits to Different Provider Specialties among EIderly Medicare Beneficiaries: Challenges for Care Coordination}

\subsection{Abstract}

Background. Newly diagnosed Diffuse Large B-Cell Lymphoma (DLBCL), a cancer with vague symptomatology, can pose significant challenges to care-coordination. Objective. We utilized a social-ecological model to understand the impact of DLBCL diagnosis on visits to primary care providers (PCPs) and specialists, a key component of care-coordination, over a three year period of cancer diagnosis and treatment. Methods. We used a retrospective longitudinal study design with SEER-Medicare linked dataset to analyze visits to PCPs and specialists by DLBCL patients $(n=5,455)$ compared to non-cancer patients $(n=14,770)$. Hurdle models and multivariable logistic regression were used to examine number of PCP visits and any visit to specialists, respectively. Results. DLBCL patients were more likely to visit PCPs (AOR $[95 \% \mathrm{CI}]: 1.25[1.18,1.31])$, and had greater number of visits to PCPs $(\beta, \mathrm{SE}: 0.384,-0.014)$ than non-cancer patients. Further, DLBCL patients were more likely to have any visit to cardiologists (AOR [95\%CI]: $1.40[1.32,1.47])$, endocrinologists $(1.43,[1.21,1.70])$, and pulmonologists $(1.51[1.36,1.67])$ than non-cancer patients. Among DLBCL patients, the number of PCP visits markedly increased during the treatment period compared to the baseline period $(\beta, \mathrm{SE}: 0.491,-$ 0.028) and then decreased to baseline levels $(-0.464,-0.022)$. Conclusions. Visits to PCPs and specialists were much higher for DLBCL than non-cancer patients, which drastically increased during the DLBCL treatment period for chronic care. Treatment adverse effects and more frequent contact with healthcare system may have increased the visits to PCPs and specialists. Interventions to improve care-coordination may need to target the DLBCL treatment period, when care-coordination is most vulnerable. Implications. Practice: DLBCL patients have higher chronic care needs during the cancer treatment and follow-up periods and should be referred to 
suitable mental health specialists when necessary. Policy: Policymakers who want to improve care-coordination for cancer patients may need to target the cancer treatment period. Research: Future studies need to investigate the cancer patients' perceived barriers to care-coordination between their primary care providers, oncologists, and specialists. 


\subsection{Introduction}

Non-Hodgkin's Lymphoma (NHL) is the most prevalent blood cancer with approximately 72,580 new cases of NHL expected to be diagnosed in $2016 .{ }^{1}$ Diffuse Large Bcell Lymphoma (DLBCL) is the most common subtype of NHL and commonly occurs in adults above 64 years of age. ${ }^{2}$ DLBCL can lead to secondary cancers, ${ }^{3}$ post-traumatic stress, ${ }^{4}$ and poor quality of life in the elderly. ${ }^{5}$ Furthermore, $82.0 \%$ of elderly individuals have pre-existing chronic physical or mental health conditions. ${ }^{6,7}$ Therefore, individuals diagnosed with DLBCL receive care from multiple providers such as the oncologists, primary care physicians (PCPs), and other medical specialists (e.g., cardiologist, endocrinologists, psychologists, and others). Although not specific to DLBCL, elderly individuals visited an average of 6 different providers in a year. ${ }^{8}$ Previous studies have found that under the fee-for-service system, such receipt of uncoordinated care from multiple providers can lead to medication errors, ${ }^{9}$ duplication of services, ${ }^{10}$ emergency room visits, ${ }^{11}$ unplanned hospital readmissions,${ }^{12}$ costs, ${ }^{10,13}$ and preventable hospitalizations ${ }^{13}$ and ultimately worsen the health outcomes of patients. ${ }^{14}$ In its report on cancer survivorship, Institute of Medicine recommended that individualized survivorship care plan should be developed to increase care coordination for cancer patients. The U.S. Department of Health and Human Services ${ }^{15}$ and the National Quality Forum ${ }^{16}$ have also developed strategic frameworks of care to identify novel models of care and include effective care coordination as one of the care quality measures.

Care coordination may be further compromised with newly diagnosed cancer ${ }^{10}$ because cancer patients need care from multiple providers for their chronic conditions as well as cancer. For example, among breast cancer patients, visits to oncologists and PCPs increased after breast cancer diagnosis. ${ }^{17-19}$ Colorectal cancer patients had more visits to PCPs after the treatment period as compared to the pre-diagnosis period..$^{20,21}$ These findings suggest that cancer patients 
may be receiving care from both oncologists and PCPs. However, DLBCL patients may consult their PCPs or other medical specialists for symptoms, before being referred to an oncologist because they may experience vague symptoms such as painless swelling of lymph nodes, fever, and weight loss. ${ }^{22}$ The visits to PCPs and other medical specialists may continue during and after the cancer treatment period because, unlike other cancers, DLBCL can affect multiple organs. ${ }^{23}$ In a cross-sectional survey conducted among NHL patients, $87.1 \%$ visited PCPs or other medical specialists, in addition to their oncologists. ${ }^{24}$ However, the investigators did not examine provider visits by patients with DLBCL which is markedly different in treatment and survival prognosis from other subtypes of NHL. ${ }^{2}$ DLBCL is an aggressive form of NHL and is often treated with intense therapeutic regimens such as stem cell transplant ${ }^{25,26}$ DLBCL treatment can worsen other chronic conditions or patients may have new diagnosis of chronic conditions due to increased contact with healthcare system. Therefore, the patterns of visits to PCPs and other medical specialists may differ. It is also plausible that due to the prioritization of cancer care, DLBCL patients may not continue to see their PCPs or other medical specialists after cancer diagnosis, specifically during the cancer treatment period. ${ }^{27}$

To the best of our knowledge, no study has investigated whether DLBCL affects visits to PCPs and other medical specialists, an indicator of care coordination. It is important to examine DLBCL patients' visits to PCPs and other medical specialists because cancer follow-up care in primary care settings is cost-effective. ${ }^{28}$ Further, oncologists are responsible for the treatment of cancer and may be less effective in providing care for other chronic conditions. ${ }^{29}$

\subsection{Theoretical Framework}

The primary objective of this study was to use the Social-Ecological model (SEM) to evaluate the impact of newly diagnosed DLBCL on visits to PCPs and other medical specialist 
among the elderly Medicare beneficiaries compared to those without any cancer. ${ }^{30}$ The SEM is an overarching framework to investigate diverse personal and socio-physical factors that impact health behavior. ${ }^{30}$ We selected this framework because patients' visits to providers can be influenced by patients' personal characteristics as well as external social and healthcare environmental factors. These factors include: (a) intra-personal factors- patient's sociodemographic characteristics, chronic conditions, and cancer treatments received; (b) interpersonal factors- county-level formal and informal social support systems c) healthcare system factors: density of physicians and facilities; (d) community factors- SEER region, urbanacity, area poverty and education. ${ }^{31-33} \mathrm{We}$ used a nationally representative linked dataset of cancer registries and Medicare claims in the United States. The secondary objective of this study was to examine the change in PCP visits and use of medical specialists before and after DLBCL diagnosis.

\subsection{Methods}

\subsubsection{Study Design}

We utilized a retrospective longitudinal design with 12-month pre-index and 24-month post-index periods. For the DLBCL patients, pre- and post-index periods were identified using the DLBCL diagnosis date as the index date. For the non-cancer patients, pre- and post-index periods were derived using randomly selected dates of service from inpatient or outpatient Medicare claims. The pre- and post-index period were divided into six equal time intervals of 6months each. For DLBCL patients, the pre-index period included baseline (t1) and pre-diagnosis (t2) and post-index period comprised of treatment (t3), post-treatment (t4), short follow-up (t5), and long follow-up (t6) periods.

\subsubsection{Data Sources}


We linked data from several sources: 1) SEER cancer registries; 2) 5\% Medicare sample for patients without any cancer; 3) Medicare claims of SEER and non-cancer patients; and 4) the Area Health Resource File (AHRF). The SEER is an epidemiologic surveillance system consisting of data from 20 population-based tumor registries (Alaska Native Tumor Registry, Arizona Indians, Cherokee Nation-Oklahoma, Connecticut, Detroit, Atlanta-Georgia, Greater Georgia, Rural Georgia, San Francisco-Oakland, San Jose-Monterey, Greater California, Hawaii, Iowa, Kentucky, Los Angeles, Louisiana, New Jersey, New Mexico, Seattle-Puget Sound, and Utah). ${ }^{34}$ The SEER cancer registries collect information for all the newly diagnosed cancer cases such as patient's demographic characteristics, cancer site, date of cancer diagnosis, and cancer pathology (e.g., stage and grade). Medicare claims can be linked to the SEER registries and contain detailed information on medical treatment, chronic conditions, healthcare utilization, and expenditures.

The AHRF is a publicly available data file provided by the Department of Health and Human Services which contains information on more than 6,000 variables for each of the US counties. ${ }^{35}$ The AHRF contains data on the availability of health professionals, healthcare facilities, and socioeconomic and environmental characteristics of each county. We used the state and county Federal Information Processing Standard (FIPS) codes to link the AHRF files with the SEER-Medicare dataset to measure the county level inter-personal, healthcare system, and community factors.

\subsubsection{Study Population}

The DLBCL was identified using the International Classification of Diseases for Oncology - Third Revision (ICD-O-3)/World Health Organization 2008 codes: 13, 14, 15, 16) during 2003-2011. The non-cancer patients were derived from a random 5\% sample of Medicare 
beneficiaries who resided in SEER areas between 2003 and 2011 and were not diagnosed with any cancer, except basal cell carcinoma. We selected a $10 \%$ random sample of non-cancer patients.

The following exclusion criteria were applied to both DLBCL population and non-cancer sample: (a) with missing values for any demographic factor (e.g., age, sex, race, region, and End Stage Renal Disease (ESRD), (b) not alive during the observation period, (c) less than 66 years of age, (d) having ESRD, (e) enrolled in managed care plans, (f) not continuously enrolled in Medicare parts A and B during the pre- and post- index periods; and (g) not having any PCP visit during the entire observation period (Appendix 2.1 and 2.2). Additional inclusion criteria were applied to the DLBCL population: we included individuals if they had only one primary cancer (except basal cell carcinoma) and if their cancer was not diagnosed from autopsy or death certificate.

\subsubsection{Measures}

Dependent variables. The dependent variables for our study included any visit to PCPs and other medical specialist. Further, we analyzed the number of PCP visits among those with at least one PCP visit. These variables were measured every 180 days (i.e. t1 through t6) and were derived from the National Claims History (NCH) files. The PCPs included general practice, family practice, internal medicine, geriatric medicine, nurse practitioner, or physician assistant. ${ }^{36}$ Visits to other medical specialists were: (a) cardiologists among patients with any heart condition; (b) endocrinologists among patients with diabetes; (c) mental health specialists (psychologist or psychiatrist) among patients with depression and/or anxiety; and (d) pulmonologists among patients with asthma or chronic obstructive pulmonary disease (COPD). We identified the specialty of a physician by using the Health Care Financing Administration 
(HCFA) specialty codes. The HCFA specialty codes from the SEER-Medicare dataset have been used in previous studies to examine the role of physician specialty in the care of breast and colorectal cancer patients. ${ }^{36-38}$

Cancer Status Independent Variable. The key independent variable was the presence of DLBCL vs. no cancer, which belonged to the domain of intra-personal factors as per SEM.

SEM Independent Variables. The independent variables in our study included both time varying and time invariant variables. The time varying factors included chronic conditions of arthritis, diabetes, any heart condition, any mental condition, and any respiratory condition and DLBCL treatments of chemotherapy, radiotherapy, and immunotherapy (only for those diagnosed with DLBCL). The time varying factors were measured repeatedly during each time interval from t1 to t6. All other intra-personal, inter-personal, healthcare, and community factors were time invariant and were measured during one year before the index date.

Intra-personal factors. (a) age at index date $(66-69,70-74,75-79$, or $>=80 \mathrm{yrs}$.); (b) sex (male or female); (c) race (Non-Hispanic White, Non-Hispanic African American, Hispanic, or others); (d) geographic region (Northeast, South, North-Central, or West); (e) rural/urban (metro, urban, or rural); (f) arthritis (osteoarthritis or rheumatoid arthritis); (g) diabetes; (h) any heart condition (cardiac arrhythmia, coronary artery disease, or congestive heart failure); (i) depression or anxiety; (j) respiratory condition (Asthma or COPD); (k) DLBCL stage from the Ann Arbor staging system (stage I, II, III or IV); (1) chemotherapy; (m) radiotherapy; (n) immunotherapy; and (o) stem cell transplant.

Inter-personal factors. Inter-personal factors included county-level racial/ethnic isolation measured by: (a) percentage of Blacks; (b) percentage of Hispanics; and (c) social or 
cultural cohesion measured by percentage of non-English speaking individuals above 18 years of age.

Healthcare system factors. Healthcare system factors were measured at the county level. These factors included: (a) health professional shortage area for PCPs (whole county, part of county, or no shortage); (b) quartiles of average number of hospitals per 10,000 elderly individuals above 65 years of age $(0.56,0.97,1.31,3.46)$; and (c) quartiles of average number of Federal Qualified Health Centers (FQHC) per 10,000 elderly individuals above 65 years of age $(0.01,0.37,0.94,3.68)$

Community factors. Community factors included: (a) county percentage of individuals between 18 and 64 years of age without health insurance quartiles $(13.10,17.70,22.57,28.72)$; (b) county average travel time to work quartiles $(19.73,24.19,27.44,30.95)$; and (c) county percentage of individuals with below high school education quartiles $(8.44,12.27,16.31,25.01)$. In addition to the variables guided by SEM, we also included time and index year as covariates in all the models.

\subsubsection{Statistical Analyses}

We used chi-square tests to analyze the model-driven differences in intra-personal, interpersonal, healthcare system, and community factors between DLBCL and the non-cancer patients. As repeated observations were made for PCP visits from t1 to t6, each subject was clustered over time. As each person had 6 observations, the observations were dependent and to account for the non-independence of observations, we used the unstructured correlation structure. We used hurdle models to analyze any visit to PCPs and the number of PCP visits. A hurdle model analyzes the two processes of generating zeroes and positive values separately. ${ }^{39}$ The first part of the model, known as 'hurdle at zero', analyzes the occurrence of an outcome 
(i.e., PCP visit or no visit). The second part of the model, known as 'above the hurdle', analyzes the positive values of the outcome (i.e., number of PCP visits above zero). ${ }^{40}$ Population-averaged logistic regression models (also known as Generalized Estimating Equations -GEE) were used to analyze the relationship between DLBCL and visit to providers. ${ }^{40}$ All analyses were conducted using STATA version $14 .{ }^{41}$ Our preliminary analysis indicated that there were significant differences in characteristics between the DLBCL and non-cancer patients. To reduce this observed selection bias between the DLBCL and non-cancer patients, we derived Inverse Probability Treatment Weights (IPTW) by conducting a logistic regression on DLBCL vs no cancer with the following independent variables: sex, race/ethnicity, age, index year, and chronic conditions. Results from the logistic regression are presented in Appendix 2.3. These IPTWs were used as weights in all the unadjusted and adjusted analyses.

\subsection{Results}

\subsubsection{Description of DLBCL and Non-Cancer Patient Characteristics}

Table 2.1 summarizes the selected characteristics of DLBCL and non-cancer patients before and after adjustments with IPTW. Before adjusting for observed selection bias with IPTW, DLBCL patients had higher percentage of males, whites, and above 75 years of age as compared to those with no cancer.

\subsubsection{Hurdle Model: Impact of DLBCL on Any Visit to PCP and Number of PCP Visits}

A higher proportion of DLBCL patients visited PCPs as compared to non-cancer patients (t1: $75.3 \%$ vs $75.1 \%$; t2: $84.1 \%$ vs $75.5 \%$; $3: 92.3 \%$ vs $82.2 \%$; 4 : $81.4 \%$ vs $75.7 \%$; $5: 80.5 \%$ vs 77.3\%; t6: $81.0 \%$ vs $77.9 \%$ ). Figure 2.1 displays the differences in any visit to PCP between

DLBCL patients and those without cancer from $t 1$ to t6. Figure 2.2 summarizes the differences in the predicted number of PCP visits between the DLBCL and non-cancer patients. Without any 
adjustments for chronic conditions, the number of visits to PCP were higher among those with DLBCL compared to the non-cancer patients ( $\mathrm{t} 1: 3.57$ vs 3.46 ; $\mathrm{t} 2: 4.29$ vs 3.44 ; $\mathrm{t} 3: 8.36$ vs 3.55 ; t4: 5.12 vs $3.61 ;$ t5: 4.41 vs 3.63 ; t6: 4.50 vs 3.82 ). After adjusting for the presence of chronic conditions at each time period, DLBCL patients still had higher number of PCP visits (predicted) compared to non-cancer patients (t1: 5.00 vs 3.27 ; t2: 4.86 vs $3.42 ;$ t $3: 5.28$ vs $3.45 ;$ t4: 4.99 vs $3.53 ; \mathrm{t} 5: 4.73$ vs $3.53 ; \mathrm{t} 6: 4.48$ vs 3.54$)$.

Table 2.2 summarizes the parameter estimates from the unadjusted and adjusted hurdle models of any visit to PCP and the number PCP visits. After adjusting for all SEM independent variables, DLBCL patients were more likely to visit $\mathrm{PCPs}(\mathrm{AOR}=1.25,95 \% \mathrm{CI}=[1.18,1.31])$ and had more PCP visits (beta $=0.384, \mathrm{SE}=-0.014$ ) than non-cancer patients.

\subsubsection{SEM Independent Variables and Any Visit to PCP and Number of PCP Visits}

Females, older individuals, other racial minorities (vs Whites), those living in South or North-Central compared to North-East, arthritis patients, heart disease patients, respiratory condition patients, mental health condition patients, and diabetes patients were more likely to visit PCPs and had higher number of PCP visits. Those living in counties with more hospitals and higher average travel time were less likely to have any PCP visit and had fewer PCP visits (Appendix 2.4).

\subsubsection{Impact of DLBCL on Any Visit to Other Medical Specialists}

Figure 2.1 displays the differences in any visit to other medical specialists between DLBCL patients and those without cancer from t1 to t6. With regard to other medical specialties, a higher percentage of DLBCL patients visited cardiologists (t1: 70.2\% vs 64.5\%; t2: 62.8\% vs 54.9\%; t3: $83.7 \%$ vs $51.9 \%$; t4: $50.7 \%$ vs $46.4 \%$; t5: $46.0 \%$ vs $45.3 \%$; t6: $46.6 \%$ vs $44.6 \%$ ), endocrinologists (t1: $7.6 \%$ vs $6.1 \%$; t2: $7.0 \%$ vs $5.3 \%$; t3: $8.8 \%$ vs $5.1 \%$; t4: $6.6 \%$ vs $4.7 \%$; t5: 
$6.0 \%$ vs $4.5 \%$; t6: $6.1 \%$ vs. $4.8 \%$ ), pulmonologists (t1: $25.8 \%$ vs $22.6 \%$; t2: $23.7 \%$ vs $17.7 \%$; t 3 : $34.1 \%$ vs $15.2 \%$; t4: $18.5 \%$ vs $13.3 \%$; t5: $15.2 \%$ vs $12.8 \%$; t6: $14.0 \%$ vs $12.1 \%$ ), and rheumatologists (t1: $18.1 \%$ vs $11.0 \%$; t2: $14.3 \%$ vs $7.9 \%$; $\mathrm{t} 3: 8.7 \%$ vs $7.5 \%$; t4: $7.4 \%$ vs $6.3 \%$; t5: $7.1 \%$ vs $6.1 \%$; t6: $6.7 \%$ vs $5.6 \%$ ) as compared to non-cancer patients. However, with regard to mental health specialists, we did not observe a clear pattern of use among DLBCL patients ( $\mathrm{t} 1$ : $34.9 \%$ vs $31.1 \%$; t2: $30.6 \%$ vs $33.9 \%$; t3: $31.7 \%$ vs $30.6 \%$; t $4: 36.7 \%$ vs $33.9 \%$; t5: $32.2 \%$ vs 35.6\%; t6: $37.1 \%$ vs $32.6 \%$ ). DLBCL patients were more likely to visit cardiologists (AOR = $1.40,95 \% \mathrm{CI}=[1.32,1.47])$, endocrinologists $(1.43[1.21,1.70])$, and pulmonologists $(1.50$ $[1.36,1.67])$ than patients with no cancer from both unadjusted and adjusted models (Table 2.3).

\subsubsection{SEM Independent Variables and Any Visit to Other Medical Specialties}

Those with arthritis, asthma, mental health condition, or diabetes were more likely to have any visit to cardiologists. The elderly with any heart condition or mental health condition were more likely to have any visit to endocrinologists. The elderly with any heart condition, mental health condition, or diabetes were more likely to have any visit to pulmonologists. Further, females, other races, those living in North-Central or West region, and rural areas were less likely to have any visit to cardiologists and pulmonologists (Appendix 2.5).

\subsubsection{Change in Number of PCP visits over Time among DLBCL Patients}

The results from the adjusted negative binomial regressions for number of PCP visits among beneficiaries with DLBCL are displayed in Table 2.4. When baseline period (t2) was used as the reference group, we observed that the number of PCP visits increased during prediagnosis ( $\mathrm{t} 1$ ) and treatment ( $\mathrm{t} 3$ ) periods and decreased during the follow-up periods ( $\mathrm{t} 5$, $\mathrm{t} 6)$. When treatment period ( $\mathrm{t} 3$ ) was used as the reference group, the number of visits during baseline, pre-diagnosis, post-treatment, and follow-up periods were significantly lower. 


\subsubsection{SEM Independent Variables and Number of PCP Visits among DLBCL Patients}

Intra-personal factors associated with higher number of visits to PCPs among DLBCL patients included greater age, female sex, South, North-Central, or West region compared to North-East, arthritis, diabetes, any heart condition, depression or anxiety, and asthma or COPD (Appendix 2.6). With respect to DLBCL treatments, those receiving radiotherapy and immunotherapy had more PCP visits while those receiving stem cell transplants had less PCP visits. The inter-personal factors positively associated with lower number of PCP visits included living in counties with a higher percentage of Blacks. With respect to community factors, those living in counties with lower number of individuals with health insurance had lower PCP visits, and those living in counties with lower education level had higher PCP visits.

\subsection{Discussion}

In this first study of its kind, we examined the impact of newly diagnosed DLBCL on visits to different provider specialties to understand the challenges for care-coordination. We analyzed the impact of DLBCL on any PCP visit, number of PCP visits, and any visit to other medical specialists by using a robust study design that compared DLBCL patients with cancerfree patients. Our study findings indicated that DLBCL patients were more likely to visit PCPs and had higher number of PCP visits as compared to those without any cancer, even after adjusting for intra-personal, inter-personal, healthcare system, and community factors. These findings are consistent with a previous study in breast cancer patients who had higher PCP visits than non-cancer patients. ${ }^{17}$

Further, we found that DLBCL patients were more likely to visit other medical specialists as compared to non-cancer patients. This is a unique finding because none of the published studies examined the relationship between cancer diagnosis and visits to other medical 
specialists, a key indicator of care coordination. This finding suggests problems for care coordination for patients enrolled in fee-for-service Medicare, because Medicare does not compensate the providers for communicating with other providers for care coordination. Providers have to face many challenges even with the availability of electronic health records due to a lack of interoperability between electronic health information systems. ${ }^{42}$

With respect to change in PCP visits, our study findings are somewhat consistent with previous studies in colorectal and breast cancer patients, who were found to increase in their visits to PCP during the post-treatment period (i.e. one year after cancer diagnosis). ${ }^{17-20}$ Our study results indicated that the PCP visits increased three fold during the treatment period. One possible explanation for more visits to PCPs and other medical specialists among DLBCL patients is the presence of multiple chronic conditions. We observed that DLBCL patients had higher prevalence of diabetes, arthritis, any heart condition, depression or anxiety, and asthma or COPD than non-cancer patients. Our findings also indicated that many patients were newly diagnosed with chronic conditions after DLBCL diagnosis and treatment, which statistically explained the variations in number of PCP visits over time. These findings suggest that visits to PCPs and other medical specialists may be greater among DLBCL patients due to higher prevalence and incidence of chronic conditions, which can complicate the management of cooccurring chronic conditions and cancer. Further, the chemotherapy and stem cell transplant are associated with significant adverse effects such as cardiotoxicity ${ }^{43}$ and loss of bone density. ${ }^{44}$ These adverse effects may be another reason for the increase in visits to specialists during the treatment period. This sharp increase in provider visits poses significant challenges to care coordination. DLBCL patients may face greater difficulties in care coordination because the 
roles of PCPs and other medical specialists have not been properly defined during the cancer treatment period..$^{45,46}$

Surprisingly, we did not find a significant difference in visits to mental health providers among elderly patients with both DLBCL and mental health conditions as compared to those without any cancer, after adjusting for time, index year, and other SEM factors. As the diagnosis and treatment of DLBCL leads to significant long term psychiatric morbidity such as anxiety, depression, post-traumatic stress disorder, and lower health status, ${ }^{47-49}$ it is concerning that DLBCL patients' visits to mental health providers did not change. PCPs and oncologists may need to be more aware that the elderly DLBCL patients with pre-existing mental health conditions are highly susceptible to further mental health deterioration and should refer such patients to suitable mental health providers when necessary.

Future studies need to investigate whether the strategic frameworks developed by the U.S. Department of Health and Human Services ${ }^{15}$ and the National Quality Forum ${ }^{16}$ can be implemented in the context of cancer care and can improve care-coordination for elderly patients with cancer and multiple chronic conditions. Another measure for improving the carecoordination between oncologists and PCPs is the use of survivorship care plans. In response to the Institute of Medicine's report on cancer survivorship, many groups have developed specific care plans for cancer patients. ${ }^{50}$ These care plans may be helpful in improving the coordination of care between providers during and after the treatment period. ${ }^{51}$

Our study findings should be interpreted in the context of some limitations. We used the HCFA provider specialty codes given in the Physician/Supplier Claims file (NCH) of the SEERMedicare dataset to identify the provider specialties in this study. Although the HCFA codes have been used in previous studies on elderly cancer patients, ${ }^{36,52,53}$ these codes may not capture 
all the visits to different provider specialties. ${ }^{54}$ The purpose of our study was to examine the burden and opportunities for care coordination during the different phases of care among elderly patients with DLBCL. We did not investigate the actual provider-provider interaction or patients' and providers' experiences of care coordination in this study. Our study results can be generalized to Medicare fee-for-service beneficiaries who resided in SEER regions only.

The strengths of our study include the use of SEER-Medicare database, which is a nationally representative data to examine the care of elderly patients with newly diagnosed cancer. We examined the visits to other medical specialists over a three year time period spanning the cancer diagnosis, treatment, and follow-up periods which had not been analyzed before. We used a comprehensive SEM framework to examine the association of various personal and contextual factors with the visits to different provider specialties among elderly DLBCL patients. Further, we utilized a robust study design with a non-cancer comparison group and time varying diagnosis of chronic conditions in our study.

\subsection{Conclusions}

The elderly Medicare beneficiaries with DLBCL were more likely to visit PCPs or other medical specialists and had higher number of visits to PCPs compared to non-cancer patients. The treatment adverse effects and more frequent contact with healthcare system may have led to increased diagnosis of other chronic conditions, which partially explained the higher visits to PCPs and specialists. The time period immediately after DLBCL diagnosis need to be targeted to implement interventions to improve care coordination between the oncologist, PCP, and other medical specialists. 


\subsection{References}

1. National cancer institute. surveillance, epidemiology, and end results program. SEER stat fact sheets: Non-hodgkin lymphoma. http://seer.cancer.gov/statfacts/html/nhl.html. Updated 2016. Accessed 05/09, 2016.

2. Shankland KR, Armitage JO, Hancock BW. Non-hodgkin lymphoma. The Lancet. 2012;380(9844):848-857.

3. Pirani M, Marcheselli R, Marcheselli L, Bari A, Federico M, Sacchi S. Risk for second malignancies in non-hodgkin's lymphoma survivors: A meta-analysis. Ann Oncol. 2011;22(8):1845-1858. doi: 10.1093/annonc/mdq697 [doi].

4. Smith SK, Zimmerman S, Williams CS, Preisser JS, Clipp EC. Post-traumatic stress outcomes in non-hodgkin's lymphoma survivors. J Clin Oncol. 2008;26(6):934-941. doi:

10.1200/JCO.2007.12.3414 [doi].

5. Smith SK, Crespi CM, Petersen L, Zimmerman S, Ganz PA. The impact of cancer and quality of life for post-treatment non-Hodgkin lymphoma survivors. Psycho-Oncology. 2010;19(12):1259-1267.

6. Lochner KA, Goodman RA, Posner S, Parekh A. Multiple chronic conditions among medicare beneficiaries: State-level variations in prevalence, utilization, and cost, 2011. Medicare \& medicaid research review. 2013;3(3).

7. Wolff JL, Starfield B, Anderson G. Prevalence, expenditures, and complications of multiple chronic conditions in the elderly. Arch Intern Med. 2002;162(20):2269-2276. 
8. Cherry D, Lucas C, Decker SL. Population aging and the use of office-based physician services. NCHS Data Brief. 2010;(41)(41):1-8.

9. Fialová D, Onder G. Medication errors in elderly people: Contributing factors and future perspectives. Br J Clin Pharmacol. 2009;67(6):641-645.

http://search.ebscohost.com/login.aspx $?$ direct=true $\& \mathrm{db}=\mathrm{cmedm} \& \mathrm{AN}=19594531 \&$ site $=$ ehost live. doi: 10.1111/j.1365-2125.2009.03419.x.

10. Skolarus TA, Zhang Y, Hollenbeck BK. Understanding fragmentation of prostate cancer survivorship care: Implications for cost and quality. Cancer. 2012;118(11):2837-2845. http://search.ebscohost.com/login.aspx?direct=true $\& \mathrm{db}=\mathrm{cmedm} \& \mathrm{AN}=22370955 \&$ site=ehostlive. doi: $10.1002 / \mathrm{cncr} .26601$.

11. Liu CW, Einstadter D, Cebul RD. Care fragmentation and emergency department use among complex patients with diabetes. Am J Manag Care. 2010;16(6):413-420.

http://search.ebscohost.com/login. aspx?direct=true $\& d b=c m e d m \& A N=20560685 \&$ site $=$ ehostlive.

12. Graboyes EM, Kallogjeri D, Saeed MJ, Olsen MA, Nussenbaum B. Postoperative care fragmentation and thirty-day unplanned readmissions after head and neck cancer surgery. Laryngoscope. 2016.

http://search.ebscohost.com/login.aspx?direct=true $\& \mathrm{db}=\mathrm{cmedm} \& A N=27740687 \&$ site=ehostlive. doi: 10.1002/lary.26301.

13. Frandsen BR, Joynt KE, Rebitzer JB, Jha AK. Care fragmentation, quality, and costs among chronically ill patients. Am J Manag Care. 2015;21(5):355-362. 
http://search.ebscohost.com/login.aspx $?$ direct=true $\& \mathrm{db}=$ cmedm \&AN=26167702\&site=ehost-

live.

14. Walunas TL, Jackson KL, Chung AH, et al. Disease outcomes and care fragmentation among patients with systemic lupus erythematosus. Arthritis Care Res (Hoboken). 2016.

http://search.ebscohost.com/login.aspx $?$ direct=true $\& \mathrm{db}=$ cmedm\&AN=27899012\&site=ehostlive. doi: 10.1002/acr.23161.

15. Parekh AK, Goodman RA, Gordon C, Koh HK. Managing multiple chronic conditions: A strategic framework for improving health outcomes and quality of life. Public Health Rep. 2011:460-471.

16. National quality forum. multiple chronic conditions measurement framework. http://www.qualityforum.org/Projects/Multiple_Chronic_Conditions_Measurement_Framework. aspx. Accessed 12/14, 2016.

17. Roorda C, de Bock GH, van der Veen, Willem Jan, Lindeman A, Jansen L, van der Meer K. Role of the general practitioner during the active breast cancer treatment phase: An analysis of health care use. Supportive Care in Cancer. 2012;20(4):705-714.

18. Jiang L, Lofters A, Moineddin R, et al. Primary care physician use across the breast cancer care continuum: CanIMPACT study using canadian administrative data. Can Fam Physician. 2016;62(10):e589-e598. doi: 62/10/e589 [pii]. 
19. Grunfeld E, Hodgson DC, Del Giudice ME, Moineddin R. Population-based longitudinal study of follow-up care for breast cancer survivors. J Oncol Pract. 2010;6(4):174-181. doi: 10.1200/JOP.200009 [doi].

20. Dobie S, Saver BG, Wang CY, Green PK, Baldwin LM. Do primary care physicians lose contact with their colorectal cancer patients? J Am Board Fam Med. 2011;24(6):704-709. doi: 10.3122/jabfm.2011.06.100192 [doi].

21. Snyder CF, Earle CC, Herbert RJ, Neville BA, Blackford AL, Frick KD. Preventive care for colorectal cancer survivors: A 5-year longitudinal study. J Clin Oncol. 2008;26(7):1073-1079. doi: 10.1200/JCO.2007.11.9859 [doi].

22. Ansell SM, Armitage J. Non-hodgkin lymphoma: Diagnosis and treatment. . 2005;80(8):1087-1097.

23. Martelli M, Ferreri AJ, Agostinelli C, Di Rocco A, Pfreundschuh M, Pileri SA. Diffuse large B-cell lymphoma. Crit Rev Oncol. 2013;87(2):146-171.

24. Forsythe LP, Arora NK, Alfano CM, et al. Role of oncologists and primary care physicians in providing follow-up care to non-hodgkin lymphoma survivors within 5 years of diagnosis: A population-based study. Supportive Care in Cancer. 2014;22(6):1509-1517.

25. Armitage JO. My treatment approach to patients with diffuse large B-cell lymphoma. . 2012;87(2):161-171.

26. Hamlin PA, Satram-Hoang S, Reyes C, Hoang KQ, Guduru SR, Skettino S. Treatment patterns and comparative effectiveness in elderly diffuse large B-cell lymphoma patients: A 
surveillance, epidemiology, and end results-medicare analysis. Oncologist. 2014;19(12):12491257. doi: 10.1634/theoncologist.2014-0113 [doi].

27. Sisler JJ, Brown JB, Stewart M. Family physicians' roles in cancer care. survey of patients on a provincial cancer registry. Can Fam Physician. 2004;50:889-896.

28. Lewis RA, Neal RD, Williams NH, et al. Follow-up of cancer in primary care versus secondary care: Systematic review. Br J Gen Pract. 2009;59(564):e234-47. doi: 10.3399/bjgp09X453567 [doi].

29. Klabunde CN, Ambs A, Keating NL, et al. The role of primary care physicians in cancer care. Journal of General Internal Medicine. 2009;24(9):1029-1036.

http://www.ncbi.nlm.nih.gov/pmc/articles/PMC2726889/. doi: 10.1007/s11606-009-1058-X.

30. Stokols D. Translating social ecological theory into guidelines for community health promotion. American journal of health promotion. 1996;10(4):282-298.

31. McLeroy KR, Bibeau D, Steckler A, Glanz K. An ecological perspective on health promotion programs. Health Education \& Behavior. 1988;15(4):351-377.

32. Mobley L, Kuo T, Urato M, Boos J, Lozano-Gracia N, Anselin L. Predictors of endoscopic colorectal cancer screening over time in 11 states. Cancer Causes \& Control. 2010;21(3):445461.

33. Levit L, Balogh E, Nass S, Ganz PA. Delivering high-quality cancer care:: Charting a new course for a system in crisis. National Academies Press; 2013. 
34. SEER-medicare linked database. https://healthcaredelivery.cancer.gov/seermedicare/. Accessed 11/09, 2016.

35. US Department of Health and Human Services. Area health resource file (AHRF). Rockville, MD: Health Resources and Services Administration. . http://ahrf.hrsa.gov/ALLVARs_search.asp.

36. Earle CC, Burstein HJ, Winer EP, Weeks JC. Quality of non-breast cancer health maintenance among elderly breast cancer survivors. J Clin Oncol. 2003;21(8):1447-1451. doi: 10.1200/JCO.2003.03.060 [doi].

37. Earle CC, Neville BA. Under use of necessary care among cancer survivors. Cancer. 2004;101(8):1712-1719.

38. Snyder CF, Frick KD, Herbert RJ, et al. Quality of care for comorbid conditions during the transition to survivorship: Differences between cancer survivors and noncancer controls. J Clin Oncol. 2013;31(9):1140-1148. doi: 10.1200/JCO.2012.43.0272 [doi].

39. Cameron AC, Trivedi PK. Regression analysis of count data. Vol 53. Cambridge university press; 2013.

40. Ballinger GA. Using generalized estimating equations for longitudinal data analysis. Organ Res Methods. 2004;7(2):127-150.

41. StataCorp L. Stata data analysis and statistical software. Special Edition Release. 2007;10. 
42. Heisey-Grove D, Danehy LN, Consolazio M, Lynch K, Mostashari F. A national study of challenges to electronic health record adoption and meaningful use. Med Care. 2014;52(2):144148. doi: 10.1097/MLR.0000000000000038 [doi].

43. Hershman DL, McBride RB, Eisenberger A, Tsai WY, Grann VR, Jacobson JS.

Doxorubicin, cardiac risk factors, and cardiac toxicity in elderly patients with diffuse B-cell nonhodgkin's lymphoma. J Clin Oncol. 2008;26(19):3159-3165. doi: 10.1200/JCO.2007.14.1242 [doi].

44. Ratcliffe MA, Lanham SA, Reid DM, Dawson AA. Bone mineral density (BMD) in patients with lymphoma: The effects of chemotherapy, intermittent corticosteroids and premature menopause. Hematol Oncol. 1992;10(3-4):181-187.

45. Klabunde CN, Han PK, Earle CC, et al. Physician roles in the cancer-related follow-up care of cancer survivors. Fam Med. 2013;45(7):463-474.

46. Klabunde CN, Ambs A, Keating NL, et al. The role of primary care physicians in cancer care. Journal of general internal medicine. 2009;24(9):1029-1036.

47. Oerlemans S, Mols F, Nijziel MR, Zijlstra WP, Coebergh JWW, van de Poll-Franse, Lonneke V. The course of anxiety and depression for patients with Hodgkin's lymphoma or diffuse large B cell lymphoma: A longitudinal study of the PROFILES registry. Journal of Cancer Survivorship. 2014;8(4):555-564. 
48. Smith SK, Zimmerman S, Williams CS, Preisser JS, Clipp EC. Post-traumatic stress outcomes in non-hodgkin's lymphoma survivors. J Clin Oncol. 2008;26(6):934-941. doi: 10.1200/JCO.2007.12.3414 [doi].

49. Andrykowski MA, Lykins E, Floyd A. Psychological health in cancer survivors. . 2008;24(3):193-201.

50. Brennan M, Gormally J, Butow P, Boyle F, Spillane A. Survivorship care plans in cancer: A systematic review of care plan outcomes. Br J Cancer. 2014;111(10):1899-1908.

51. Brennan ME, Boyle FM, Butow PN, Spillane AJ. Evaluation of a survivorship care plan: Long-term use, care coordination and quality of life in breast cancer survivors. Breast Cancer. 2015;4(3):145-157.

52. Earle CC, Neville BA. Under use of necessary care among cancer survivors. Cancer. 2004;101(8):1712-1719.

53. Snyder CF, Frick KD, Herbert RJ, et al. Quality of care for comorbid conditions during the transition to survivorship: Differences between cancer survivors and noncancer controls. J Clin Oncol. 2013;31(9):1140-1148. doi: 10.1200/JCO.2012.43.0272 [doi].

54. Baldwin LM, Adamache W, Klabunde CN, Kenward K, Dahlman C, L Warren J. Linking physician characteristics and medicare claims data: Issues in data availability, quality, and measurement. Med Care. 2002;40(8 Suppl):IV-82-95. doi:

10.1097/01.MLR.0000020933.36849.20 [doi]. 
Table 2.1 Description of Selected Characteristics of Elderly Medicare Beneficiaries with Diffuse Large B-Cell Lymphoma (DLBCL) and Non-Cancer Patients before and after Inverse Probability Treatment Weights. Surveillance Epidemiology and End Results Program (SEER) - Medicare 2003-2011.

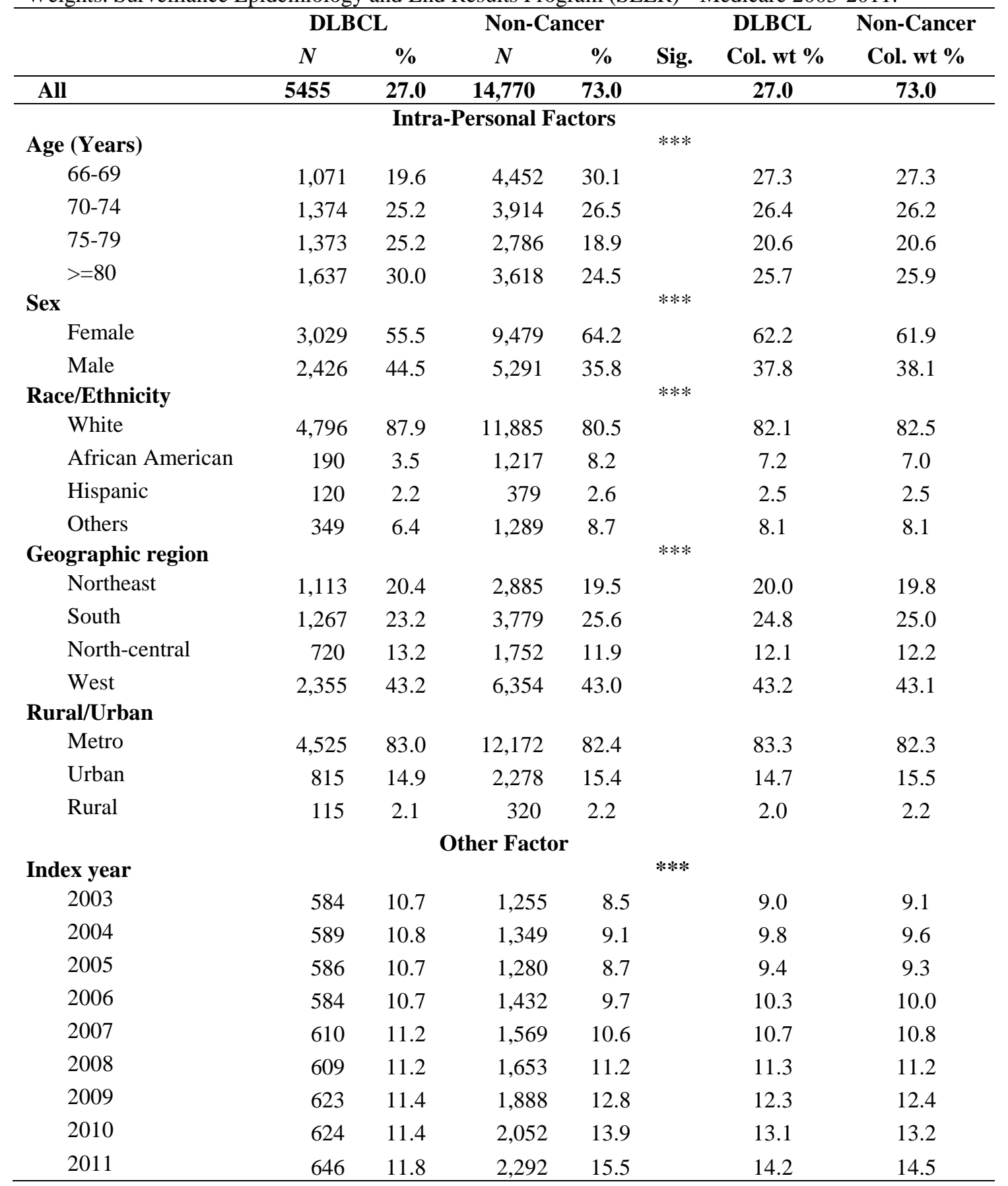

Note. Based on 5,455 Medicare beneficiaries with Diffuse Large B-Cell Lymphoma and a random sample of 14,770 beneficiaries without any cancer who resided in SEER areas. Weighted percentages were derived with using inverse probability treatment weights.

Sig.: significance level; wt: Weighted $* * * \mathrm{p}<.001$ 
Table 2.2 Unadjusted and Adjusted Parameter Estimates of DLBCL vs No Cancer from Hurdle Models on Any Visit to PCP and Number of PCP Visits with Inverse Probability Treatment Weights. Surveillance Epidemiology and End Results Program (SEER)Medicare 2003-2011.

\begin{tabular}{|c|c|c|c|c|c|c|c|c|c|c|}
\hline & \multicolumn{4}{|c|}{ Any PCP Visit } & \multicolumn{6}{|c|}{ Number of PCP Visits } \\
\hline & \multicolumn{2}{|c|}{ DLBCL } & \multicolumn{2}{|c|}{ Time } & \multicolumn{2}{|c|}{ DLBCL } & \multicolumn{2}{|c|}{ Time } & \multicolumn{2}{|c|}{ DLBCL*Time } \\
\hline & OR & $95 \% \mathrm{CI}$ & OR & $95 \% \mathrm{CI}$ & $\boldsymbol{\beta}$ & SE & $\boldsymbol{\beta}$ & SE & $\beta$ & SE \\
\hline Model 1 & $1.388 * * *$ & {$[1.317,1.463]$} & $1.034 * * *$ & {$[1.026,1.042]$} & $0.428 * * *$ & -0.015 & $0.016 * * *$ & -0.002 & $-0.050 * * *$ & -0.004 \\
\hline Model 2 & $1.386 * * *$ & {$[1.316,1.461]$} & $1.034 * * *$ & {$[1.026,1.042]$} & $0.439 * * *$ & -0.015 & $0.016 * * *$ & -0.002 & $-0.052 * * *$ & -0.004 \\
\hline Model 3 & $1.243 * * *$ & {$[1.179,1.309]$} & $0.950 * * *$ & {$[0.941,0.958]$} & $0.382 * * *$ & -0.014 & $-0.034 * * *$ & -0.002 & $-0.050 * * *$ & -0.004 \\
\hline Model 4 & $1.245^{* * *}$ & {$[1.182,1.312]$} & $0.948 * * *$ & {$[0.940,0.957]$} & $0.384 * * *$ & -0.014 & $-0.034 * * *$ & -0.002 & $-0.049 * * *$ & -0.004 \\
\hline
\end{tabular}

Note. Model 1: Unadjusted; Model 2: Adjusted for age, sex, race, region, rural/urban, index year; Model 3: Adjusted for age, sex, race, region, rural/urban, index year, arthritis, diabetes, heart conditions, depression/anxiety, asthma/chronic obstructive pulmonary disease; Model 4: Adjusted for age, sex, race, region, rural/urban, arthritis, diabetes, any heart condition, depression/anxiety, asthma/chronic obstructive pulmonary disease, county $\%$ black, county $\%$ hospitals, county $\%$ without health insurance, county average travel time, and county\% below high school education.

Based on 5,455 Medicare beneficiaries with Diffuse Large B-Cell Lymphoma and 19,215 beneficiaries without any cancer who resided in SEER areas. OR: Odds Ratios; CI: Confidence intervals; DLBCL: Diffuse Large B-Cell Lymphoma; SE: Standard errors.

$* * * \mathrm{p}<.001$ 
Table 2.3 Unadjusted and Adjusted Estimates from Logistic Regression with Generalized Estimating Equation on Any Visit to Other Medical Specialists with Inverse Probability Treatment Weights. Surveillance Epidemiology and End Results Program (SEER)-Medicare 2003-2011.

\begin{tabular}{|c|c|c|c|c|c|c|}
\hline & \multicolumn{2}{|c|}{ Cardiologist } & \multicolumn{2}{|c|}{ Endocrinologist } & \multicolumn{2}{|c|}{ Pulmonologist } \\
\hline & OR & $95 \% \mathrm{CI}$ & OR & $95 \% \mathrm{CI}$ & OR & $95 \% \mathrm{CI}$ \\
\hline Model 1 & & & & & & \\
\hline DLF & $1.409 * * *$ & {$[1.336,1.485]$} & $1.485^{* * *}$ & {$[1.250,1.764]$} & $1.578 * * *$ & {$[1.423,1.749]$} \\
\hline Time & $0.940 * * *$ & {$[0.932,0.948]$} & 1.024 & {$[1.000,1.050]$} & $0.936 * * *$ & {$[0.919,0.953]$} \\
\hline Mo & & & & & & \\
\hline DLBCL & $1.396 * * *$ & {$[1.324,1.472]$} & $1.431 * * *$ & {$[1.206,1.696]$} & $1.505^{* * *}$ & {$[1.358,1.667]$} \\
\hline Time & $0.923 * * *$ & {$[0.914,0.932]$} & 1.008 & {$[0.981,1.035]$} & $0.906 * * *$ & {$[0.889,0.925]$} \\
\hline
\end{tabular}

Note. Model 1: Unadjusted; Model 2: Adjusted for age, sex, race, region, rural/urban, arthritis, diabetes, any heart condition, depression/anxiety, asthma/chronic obstructive pulmonary disease, county\% black, county\% hospitals, county average travel time, county\% without health insurance, and county\% below high school education. Any visit to other medical specialist was analyzed only among those with the corresponding chronic condition (e.g., any visit to endocrinologists was analyzed among those with diabetes).

CI: Confidence intervals; OR: Odds ratios.

$* * * \mathrm{p}<.001$ 
Table 2.4 Unadjusted and Adjusted Estimates from Negative Binomial Regressions with Generalized Estimating Equation on Number of Visits to Primary Care Physicians (PCPs) among elderly with Diffuse Large B-Cell Lymphoma (DLBCL). Surveillance Epidemiology and End Results Program (SEER)-Medicare 2003-2011.

\begin{tabular}{lcccccc}
\hline & \multicolumn{2}{c}{ Model 1 } & \multicolumn{2}{c}{ Model 2 } & \multicolumn{2}{c}{ Model 3 } \\
& \multicolumn{1}{c}{$\beta$} & SE & $\beta$ & SE & $\beta$ & SE \\
\hline Time & Ref. & & Ref. & & $-0.491 * * *$ & -0.0284 \\
Baseline, t1 & & & & & \\
Pre-diagnosis, t2 & $0.201 * * *$ & -0.017 & $0.134 * * *$ & -0.016 & $-0.357 * * *$ & -0.028 \\
Treatment, t3 & $0.872 * * *$ & -0.020 & $0.491 * * *$ & -0.028 & Ref. & \\
Post-treatment, t4 & $0.337 * * *$ & -0.020 & 0.027 & -0.022 & $-0.464 * * *$ & -0.022 \\
Short follow-up, t5 & $0.188 * * *$ & -0.020 & $-0.121 * * *$ & -0.020 & $-0.612 * * *$ & -0.026 \\
Long follow-up, t6 & $0.220 * * *$ & -0.020 & $-0.108 * * *$ & -0.022 & $-0.599 * * *$ & -0.027 \\
\hline
\end{tabular}

Note. Model 1: Unadjusted; Model 2\&3:Adjusted for age, sex, race, region, rural/urban, marital status, arthritis, diabetes, any heart condition, depression/anxiety, asthma/chronic obstructive pulmonary disease, DLBCL stage, radiotherapy, chemotherapy, immunotherapy, stem cell transplant, county\% black, county\% hospitals, county\% without health insurance, and county\% below high school education.

SE: Standard errors.

$* * .05<\mathrm{p}<.01, * * * .01<\mathrm{p}<.001$ 
Figure 2.1 Differences in Any Visit to Primary Care Physician and Other Medical Specialists between Elderly Medicare Beneficiaries with Diffuse Large B-Cell Lymphoma and No Cancer. SEER Medicare 2003-2011.

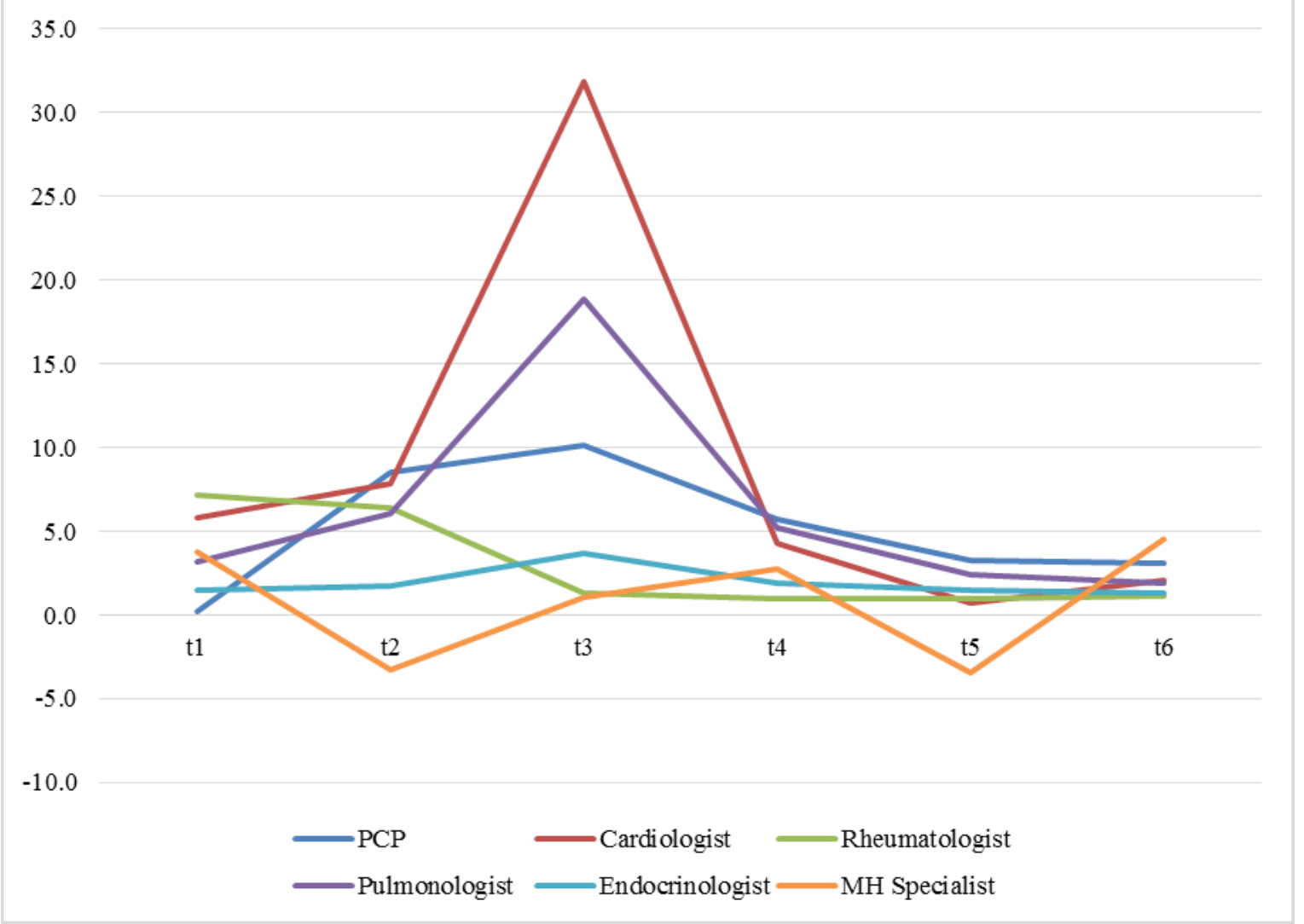

Note: Based on the differences in percentages of patients with any visit to provider between DLBCL and non-cancer patients for each time point. 
Figure 2.2 Unadjusted and Adjusted Differences in Average Number of Visits to Primary Care Physicians between Elderly Medicare Beneficiaries with Diffuse Large B-Cell Lymphoma and No Cancer. SEER Medicare 2003-2011.

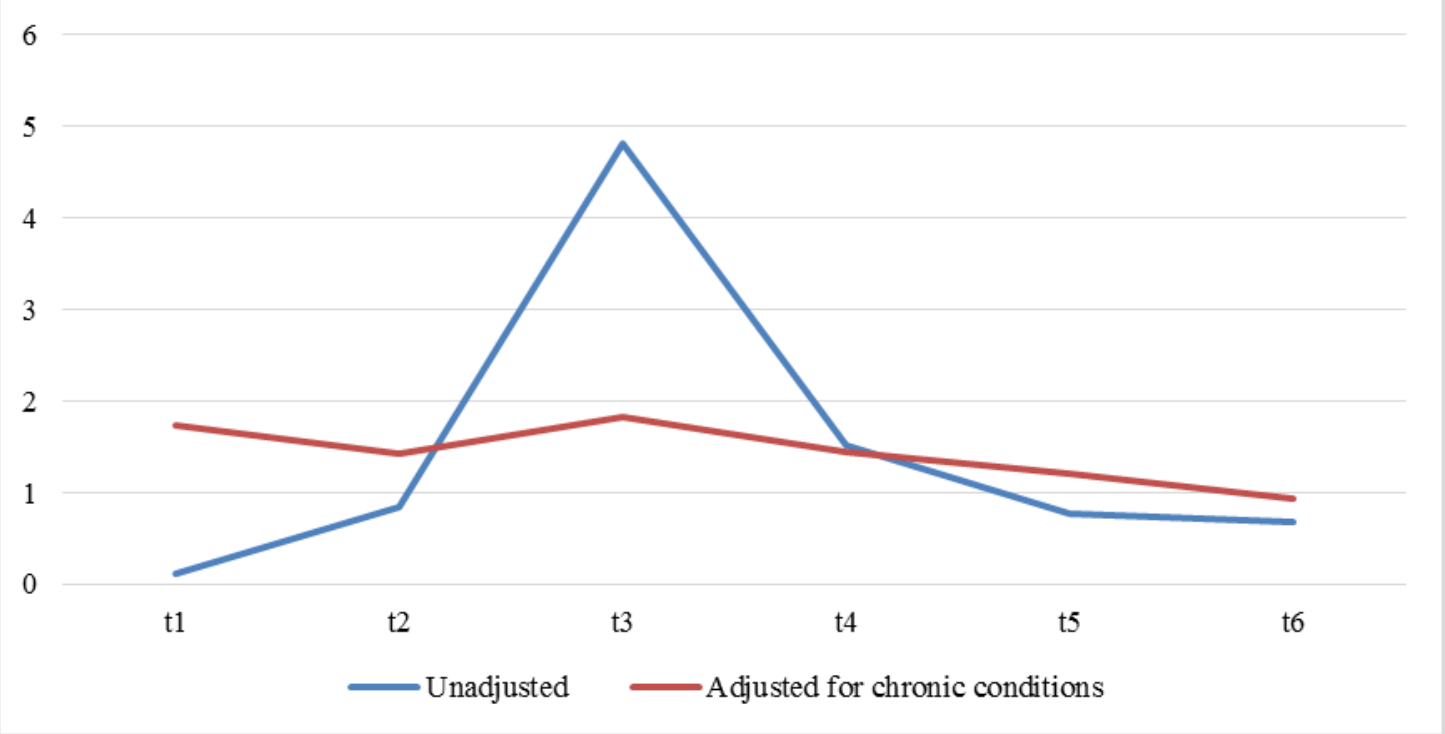

Note. Calculated among those with at least one primary care physician visit. 
Appendix 2.1 Flowchart of Sample Selection for Elderly Medicare Beneficiaries with Diffuse Large B-Cell Lymphoma.

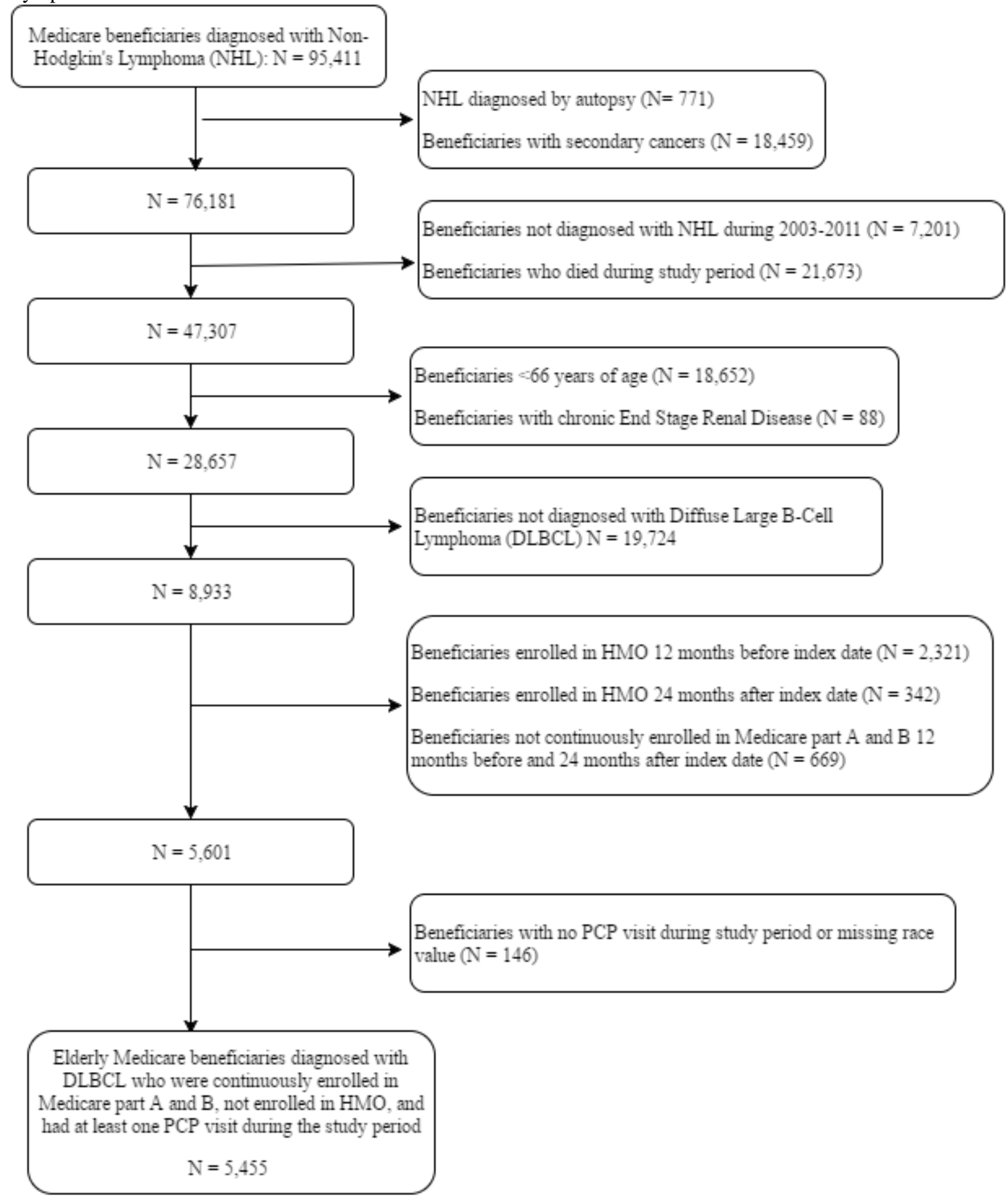


Appendix 2.2 Flowchart of Sample Selection for Elderly Medicare Beneficiaries with No Cancer.

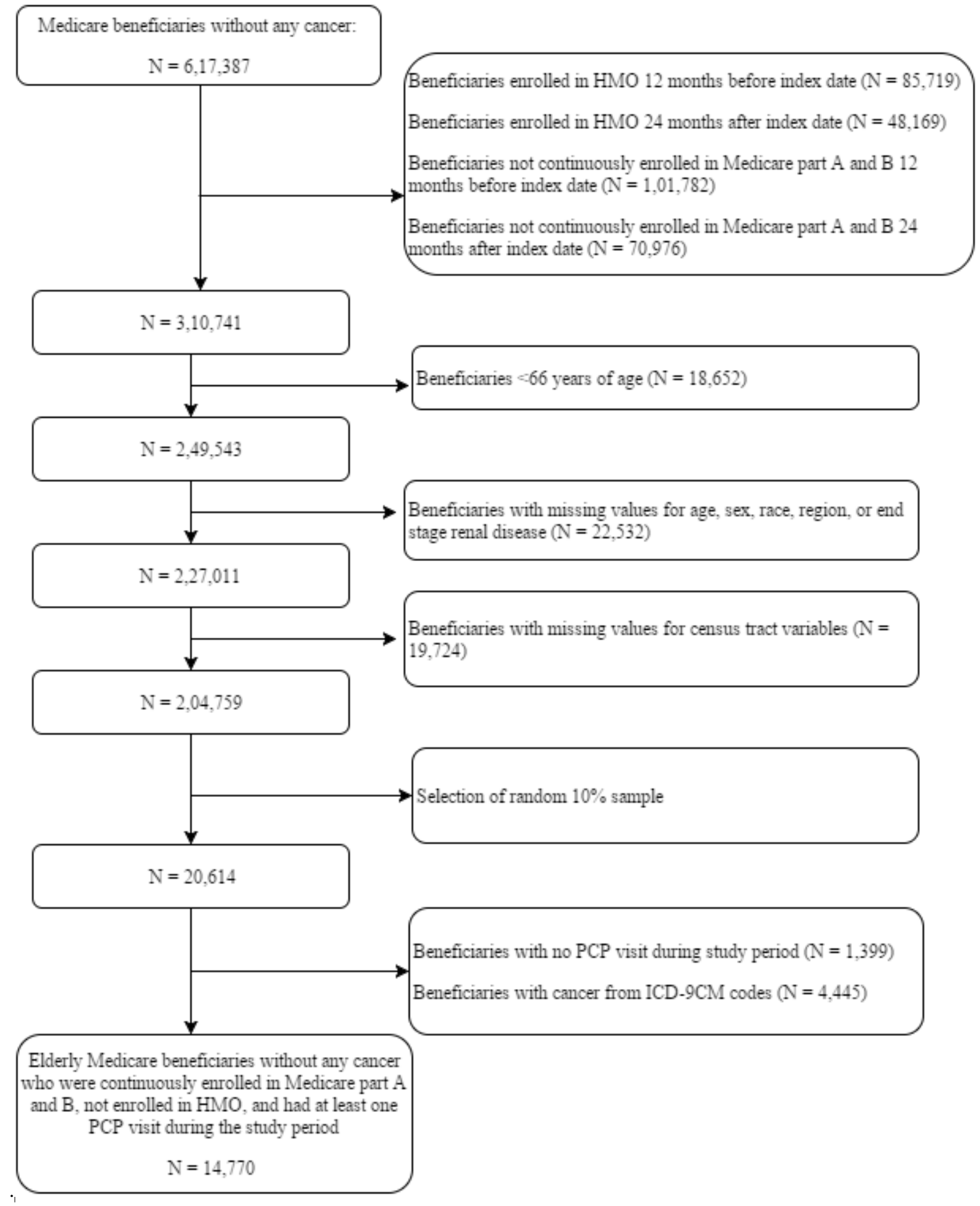


Appendix 2.3 Adjusted Estimates from Logistic Regressions on

Diffuse Large B-Cell Lymphoma vs. No Cancer by Selected

Characteristics of Elderly Medicare Beneficiaries. Surveillance

Epidemiology and End Results Program (SEER)-Medicare 2003-2011.

\begin{tabular}{lllll}
\hline & & AOR & $95 \%$ CI & Sig. \\
\hline Sex & Female & 0.66 & {$[0.62,0.70]$} & $* * *$ \\
& Male & Ref. & &
\end{tabular}

Age

$\begin{array}{cccc}70-74 & 1.40 & {[1.28,1.54]} & * * * \\ 75-79 & 1.92 & {[1.74,2.11]} & * * * \\ >=80 & 1.81 & {[1.65,1.99]} & * * * \\ 66-69 & \text { Ref. } & & \end{array}$

Race

$\begin{array}{lrrl}\text { African American } & 0.41 & {[0.35,0.49]} & * * * \\ \text { Hispanic } & 0.73 & {[0.59,0.91]} & * * \\ \text { Others } & 0.66 & {[0.58,0.75]} & * * * \\ \text { White } & \text { Ref. } & & \end{array}$

Index Year

$\begin{array}{lrrl}2003 & \text { Ref. } & & \\ 2004 & 0.94 & {[0.81,1.08]} & \\ 2005 & 0.96 & {[0.83,1.10]} & \\ 2006 & 0.85 & {[0.74,0.98]} & * \\ 2007 & 0.81 & {[0.71,0.93]} & * * \\ 2008 & 0.78 & {[0.68,0.89]} & * * * \\ 2009 & 0.70 & {[0.61,0.81]} & * * * \\ 2010 & 0.66 & {[0.58,0.76]} & * * * \\ 2011 & 0.62 & {[0.54,0.71]} & * * *\end{array}$

Region

$\begin{array}{lcc}\text { South } & 0.95 & {[0.86,1.04]} \\ \text { North-central } & 1.07 & {[0.95,1.20]} \\ \text { West } & 1.03 & {[0.94,1.12]} \\ \text { North East } & \text { Ref. } & \end{array}$

Baseline arthritis

$\begin{array}{lcc}\text { Yes } & 1.20 & {[1.12,1.29]}\end{array}$ ***

Baseline any heart condition

$\begin{array}{lrr}\text { Yes } & 1.23 & {[1.15,1.32] \quad * * *} \\ \text { No } & \text { Ref. } & \end{array}$

Baseline diabetes

No Ref.

\begin{tabular}{rcc} 
Yes & 1.06 & {$[0.99,1.14]$} \\
No & Ref. & \\
Baseline asthma or COPD & & \\
Yes & 1.08 & {$[1.00,1.17]$} \\
No & Ref. & \\
\hline
\end{tabular}

Note. Based on 5,455 Medicare beneficiaries with Diffuse Large B-Cell Lymphoma and 14,770 beneficiaries without any cancer who resided in SEER areas. AOR: Adjusted odds ratios; COPD: Chronic Obstructive Pulmonary Disease; Sig. significance.

$* * * \mathrm{p}<.001 * * .001 \leq \mathrm{p}<.01 * \mathrm{p}<.05$ 
Appendix 2.4 Adjusted Parameter Estimates from Hurdle Models on Any Visit to PCP and Number of PCP Visits with Inverse Probability Treatment Weights. Surveillance

Epidemiology and End Results Program (SEER) Medicare 2003-2011.

\begin{tabular}{|c|c|c|c|c|c|}
\hline & & \multicolumn{2}{|c|}{ Any Visit to PCP } & \multicolumn{2}{|c|}{ Number of PCP Visits } \\
\hline & & AOR & $95 \% \mathrm{CI}$ & $\beta$ & SE \\
\hline \multicolumn{6}{|l|}{ DLBCL } \\
\hline & $\begin{array}{c}\text { Yes } \\
\text { No Cancer }\end{array}$ & $\begin{array}{l}1.245^{* * *} \\
\text { Ref. }\end{array}$ & {$[1.182,1.312]$} & $\begin{array}{l}0.384 * * * \\
\text { Ref. }\end{array}$ & -0.014 \\
\hline Time & & $0.948 * * *$ & {$[0.940,0.957]$} & $-0.034 * * *$ & -0.002 \\
\hline \multirow{2}{*}{$\begin{array}{l}\text { DLBCL*Time } \\
\text { Sex }\end{array}$} & & NA & NA & $-0.049 * * *$ & -0.004 \\
\hline & $\begin{array}{l}\text { Female } \\
\text { Male }\end{array}$ & $\begin{array}{c}1.382^{* * *} \\
\text { Ref. }\end{array}$ & {$[1.322,1.446]$} & $\begin{array}{c}0.067 * * * \\
\text { Ref. }\end{array}$ & -0.010 \\
\hline \multicolumn{6}{|l|}{ Age (Years) } \\
\hline & $70-74$ & $1.113 * * *$ & {$[1.052,1.178]$} & $0.039 * *$ & -0.013 \\
\hline & $75-79$ & $1.169 * * *$ & {$[1.097,1.245]$} & $0.065 * * *$ & -0.015 \\
\hline & $\begin{array}{l}>=80 \\
66-69\end{array}$ & $\begin{array}{c}1.308 * * * \\
\text { Ref. }\end{array}$ & {$[1.230,1.390]$} & $\begin{array}{c}0.145^{* * *} \\
\text { Ref. }\end{array}$ & -0.013 \\
\hline \multicolumn{6}{|l|}{ Race } \\
\hline & African American & $0.893 *$ & {$[0.812,0.982]$} & 0.012 & -0.018 \\
\hline & Hispanic & $0.742 * * *$ & {$[0.647,0.850]$} & 0.038 & -0.028 \\
\hline & Others & $1.243 * * *$ & {$[1.134,1.363]$} & $0.077 * * *$ & -0.021 \\
\hline & White & Ref. & & Ref. & \\
\hline \multicolumn{6}{|l|}{ Region } \\
\hline & South & $1.553 * * *$ & {$[1.422,1.697]$} & $0.072 * * *$ & -0.018 \\
\hline & North-Central & 1.071 & {$[0.980,1.171]$} & $0.111^{* * *}$ & -0.018 \\
\hline & West & 1.058 & {$[0.977,1.145]$} & $0.069 * * *$ & -0.017 \\
\hline & North East & Ref. & & Ref. & \\
\hline \multicolumn{6}{|l|}{ Rural/Urban } \\
\hline & Rural & $0.858 * * *$ & {$[0.795,0.925]$} & 0.016 & -0.016 \\
\hline & Urban & $0.734 * * *$ & {$[0.622,0.866]$} & 0.012 & -0.034 \\
\hline & Metro & Ref. & & Ref. & \\
\hline \multicolumn{6}{|l|}{ Arthritis } \\
\hline & Yes & $1.567 * * *$ & {$[1.501,1.636]$} & $0.190 * * *$ & -0.009 \\
\hline & No & Ref. & & Ref. & \\
\hline \multicolumn{6}{|c|}{ Any heart condition } \\
\hline & Yes & $1.508 * * *$ & {$[1.446,1.573]$} & $0.333 * * *$ & -0.010 \\
\hline & No & Ref. & & Ref. & \\
\hline \multicolumn{6}{|c|}{ Asthma or COPD } \\
\hline & Yes & $1.464 * * *$ & {$[1.391,1.540]$} & $0.227 * * *$ & -0.011 \\
\hline & No & Ref. & & Ref. & \\
\hline \multicolumn{6}{|c|}{ Depression/anxiety } \\
\hline & Yes & $2.233 * * *$ & {$[2.076,2.403]$} & $0.333 * * *$ & -0.013 \\
\hline & No & Ref. & & Ref. & \\
\hline \multicolumn{6}{|l|}{ Diabetes } \\
\hline & Yes & $1.824 * * *$ & {$[1.741,1.911]$} & $0.202 * * *$ & -0.010 \\
\hline & No & Ref. & & Ref. & \\
\hline \multicolumn{6}{|c|}{ County\% Blacks } \\
\hline
\end{tabular}


Appendix 2.4 Adjusted Parameter Estimates from Hurdle Models on Any Visit to PCP and Number of PCP Visits with Inverse Probability Treatment Weights. Surveillance

Epidemiology and End Results Program (SEER) Medicare 2003-2011.

\begin{tabular}{lccccc}
\hline & 4.51 & $0.922^{*}$ & {$[0.861,0.988]$} & -0.026 & -0.015 \\
& 9.85 & 0.960 & {$[0.886,1.041]$} & 0.006 & -0.017 \\
County\% Hospitals & 30.52 & 0.970 & {$[0.887,1.061]$} & $-0.044^{*}$ & -0.018 \\
& & & & & \\
& 0.56 & Ref. & & Ref. & \\
0.97 & 1.035 & {$[0.967,1.107]$} & 0.012 & -0.016 \\
1.31 & 1.005 & {$[0.938,1.076]$} & -0.009 & -0.015 \\
3.46 & $0.900^{*}$ & {$[0.829,0.976]$} & $-0.039^{*}$ & -0.017 \\
County\% without health insurance & & & & \\
13.10 & Ref. & & Ref. & \\
17.70 & $0.920^{*}$ & {$[0.853,0.992]$} & 0.001 & -0.015 \\
22.57 & $0.751^{* * *}$ & {$[0.687,0.822]$} & -0.020 & -0.018 \\
28.72 & $0.782^{* * *}$ & {$[0.706,0.865]$} & -0.031 & -0.020 \\
County average travel time & & & & \\
19.73 & Ref. & & Ref. & \\
24.19 & 0.968 & {$[0.905,1.035]$} & $-0.038^{* *}$ & -0.014 \\
27.44 & $0.902^{* *}$ & {$[0.839,0.970]$} & -0.018 & -0.015 \\
30.95 & $0.827^{* * *}$ & {$[0.764,0.894]$} & $-0.061^{* * *}$ & -0.016 \\
County\% less than high school & & & & \\
education & & & & \\
& 8.44 & Ref. & & Ref. & \\
12.27 & 0.978 & {$[0.912,1.049]$} & 0.005 & -0.014 \\
16.31 & 1.03 & {$[0.952,1.116]$} & $0.042^{* *}$ & -0.016 \\
25.01 & 1.032 & {$[0.943,1.130]$} & $0.081^{* * *}$ & -0.018 \\
\hline
\end{tabular}

Note. Based on 5,455 Medicare beneficiaries with Diffuse Large B-Cell Lymphoma (DLBCL) and 14,770 beneficiaries without any cancer who resided in SEER areas. Adjusted beta coefficients and standard errors are from Generalized Estimating Equation with negative binomial distribution and unstructured correlation matrix. AOR: Adjusted odds ratios; CI: Confidence interval; COPD: Chronic Obstructive Pulmonary Disease; PCP: Primary Care Physician; Sig. significance.

$* * * \mathrm{p}<.001 * * .001<\mathrm{p}<.01 * \mathrm{p}<.05$ 
Appendix 2.5 Adjusted Parameter Estimates from Logistic Regression with Generalized Estimating Equations on Any Visit to Other Medical Specialists with Inverse Probability Treatment Weights. Surveillance Epidemiology and End Results Program (SEER) Medicare 2003-2011.

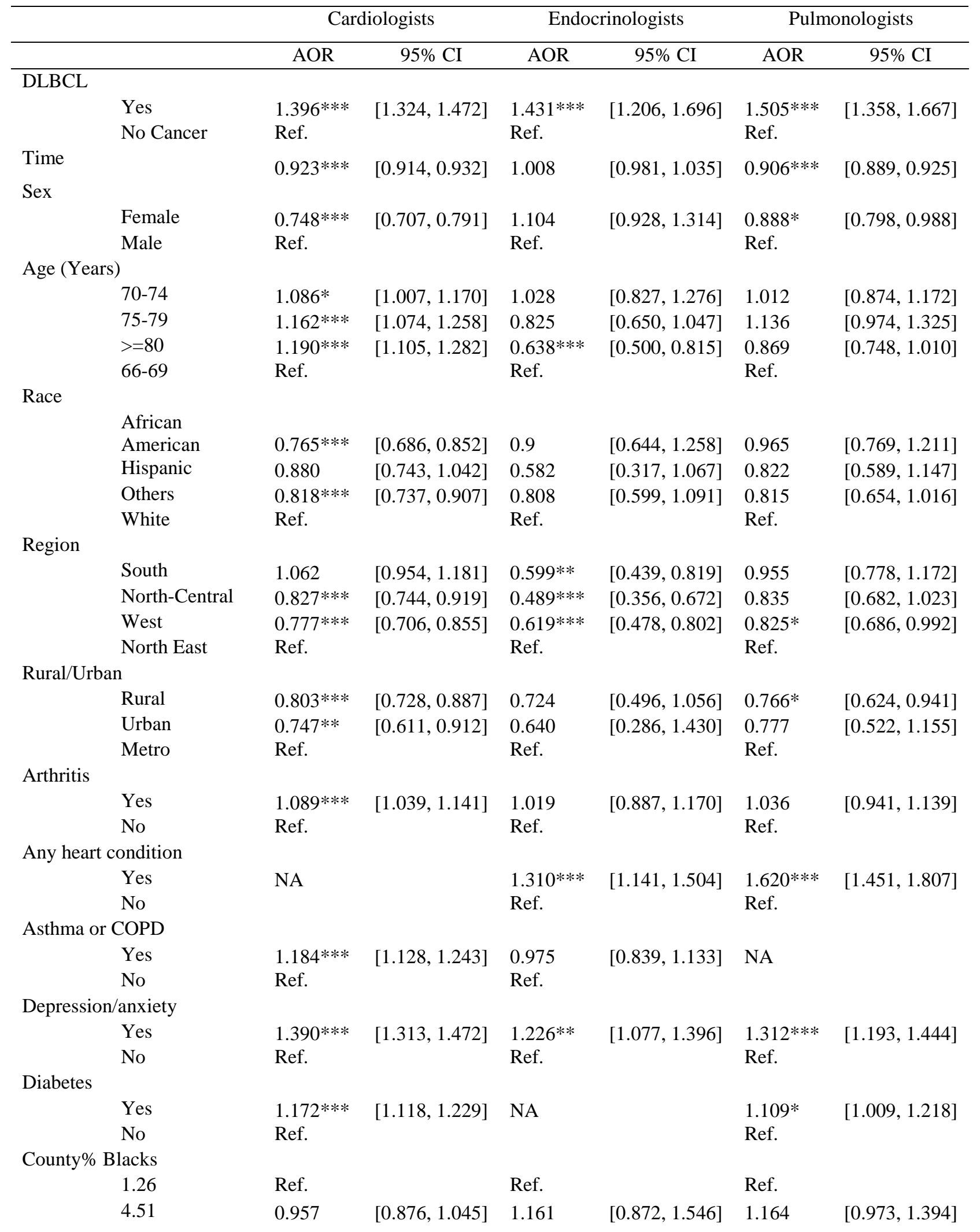


Appendix 2.5 Adjusted Parameter Estimates from Logistic Regression with Generalized Estimating Equations on Any Visit to Other Medical Specialists with Inverse Probability Treatment Weights. Surveillance Epidemiology and End Results Program (SEER) Medicare 2003-2011.

\begin{tabular}{|c|c|c|c|c|c|c|}
\hline 9.85 & 0.965 & {$[0.875,1.065]$} & 1.212 & {$[0.881,1.668]$} & $1.253^{*}$ & {$[1.032,1.522]$} \\
\hline 30.52 & 0.978 & {$[0.877,1.089]$} & 1.345 & {$[0.947,1.910]$} & 1.172 & {$[0.954,1.440]$} \\
\hline \multicolumn{7}{|l|}{ County\% Hospitals } \\
\hline 0.56 & Ref. & & Ref. & & Ref. & \\
\hline 0.97 & 0.953 & {$[0.877,1.035]$} & 0.916 & {$[0.725,1.156]$} & 0.955 & {$[0.814,1.122]$} \\
\hline 1.31 & 0.942 & {$[0.866,1.026]$} & $0.762 *$ & {$[0.592,0.982]$} & 0.984 & {$[0.832,1.164]$} \\
\hline 3.46 & 0.940 & {$[0.847,1.042]$} & 0.772 & {$[0.530,1.124]$} & 0.881 & {$[0.712,1.091]$} \\
\hline \multicolumn{7}{|c|}{$\begin{array}{l}\text { County\% without health } \\
\text { insurance }\end{array}$} \\
\hline 13.10 & Ref. & & Ref. & & Ref. & \\
\hline 17.70 & 0.968 & {$[0.883,1.061]$} & 1.117 & {$[0.859,1.451]$} & 1.021 & {$[0.859,1.214]$} \\
\hline 22.57 & 1.000 & {$[0.896,1.115]$} & $1.541^{*}$ & {$[1.106,2.148]$} & 0.955 & {$[0.776,1.176]$} \\
\hline 28.72 & 0.945 & {$[0.834,1.070]$} & 1.356 & {$[0.935,1.966]$} & 0.946 & {$[0.747,1.199]$} \\
\hline \multicolumn{7}{|c|}{ County average travel time } \\
\hline 19.73 & Ref. & & Ref. & & Ref. & \\
\hline 24.19 & 1.042 & {$[0.957,1.134]$} & 1.165 & {$[0.867,1.566]$} & 0.920 & {$[0.776,1.089]$} \\
\hline 27.44 & 1.054 & {$[0.964,1.152]$} & $1.391^{*}$ & {$[1.031,1.877]$} & 1.006 & {$[0.844,1.198]$} \\
\hline 30.95 & $1.129 *$ & {$[1.025,1.244]$} & $1.595^{* *}$ & {$[1.181,2.155]$} & 1.051 & {$[0.870,1.271]$} \\
\hline \multicolumn{7}{|c|}{$\begin{array}{l}\text { County\% less than high } \\
\text { school education }\end{array}$} \\
\hline 8.44 & Ref. & & Ref. & & Ref. & \\
\hline 12.27 & 0.987 & {$[0.904,1.077]$} & 0.804 & {$[0.618,1.047]$} & 0.928 & {$[0.782,1.101]$} \\
\hline 16.31 & 0.987 & {$[0.894,1.089]$} & 0.771 & {$[0.554,1.074]$} & 0.879 & {$[0.728,1.060]$} \\
\hline 25.01 & 0.992 & {$[0.887,1.111]$} & $0.622 * *$ & {$[0.437,0.885]$} & 0.857 & {$[0.689,1.065]$} \\
\hline
\end{tabular}

Note. Any visit to other medical specialist was analyzed only among those with the corresponding chronic condition (e.g., any visit to endocrinologists was analyzed among those with diabetes).

CI: Confidence intervals; COPD: Chronic Obstructive Pulmonary Disease; OR: Odds ratios.

$* * * \mathrm{p}<.001 * * .001<\mathrm{p}<.01 * \mathrm{p}<.05$ 
Appendix 2.6 Adjusted Estimates from Negative Binomial Regression with Generalized Estimating Equation on Number of PCP Visits with Inverse Probability Treatment Weights among Elderly with Diffuse Large B-Cell Lymphoma. Surveillance Epidemiology and End Results Program (SEER) Medicare 2003-2011.

\begin{tabular}{|c|c|c|c|}
\hline & & \multicolumn{2}{|c|}{ Number of PCP Visits } \\
\hline & & $\beta$ & SE \\
\hline \multicolumn{3}{|l|}{ Time } & \\
\hline & Baseline, $\mathrm{t} 1$ & Ref. & \\
\hline & Pre-diagnosis,t2 & $0.133 * * *$ & 0.016 \\
\hline & Treatment,t3 & $0.491 * * *$ & 0.028 \\
\hline & Post-treatment,t4 & 0.027 & 0.022 \\
\hline & Short followup,t5 & $-0.121 * * *$ & 0.02 \\
\hline & Long followup,t6 & $-0.108 * * *$ & 0.022 \\
\hline \multicolumn{4}{|c|}{ Age groups } \\
\hline & $66-69$ & Ref. & \\
\hline & $70-74$ & 0.041 & 0.024 \\
\hline & $74-79$ & 0.046 & 0.025 \\
\hline & $>=80$ & $0.082 * * *$ & 0.025 \\
\hline \multicolumn{4}{|l|}{ Sex } \\
\hline & Female & $0.059 * * *$ & 0.017 \\
\hline & Male & Ref. & \\
\hline \multicolumn{4}{|l|}{ Race } \\
\hline & Whites & Ref. & \\
\hline & African American & -0.065 & 0.04 \\
\hline & Hispanics & 0.070 & 0.055 \\
\hline & Others & 0.065 & 0.033 \\
\hline \multicolumn{4}{|c|}{ Marital status } \\
\hline & Single & Ref. & \\
\hline & Married & -0.049 & 0.037 \\
\hline & Separated/Divorced/ & & \\
\hline & Widowed & -0.036 & 0.039 \\
\hline \multicolumn{4}{|l|}{ Region } \\
\hline & Northeast & Ref. & \\
\hline & South & $0.089 * *$ & 0.032 \\
\hline & North-Central & $0.139 * * *$ & 0.033 \\
\hline & West & $0.100 * * *$ & 0.027 \\
\hline \multicolumn{4}{|c|}{ Rural/Urban } \\
\hline & Metro & Ref. & \\
\hline & Urban & 0.044 & 0.027 \\
\hline & Rural & 0.005 & 0.056 \\
\hline \multicolumn{4}{|c|}{ DLBCL stage } \\
\hline & Stage I & Ref. & \\
\hline & Stage II & -0.020 & 0.023 \\
\hline & Stage III & -0.007 & 0.025 \\
\hline & Stage IV & 0.030 & 0.021 \\
\hline \multicolumn{4}{|c|}{ Radiotherapy } \\
\hline & Yes & $0.085 * * *$ & 0.023 \\
\hline & No & Ref. & \\
\hline \multicolumn{4}{|c|}{ Chemotherapy } \\
\hline & Yes & -0.025 & 0.024 \\
\hline & No & Ref. & \\
\hline \multicolumn{4}{|c|}{ Immunotherapy } \\
\hline & Yes & $0.099 * * *$ & 0.028 \\
\hline
\end{tabular}


Appendix 2.6 Adjusted Estimates from Negative Binomial

Regression with Generalized Estimating Equation on Number of PCP Visits with Inverse Probability Treatment Weights among

Elderly with Diffuse Large B-Cell Lymphoma. Surveillance

Epidemiology and End Results Program (SEER) Medicare

2003-2011.

\begin{tabular}{|c|c|c|}
\hline & \multicolumn{2}{|c|}{ Number of PCP Visits } \\
\hline & $\beta$ & SE \\
\hline No & Ref. & \\
\hline Stem cell transplan & & \\
\hline Yes & $-0.060 * * *$ & 0.017 \\
\hline No & Ref. & \\
\hline Arthritis & & \\
\hline Yes & $0.171 * * *$ & 0.016 \\
\hline No & Ref. & \\
\hline Diabetes & & \\
\hline Yes & $0.209 * * *$ & 0.016 \\
\hline No & Ref. & \\
\hline Any heart conditior & & \\
\hline Yes & $0.295 * * *$ & 0.016 \\
\hline No & Ref. & \\
\hline Depression/Anxiety & & \\
\hline Yes & $0.324 * * *$ & 0.021 \\
\hline No & Ref. & \\
\hline Asthma/COPD & & \\
\hline Yes & $0.170 * * *$ & 0.017 \\
\hline No & Ref. & \\
\hline County\% blacks & & \\
\hline 1.14 & Ref. & \\
\hline 4.21 & $-0.059 *$ & 0.025 \\
\hline 9.46 & -0.007 & 0.03 \\
\hline 28.38 & $-0.093 * *$ & 0.032 \\
\hline County\% hospitals & & \\
\hline 0.56 & Ref. & \\
\hline 0.96 & 0.024 & 0.025 \\
\hline 1.30 & -0.001 & 0.024 \\
\hline 3.48 & -0.038 & 0.028 \\
\hline
\end{tabular}

County\% without health insurance

12.89
17.21
22.07
28.24

Ref.

$0.015 \quad 0.025$

$-0.048 \quad 0.03$

$-0.074 * \quad 0.033$

County average travel time

19.50

24.09

27.42

31.06

Ref.

$-0.037 \quad 0.023$

$-0.010 \quad 0.025$

$-0.050 \quad 0.027$

County\% less than high school

education

$\begin{array}{lll}8.27 & & \\ 11.99 & 0.039 & 0.024 \\ 15.75 & 0.082^{* *} & 0.028 \\ 24.52 & 0.118^{* * *} & 0.031\end{array}$

Note. Based on 5,455 Medicare beneficiaries with Diffuse Large B-Cell Lymphoma (DLBCL) who had at least one PCP visit during t1 to t6. Adjusted beta coefficients and standard errors are from Generalized Estimating Equation 
with negative binomial distribution and unstructured correlation matrix. COPD: Chronic Obstructive Pulmonary Disease; PCP: Primary Care Physician.

$* * * \mathrm{p}<.001 * * .001<\mathrm{p}<.01 * \mathrm{p}<.05$ 


\section{Chapter 3: Receipt of Mammography and Bone Density Testing by Women with Diffuse Large B-Cell Lymphoma.}

\subsection{Abstract}

Background. Women with Diffuse Large B-Cell Lymphoma (DLBCL) are at a higher risk of breast cancer and osteoporosis than the general population. The receipt of mammography and bone mineral density testing (BDT) by women with DLBCL is unknown. Objective. We utilized a social-ecological model (SEM) with Surveillance, Epidemiology, and End Results (SEER)-Medicare linked dataset to analyze the receipt of mammography among female DLBCL patients $(n=1,137)$ aged $66-74$ years and BDT among those aged $\geq 66$ years $(n=3,029)$ compared to female non-cancer patients ( $n=6,376 \& 13,366$, respectively). Methods. We used multivariable logistic regressions with Inverse Probability Treatment Weights to control for observed selection bias. Results. There was no significant difference in mammography between women with DLBCL (59.8\%) and no cancer (60.2\%); both of which were well below the Healthy People 2020 target $(81.1 \%$; both $\mathrm{p}<.0001)$. Female DLBCL patients had slightly lower rate of BDT $(18.5 \%)$ than non-cancer patients $(19.6 \% ; \mathrm{p}>.05)$. After adjusting for PCP visits, DLBCL patients were less likely to have mammography (AOR [95\%CI]: $0.82[0.71,0.94]$ ) and BDT $(0.80[0.71,0.90])$ than non-cancer patients. Further, those with more primary care physician visits were more likely to have mammography $(1.62[1.48,1.77])$ and $\operatorname{BDT}(1.60[1.50,1.71])$. Radiotherapy and stem cell transplant were not associated with mammography and BDT, respectively (both $\mathrm{p}>.05$ ). Conclusions. Prioritization of cancer and chronic care may be causing sub-optimal mammography and BDT among female DLBCL patients. Providers should increase the recommendations for mammography in those receiving radiotherapy and BDT in stem cell transplant patients, to reduce the morbidity and mortality from breast cancer and fractures in women with DLBCL. 


\subsection{Introduction}

Non-Hodgkin's Lymphoma (NHL) is the most common hematologic cancer in the United States, with about 72,580 new cases diagnosed in $2016 .{ }^{1}$ Diffuse Large B-Cell Lymphoma (DLBCL) is the most common subtype of NHL and commonly occurs in adults above 64 years of age. ${ }^{2}$ Advances in the treatment of DLBCL such as immunotherapy with Rituximab ${ }^{3}$ and hematopoietic stem cell transplantation ${ }^{4}$ have led to a marked improvement in the five-year survival rate to approximately $60.5 \% .^{5}$ However, DLBCL patients are at a higher risk of secondary cancers and adverse treatment effects than general population. ${ }^{6,7}$ Of particular concern are the risks of breast cancer and loss of bone mineral density among women with DLBCL. 4,6

\subsubsection{Risk of Breast Cancer}

Breast cancer is the most common cancer among women, with 246,660 new cases expected to be diagnosed in $2016 .{ }^{8}$ Older female DLBCL patients who received radiotherapy are at a threefold risk of breast cancer than general population. ${ }^{6,9,10}$ Female breast cancer patients with a history of lymphoma had significantly lower five-year disease free survival (54\%) and overall survival (87\%) as compared to breast cancer patients with no history of lymphoma (91\% and $98 \%$, respectively). ${ }^{11}$ Breast cancer screening with mammography can lead to early treatment due to good sensitivity (68\%) and high specificity (93\%) for detecting breast cancer in lymphoma patients. ${ }^{12-14}$

Increasing the rate of mammography screenings is essential to meet the Healthy People 2020 target of $81.1 \%$ for women aged 50-74 years. ${ }^{15}$ Since 2009 , the US Preventive Services Task Force (USPSTF) recommends biennial mammography screening for women between 50-74 years of age. ${ }^{16}$ Consistent with the USPSTF guidelines, the American Cancer Society also 
recommends mammograms every 2 years for women aged 55 and older. ${ }^{17}$ It is critical to examine the receipt of mammography among DLBCL patients as mammography use can be negatively affected by the competing demands of acute DLBCL treatment, which the provider may deem more necessary for patient's survival. ${ }^{18-20}$

\subsubsection{Risk of Bone Density Loss}

Another well-known adverse consequence of DLBCL treatment is the loss of bone density in women, which can lead to negative sequelae such as osteoporosis and fractures. ${ }^{4,21}$ Bone density loss is high in elderly post-menopausal women, ${ }^{22}$ which can be aggravated by chemotherapy, corticosteroids, and hematopoietic cell transplantation in women with DLBCL. ${ }^{23-}$

${ }^{25}$ For example, female lymphoma patients who received stem cell transplant had eightfold odds of reporting osteoporosis than siblings without cancer. ${ }^{24}$ NHL patients with chemotherapy had higher rates of fractures (31\%) and osteoporosis (10\%) as compared to NHL patients who did not receive chemotherapy (19\% and $8 \%$, respectively). The USPSTF recommends bone mineral density testing (BDT) for osteoporosis in women aged $\geq 65$ years without previous known fractures or secondary causes of osteoporosis. ${ }^{26} \mathrm{BDT}$ by dual photon densitometry at one year is recommended among stem cell transplant recipients due to their elevated risk of having bone density loss. ${ }^{27}$

Older Medicare beneficiaries have been found to have low rates of BDT in a previous study ${ }^{28}$ Some reasons for underuse of BDT include the uncertainty of site and frequency of testing, lack of a cut-off value for fracture risk, and limited predictive value of BDT for fractures. ${ }^{29}$ Further, there are several other risk factors for fractures which are independent of bone mineral density such as history of fracture, maternal history of fracture, age, and low serum levels of estradiol. ${ }^{29}$ However, BDT is currently the most effective measure for predicting the 
risk of fractures in post-menopausal women ${ }^{30-3233}$ and should be provided to female DLBCL patients. Increasing the rates of BDT is crucial to achieve the Healthy People 2020 target of reducing osteoporosis cases and hospitalizations due to fractures. ${ }^{34}$

\subsubsection{Predictors of Screenings}

Cancer patients have been found to be more likely to have preventive screenings than non-cancer patients. For example, breast cancer patients were more likely to receive mammography (74.0\%) and BDT (8.3\%) than matched non-cancer controls (41.0\% and 6.8\%, respectively). ${ }^{35}$ Similarly, colorectal cancer patients were more likely to receive a mammogram (49.8\%) than matched non-cancer patients $(47.4 \%) .{ }^{36}$ Primary Care Physicians (PCPs) play an important role in providing preventive screenings to women with cancer, ${ }^{35,37,38}$ and recommendation by PCP is the one of the best predictors of cancer screening adherence. ${ }^{39,40}$ Breast cancer patients with more visits to $\mathrm{PCP}$ were twice as likely to receive mammography ${ }^{37}$ and colorectal patients with more PCP visits were twice as likely to receive BDT. ${ }^{41} \mathrm{We}$ could not identify any study examining the use of mammography and BDT among women with DLBCL; research investigating mammography and BDT in this population is needed, as DLBCL is a more aggressive cancer and is treated with an intense therapeutic regimen, which may increase the risk for second primary cancers. ${ }^{42}$ DLBCL treatment increases the risk of breast cancer and loss of bone density in women, and it is necessary to analyze the factors that can affect mammography screening and BDT in these patients to improve their quality and quantity of life.

\subsection{Theoretical Framework}

We utilized the Social Ecological Model (SEM) to examine the factors that can affect the receipt of mammography and BDT. The SEM is an overarching theoretical framework to examine the association of diverse personal and surrounding socio-physical factors with a health 
behavior. ${ }^{43,44}$ These factors consist of: 1) intra-personal factors - patient's demographic characteristics, other chronic conditions, and treatments received for DLBCL; 2) inter-personal factors - patients' social network of friends, family, or colleagues; (c) healthcare system factors - availability of hospitals and physicians; and (d) community factors - characteristics of the surrounding geographical area including SEER region, urban/rural region, area poverty, and area education. ${ }^{44-46}$ Previous studies have used the SEM to examine the geographic variations in mammography and colorectal screenings. ${ }^{45,47,48}$ We utilized this framework to examine the association of multiple individual and contextual factors with the receipt of mammography and BDT in women with DLBCL as compared to women without any cancer.

\subsection{Methods}

\subsubsection{Study Design}

We used a retrospective cohort study design with 12 month baseline and 24 month follow-up periods. We identified the baseline and follow-up periods using the DLBCL diagnosis date as the index date for DLBCL patients. For the non-cancer patients, we derived the baseline and follow-up periods by using a random service date from inpatient or outpatient Medicare claims.

\subsubsection{Data Sources}

We utilized the following data sources for this study: 1) Surveillance, Epidemiology and End Results Program (SEER) cancer registry data; 2) 5\% sample of Medicare patients without any cancer; 3) Medicare claims of patients from SEER and non-cancer patients; and 4) the Area Health Resource File (AHRF). SEER is an epidemiologic cancer surveillance system including data from 20 cancer registries (Alaska Native Tumor Registry, Arizona Indians, Cherokee Nation-Oklahoma, Connecticut, Detroit, Atlanta-Georgia, Greater Georgia, Rural Georgia, San 
Francisco-Oakland, San Jose-Monterey, Greater California, Hawaii, Iowa, Kentucky, Los Angeles, Louisiana, New Jersey, New Mexico, Seattle-Puget Sound, and Utah). ${ }^{49}$ These cancer registries collect information for patients with newly diagnosed cancers such as patient's demographic characteristics, site of cancer diagnosis, date of cancer diagnosis, and cancer stage or grade (e.g., DLBCL stage). Medicare claims of beneficiaries who resided in SEER areas can be linked to the SEER registries to collect detailed information on medical treatment, chronic conditions, healthcare utilization, and costs.

The AHRF is a publicly available data provided by the Department of Health and Human Services. ${ }^{50}$ We used the AHRF file to obtain information on the availability of health professionals, healthcare facilities, and socioeconomic and environmental characteristics of each county. We used the state and county Federal Information Processing Standard (FIPS) codes to link the SEER-Medicare dataset with AHRF files.

\subsubsection{Study Sample}

For the outcome of BDT, we included 3,029 female Medicare beneficiaries with age $\geq 66$ years with a primary diagnosis of DLBCL (International Classification of Diseases for Oncology - Third Revision (ICD-O-3)/World Health Organization 2008 codes: 13, 14, 15, 16) during 20032011 (Appendix 3.1). For mammography screening, we included 1,137 female beneficiaries with a primary diagnosis of DLBCL who were between 66-74 years of age (Appendix 3.1). We only included patients who had one primary DLBCL cancer diagnosis (except basal cell carcinoma) and who were not diagnosed with cancer from autopsy.

We selected the non-cancer patients from a random 5\% sample of Medicare beneficiaries who resided in SEER areas during 2003-2011 and were not diagnosed with any cancer, except basal cell carcinoma. From this non-cancer dataset, we selected a 10\% random sample of female 
Medicare beneficiaries as the comparison group. We included 11,956 female Medicare beneficiaries $\geq 66$ years of age for BDT and 5,686 female beneficiaries between 66-74 years of age for mammography screening as the non-cancer comparison group (Appendix 3.2).

We applied the following exclusion criteria to both DLBCL and non-cancer patients: 1) less than 66 years of age; 2) having End Stage Renal Disease (ESRD); 3) not alive during the baseline or follow-up periods; 4) enrolled in managed care plans; 5) not continuously enrolled in Medicare parts A and B during the baseline and follow-up periods; 6) not having any PCP visit during the baseline and follow-up periods; and 7) missing values for age, sex, race, region, or ESRD.

\subsubsection{Measures}

Dependent variables. We analyzed two dependent variables in this study: the receipt of mammography screening and the receipt of BDT. Before 2009, mammography screening was recommended every 1-2 years for women aged 40 and older. ${ }^{51}$ In 2009, the USPSTF revised the recommended screening mammography interval to every two years. To examine if the rates of mammography are consistent with the current USPSTF and American Cancer Society guidelines, we used the time interval of two years for mammography screening in our study. For osteoporosis screening, although the USPSTF has not recommended an optimal interval for repeated screening, a minimum of two years period has been suggested to reliably detect a change in bone mineral density. ${ }^{31,52}$ Hence, we measured the receipt of osteoporosis screening during the two year follow-up period. Further, we adjusted for the year of index date as one of the independent variable. We used the diagnosis and procedure codes in inpatient and outpatient Medicare claims files to measure these variables. We excluded diagnostic mammography screening from the analysis and only included the codes for screening mammography. We 
included BDT with dual energy X-Ray absorptiometry, photon absorptiometry, or Computed Tomography scan in this study. ${ }^{29}$

Key Independent Variable - Cancer Status. The key independent variable for this study was the presence of DLBCL compared with no cancer. The diagnosis of DLBCL belonged to the domain of intra-personal factors from the SEM.

\section{SEM Independent Variables}

The intra-personal factors of radiotherapy, chemo-immunotherapy and stem cell transplant for DLBCL patients were measured during one year after the DLBCL diagnosis. All other intra-personal, inter-personal, healthcare system, and community factors were measured during the one year baseline period before the index date.

Intra-personal factors. 1) Average monthly PCP visits before first mammography or first BDT: PCP specialties included general practice, family practice, internal medicine, geriatric medicine, nurse practitioner, physician assistant, or obstetrics-gynecology. ${ }^{35}$ ObstetricsGynecologists serve as PCPs for many women ${ }^{53-55}$ and have been included as a PCP specialty in previous studies. ${ }^{56}$ Among those who did not receive mammography or BDT, we calculated the average monthly visits to PCP during the follow-up period of 24 months. We identified PCP

specialty by using the Health Care Financing Administration (HCFA) specialty codes ${ }^{35,57,58} ; 2$ ) age at index date (66-69 or 70-74 yrs.); 3) race (Non-Hispanic White, Non-Hispanic African American, Hispanic, or others); 4) rurality: We used urban/rural recode to classify region into metro (counties with $<250,000$ to one million population), urban (counties with 2,500 to $>20,000$ population), and rural (counties with less than 2,500 population) $\left.{ }^{49} ; 5\right)$ geographic region (Northeast, South, North-Central, or West); 6) arthritis (osteoarthritis or rheumatoid arthritis); 7) any heart condition (cardiac arrhythmia, congestive heart failure, or coronary artery disease); 8) 
diabetes; 9) depression or anxiety; and 10) Asthma or Chronic Obstructive Pulmonary Disease (COPD). The intra-personal factors specific to DLBCL patients included: 1) Ann Arbor stage of DLBCL (stage I, II, III or IV); 2) radiotherapy; 3) chemo-immunotherapy; and 4) stem cell transplant.

Inter-personal factors. Inter-personal factors included county-level 1) percentage of Blacks; 2) percentage of Hispanics; and 3) percentage of non-English speaking individuals above 18 years of age.

Healthcare system factors. Healthcare system factors included county level: 1) average number of hospitals per 10,000 individuals above 65 years of age; 2) PCP shortage area (whole county, part of county, or no shortage); and 3) average number of Federal Qualified Health Centers (FQHC) per 10,000 individuals above 65 years of age.

Community factors. Community factors included county level: 1) percentage of individuals without health insurance; 2) average travel time to work; and 3) percentage of individuals with below high school education.

In addition to the SEM factors, we included year of index date as a covariate in all the analyses. A small number of individuals received BDT during 2003 to 2006. Hence, we combined the index years 2003-2006 into a single level and used the following categories for the outcome of BDT: 2003-2006, 2007, 2008, 2009, 2010, and 2011. For mammography, the year of index date was categorized into two groups of: before 2009 and after 2009 to examine the impact of change in USPSTF guidelines in $2009 .{ }^{51}$

\subsubsection{Statistical Analyses}

We analyzed the differences in intra-personal, inter-personal, healthcare, and community factors between the DLBCL and the non-cancer patients by using chi-square tests. We used 
logistic regressions to analyze the relationship of DLBCL diagnosis, PCP visits, and other intrapersonal, inter-personal, healthcare system, and community factors with the receipt of mammography screening and BDT. From our preliminary analysis, we found that there were significant differences in some characteristics between the DLBCL and non-cancer patients. In order to decrease this observed selection bias, we estimated Inverse Probability Treatment Weights (IPTW) by conducting logistic regression on DLBCL compared with no cancer with the independent variables of age, race/ethnicity, index year, geographic region, diabetes, any heart condition, asthma/COPD, arthritis, and depression/anxiety. We used these IPTWs as weights in all the unadjusted and adjusted analyses. All analyses were conducted using SAS version 9.4. ${ }^{59}$

\subsection{Results}

\subsubsection{Characteristics of Female DLBCL and Non-Cancer Patients}

Table 3.1 summarizes the selected characteristics of female DLBCL and non-cancer patients above 65 years of age, before and after adjusting with IPTW. Before adjusting with IPTW, a higher percentage of Whites compared to Blacks, those aged $\geq 70$ years compared to 6669 years, living in Northeast compared to South, those with arthritis compared to those without arthritis, those with any heart condition compared to those without any heart condition, and those with asthma/COPD compared to those without asthma/COPD had DLBCL.

\subsubsection{DLBCL and Mammography}

Table 3.2 summarizes the characteristics of female Medicare beneficiaries by the receipt of mammography screening. From chi-square tests, rates of mammography between DLBCL (59.8\%) and non-cancer patients (60.2\%) did not differ. Further, the mammography rates for both DLBCL and non-cancer female patients were significantly lower than the Healthy People 2020 target of $81.1 \%$ (both $\mathrm{p}<.0001$ ). From logistic regression model 1, without adjusting for 
PCP visits, screening mammography between DLBCL and non-cancer patients did not differ (adjusted odds ratio [95\%CI]: $0.98[0.86,1.13]$ ). However, after adjusting for monthly PCP visits in model 2, DLBCL patients were less likely than non-cancer patients to receive mammography screening (0.82 [0.71, 0.94]).

\subsubsection{PCP Visits and Mammography}

From model 2, female beneficiaries with more monthly visits to PCPs were more likely to receive mammography screening $(1.62[1.48,1.77])$ (Table 3.2). Further, those aged 70-74 years compared to 66-69 years, those with other races compared to Whites, those with asthma/COPD compared to those without asthma/COPD, those with depression/anxiety compared to those without depression/anxiety, those with diabetes compared to those without diabetes, tobacco users compared to non-tobacco users, and those living in counties with more African Americans compared to counties with less African Americans were less likely to have mammography. Also, those living in metro compared to rural regions and those with arthritis compared to those without arthritis were more likely to have mammography.

\subsubsection{DLBCL and Bone Density Testing}

Table 3.3 summarizes the characteristics of female Medicare beneficiaries by the receipt of BDT. From chi-square test, the receipt of BDT between DLBCL (18.5\%) and non-cancer patients $(19.6 \%)$ did not differ $(\mathrm{p}=.173)$. From logistic regression model 3, without adjusting for PCP visits, BDT between DLBCL and non-cancer patients did not differ $(0.94[0.84,1.05])$. After adjusting for monthly PCP visits in model 4, DLBCL patients were less likely than noncancer patients to receive BDT $(0.80[0.71,0.90])$.

\subsubsection{PCP Visits and Bone Density Testing}


From model 4, female beneficiaries with more monthly visits to PCPs were more likely to receive BDT $(1.60[1.50,1.71])$ (Table 3.3). Further, those aged above 70 years compared to 66-69 years, African Americans compared to Whites, those living in urban compared to rural regions, those with any heart condition compared to those without any heart condition, those with depression/anxiety compared to those without depression/anxiety, and those with diabetes compared to those without diabetes were less likely to have BDT. Also, those living in South compared to North-East, those with index years $\geq 2007$ compared to 2003-2006, those with arthritis compared to those without arthritis, and those living in counties with more Hispanics compared to counties with less Hispanics were more likely to have BDT.

\subsubsection{Mammography and BDT among DLBCL Patients}

Among female DLBCL patients, more monthly PCP visits was associated with higher odds of receiving mammography screening $(1.34[1.17,1.54])$ and $\operatorname{BDT}(1.47[1.32,1.63])$. Further, among DLBCL patients, those with other races compared to Whites $(0.45[0.26,0.79])$ and those living in counties with more travel time $(0.44[0.29,0.67])$ compared to less travel time were less likely to have mammography. Also, married women compared to unmarried women $(2.10[1.32,3.36])$ were more likely to receive mammography screening. Radiotherapy was not significantly associated with mammography $(1.04[0.77,1.39])$.

With respect to BDT, more visits to PCPs was associated with higher odds of BDT among DLBCL patients (1.46 [1.31, 1.62]). Further, among DLBCL patients, African Americans compared to Whites $(0.38[0.19,0.75])$ were less likely and those living in counties with more Hispanics compared to counties with less Hispanics $(2.67[1.69,4.23])$ were more likely to receive BDT. With respect to DLBCL treatments, patients receiving chemo-immunotherapy 
were more likely to receive BDT $(2.27[1.42,3.62])$. Stem cell transplant was not significantly associated with BDT $(1.15[0.94,1.41])$.

\subsection{Discussion}

We conducted this study to examine the receipt of mammography and BDT among female patients with DLBCL who are at a higher risk of breast cancer and loss of bone density than general population. We used a social-ecological model to analyze the relationship of diverse personal and environmental factors which can influence the receipt of mammography and BDT among female Medicare beneficiaries with DLBCL compared to those without cancer.

The rates of mammography need to be increased for both DLBCL and non-cancer female patients to meet the Healthy People 2020 target. ${ }^{15}$ Although DLBCL patients are at a higher risk of breast cancer and osteoporosis, without adjusting for PCP visits, there was no significant difference in mammography and BDT between DLBCL patients and non-cancer patients. These results are inconsistent with previous studies in breast and colorectal cancer patients, which found that cancer patients receive more mammograms and BDT than non-cancer patients. ${ }^{35,36,60}$ One explanation is that DLBCL is a more aggressive form of cancer and requires more intensive treatment than breast and colorectal cancer. Further, we found that DLBCL patients with chronic conditions such as diabetes and depression/anxiety were less likely to receive mammography screening and BDT. The providers may be prioritizing the acute DLBCL treatment and management of other comorbid conditions than preventive screenings in DLBCL patients.

After adjusting for PCP visits, DLBCL patients were less likely than non-cancer patients to receive mammography and BDT. Further, more PCP visits was associated with higher mammography and BDT, which indicates the importance of visiting PCPs for receiving preventive screenings. ${ }^{39}$ Providers should increase the recommendations for mammography and 
BDT in DLBCL patients, and perhaps DLBCL will benefit the most from seeing their PCP, particularly in terms of preventive screenings. DLBCL patients have a favorable prognosis and most patients have long survival period after treatment. These patients can benefit by receiving preventive screenings to further improve their quality of life. Further, oncologists should encourage their patients to visit their PCPs frequently to increase their mammography screening and BDT. Although arthritis patients have been found to have lower risk of breast cancer, ${ }^{61-64}$ we found that those with arthritis were more likely to receive mammography. Future studies need to examine the reason for higher mammography use among arthritis patients. We found that the rates of BDT increased four times after 2006. Even though the rates of BDT remain lower than nationally recommended levels, it shows the increase in availability and awareness of BDT in recent years among elderly Medicare beneficiaries.

The risk of breast cancer and osteoporosis varies with the treatment received among DLBCL patients. Female DLBCL patients receiving radiotherapy are at a higher risk of breast cancer ${ }^{6}$ and those receiving stem cell transplant are at a higher risk of osteoporosis. ${ }^{24}$ However, we did not find a significant relationship between radiotherapy and mammography screening. Further, the stem cell transplant was not associated with BDT in female DLBCL patients. These results indicate the need for higher mammography screening among female DLBCL patients receiving radiotherapy and higher BDT among stem cell transplant recipients.

The rate of mammography was lower among women aged 70-74 years as compared to 66-69 years, and BDT was lower among those aged above 70 years as compared to 66-69 years, which is consistent with previous studies. ${ }^{36,65}$ It may be due to belief that preventive services may provide little gain in life expectancy for those with higher age. However, we adjusted for patients' other chronic conditions to control for their physical and mental comorbidities. Also, 
continuing mammography screening in women between $70-74$ years of age has been found to be cost-effective and can increase survival. ${ }^{65-67}$ Similarly, BDT can prevent fractures among elderly women. ${ }^{68-70}$ Hence, mammography should be not be stopped for women with $70-74$ years of age and BDT should be continued among women above 70 years of age as recommended by the USPSTF guidelines.

Our study has some limitations. We used the HCFA specialty codes given in the SEERMedicare dataset to identify the PCP specialties in this study. The HCFA codes have been used in previous studies, ${ }^{20,35,71}$ but these codes may not capture all the visits to different provider specialties. ${ }^{72}$ Our study results are generalizable to female beneficiaries enrolled in fee-forservice Medicare. A strength of our study is that we used a large nationally representative data of patients with newly diagnosed cancer. We examined a comprehensive set of personal and contextual factors in our multivariate models. Further, we used a robust study design with IPTW adjusted analyses to reduce observed selection bias between women with DLBCL and no cancer.

\subsection{Conclusions}

There was no significant difference in mammography and BDT between female DLBCL patients and women with no cancer. After adjusting for PCP visits, women DLBCL patients were less likely than non-cancer patients to receive mammography and BDT. Those with more PCP visits were more likely to have mammography and BDT. Further, those between 70-75 years of age were less likely to receive mammography and those aged above 70 years were less likely to receive BDT than women between 66-69 years of age. Female DLBCL survivors are at a higher risk of breast cancer and osteoporosis and need to receive more preventive screenings.

\section{Implications for Practice and/or Policy}


Our study results suggest that providers should increase their recommendations for breast cancer screening and BDT in women with DLBCL. Rates of mammograms need to be increased for women treated with radiotherapy while BDT should be increased among women who received stem cell transplant. Current guidelines recommend breast cancer screening for women with Hodgkin's lymphoma and BDT for stem cell transplant recipients. Similar clinical guidelines are required for preventive screenings for women with Non-Hodgkin's Lymphoma, which is four times more common than Hodgkin's Lymphoma. 


\subsection{References}

1. National cancer institute. surveillance, epidemiology, and end results program. SEER stat fact sheets: Non-hodgkin lymphoma. http://seer.cancer.gov/statfacts/html/nhl.html. Updated 2016. Accessed 05/09, 2016.

2. Shankland KR, Armitage JO, Hancock BW. Non-hodgkin lymphoma. The Lancet. 2012;380(9844):848-857.

3. Habermann TM, Weller EA, Morrison VA, et al. Rituximab-CHOP versus CHOP alone or with maintenance rituximab in older patients with diffuse large B-cell lymphoma. J Clin Oncol. 2006;24(19):3121-3127. doi: JCO.2005.05.1003 [pii].

4. Paccou J, Merlusca L, Henry-Desailly I, et al. Alterations in bone mineral density and bone turnover markers in newly diagnosed adults with lymphoma receiving chemotherapy: A 1-year prospective pilot study. Ann Oncol. 2014;25(2):481-486. doi: 10.1093/annonc/mdt560 [doi].

5. DeSantis CE, Lin CC, Mariotto AB, et al. Cancer treatment and survivorship statistics, 2014. CA: a cancer journal for clinicians. 2014;64(4):252-271.

6. Tward JD, Wendland MM, Shrieve DC, Szabo A, Gaffney DK. The risk of secondary malignancies over 30 years after the treatment of non-Hodgkin lymphoma. Cancer. 2006;107(1):108-115.

7. Travis LB, Curtis RE, Glimelius B, et al. Second cancers among long-term survivors of nonhodgkin's lymphoma. J Natl Cancer Inst. 1993;85(23):1932-1937. 
8. SEER stat fact sheets: Female breast cancer. https://seer.cancer.gov/statfacts/html/breast.html. Accessed 12/07, 2016.

9. Henderson TO, Amsterdam A, Bhatia S, et al. Systematic review: Surveillance for breast cancer in women treated with chest radiation for childhood, adolescent, or young adult cancer. Ann Intern Med. 2010;152(7):444-455.

10. Clemons M, Loijens L, Goss P. Breast cancer risk following irradiation for Hodgkin's disease. Cancer Treat Rev. 2000;26(4):291-302.

11. Sanna G, Lorizzo K, Rotmensz N, et al. Breast cancer in hodgkin's disease and non-hodgkin's lymphoma survivors. Ann Oncol. 2007;18(2):288-292. doi: mdl399 [pii].

12. Ng AK, Garber JE, Diller LR, et al. Prospective study of the efficacy of breast magnetic resonance imaging and mammographic screening in survivors of hodgkin lymphoma. J Clin Oncol. 2013;31(18):2282-2288. doi: 10.1200/JCO.2012.46.5732 [doi].

13. Diller L, Medeiros Nancarrow C, Shaffer K, et al. Breast cancer screening in women previously treated for hodgkin's disease: A prospective cohort study. J Clin Oncol. 2002;20(8):2085-2091. doi: 10.1200/JCO.2002.08.031 [doi].

14. Howell SJ, Searle C, Goode V, et al. The UK national breast cancer screening programme for survivors of hodgkin lymphoma detects breast cancer at an early stage. Br J Cancer. 2009;101(4):582-588. 
15. Brown ML. Challenges in meeting healthy people 2020 objectives for cancer-related preventive services, national health interview survey, 2008 and 2010. Preventing chronic disease. 2014;11.

16. US Preventive Services Task Force. Screening for breast cancer: U.S. preventive services task force recommendation statement. Ann Intern Med. 2009;151(10):716-26, W-236. doi: 10.7326/0003-4819-151-10-200911170-00008 [doi].

17. Oeffinger KC, Fontham ET, Etzioni R, et al. Breast cancer screening for women at average risk: 2015 guideline update from the american cancer society. JAMA. 2015;314(15):1599-1614.

18. Nutting PA. Competing demands of primary care: A model for the delivery of clinical preventive services. J Fam Pract. 1994;38(0):167.

19. Nutting PA, Baier M, Werner JJ, Cutter G, Conry C, Stewart L. Competing demands in the office visit: What influences mammography recommendations? J Am Board Fam Pract. 2001;14(5):352-361.

20. Earle CC, Neville BA. Under use of necessary care among cancer survivors. Cancer. 2004;101(8):1712-1719.

21. Morrison A, Fan T, Sen SS, Weisenfluh L. Epidemiology of falls and osteoporotic fractures: A systematic review. Clinicoecon Outcomes Res. 2013;5:9-18. doi: 10.2147/CEOR.S38721 [doi].

22. Edwards M, Jameson K, Denison H, et al. Clinical risk factors, bone density and fall history in the prediction of incident fracture among men and women. Bone. 2013;52(2):541-547. 
23. Zelenetz AD, Abramson JS, Advani RH, et al. NCCN clinical practice guidelines in oncology: Non-hodgkin's lymphomas. J Natl Compr Canc Netw. 2010;8(3):288-334.

24. Majhail NS, Ness KK, Burns LJ, et al. Late effects in survivors of hodgkin and non-hodgkin lymphoma treated with autologous hematopoietic cell transplantation: A report from the bone marrow transplant survivor study. Biology of Blood and Marrow Transplantation. 2007;13(10):1153-1159.

25. Ratcliffe MA, Lanham SA, Reid DM, Dawson AA. Bone mineral density (BMD) in patients with lymphoma: The effects of chemotherapy, intermittent corticosteroids and premature menopause. Hematol Oncol. 1992;10(3-4):181-187.

26. U.S. Preventive Services Task Force. Screening for osteoporosis: U.S. preventive services task force recommendation statement. Ann Intern Med. 2011;154(5):356-364. doi:

10.7326/0003-4819-154-5-201103010-00307 [doi].

27. Majhail NS, Rizzo JD, Lee SJ, et al. Recommended screening and preventive practices for long-term survivors after hematopoietic cell transplantation. Hematology/oncology and stem cell therapy. 2012;5(1):1-30.

28. Curtis JR, Carbone L, Cheng H, et al. Longitudinal trends in use of bone mass measurement among older americans, 1999-2005. Journal of Bone and Mineral Research. 2008;23(7):10611067.

29. Cummings SR, Bates D, Black DM. Clinical use of bone densitometry: Scientific review. JAMA. 2002;288(15):1889-1897. 
30. Lewiecki EM, Laster AJ, Miller PD, Bilezikian JP. More bone density testing is needed, not less. Journal of Bone and Mineral Research. 2012;27(4):739-742.

31. Gourlay ML, Fine JP, Preisser JS, et al. Bone-density testing interval and transition to osteoporosis in older women. N Engl J Med. 2012;366(3):225-233.

32. Marshall D, Johnell O, Wedel H. Meta-analysis of how well measures of bone mineral density predict occurrence of osteoporotic fractures. BMJ. 1996;312(7041):1254-1259.

33. Leslie WD, Tsang JF, Caetano PA, Lix LM. Effectiveness of bone density measurement for predicting osteoporotic fractures in clinical practice. The Journal of Clinical Endocrinology \& Metabolism. 2007;92(1):77-81.

34. Office of the Surgeon General (US). Bone health and osteoporosis: A report of the surgeon general. rockville, MD 2004. Reports of the Surgeon General. 2015.

35. Earle CC, Burstein HJ, Winer EP, Weeks JC. Quality of non-breast cancer health maintenance among elderly breast cancer survivors. J Clin Oncol. 2003;21(8):1447-1451. doi: 10.1200/JCO.2003.03.060 [doi].

36. Yu X, McBean AM, Virnig BA. Physician visits, patient comorbidities, and mammography use among elderly colorectal cancer survivors. Journal of Cancer Survivorship. 2007;1(4):275282.

37. Doubeni CA, Field TS, Ulcickas Yood M, et al. Patterns and predictors of mammography utilization among breast cancer survivors. Cancer. 2006;106(11):2482-2488. 
38. Snyder CF, Earle CC, Herbert RJ, Neville BA, Blackford AL, Frick KD. Trends in follow-up and preventive care for colorectal cancer survivors. Journal of general internal medicine. 2008;23(3):254-259.

39. Finkelstein MM. Preventive screening. what factors influence testing? Can Fam Physician. 2002;48:1494-1501.

40. Hawley ST, Earp JA, O'Malley M, Ricketts TC. The role of physician recommendation in women's mammography use: Is it a 2-stage process? Med Care. 2000;38(4):392-403.

41. Snyder CF, Earle CC, Herbert RJ, Neville BA, Blackford AL, Frick KD. Preventive care for colorectal cancer survivors: A 5-year longitudinal study. J Clin Oncol. 2008;26(7):1073-1079. doi: 10.1200/JCO.2007.11.9859 [doi].

42. Martelli M, Ferreri AJ, Agostinelli C, Di Rocco A, Pfreundschuh M, Pileri SA. Diffuse large B-cell lymphoma. Crit Rev Oncol. 2013;87(2):146-171.

43. Stokols D. Translating social ecological theory into guidelines for community health promotion. American journal of health promotion. 1996;10(4):282-298.

44. McLeroy KR, Bibeau D, Steckler A, Glanz K. An ecological perspective on health promotion programs. Health Education \& Behavior. 1988;15(4):351-377.

45. Mobley L, Kuo T, Urato M, Boos J, Lozano-Gracia N, Anselin L. Predictors of endoscopic colorectal cancer screening over time in 11 states. Cancer Causes \& Control. 2010;21(3):445461. 
46. Levit L, Balogh E, Nass S, Ganz PA. Delivering high-quality cancer care:: Charting a new course for a system in crisis. National Academies Press; 2013.

47. Mobley LR, Driscoll D, Clayton L, Anselin L. Heterogeneity in mammography use across the nation: Separating evidence of disparities from the disproportionate effects of geography. International journal of health geographics. 2008;7(1):1.

48. Mobley LR, Clayton LJ, Evans WD. Mammography facilities are accessible, so why is utilization so low? Cancer Causes \& Control. 2009;20(6):1017-1028.

49. SEER-medicare linked database. https://healthcaredelivery.cancer.gov/seermedicare/. Accessed 11/09, 2016.

50. US Department of Health and Human Services. Area health resource file (AHRF). Rockville, MD: Health Resources and Services Administration. . http://ahrf.hrsa.gov/ALLVARs_search.asp.

51. Block LD, Jarlenski MP, Wu AW, Bennett WL. Mammography use among women ages 4049 after the 2009 US preventive services task force recommendation. Journal of general internal medicine. 2013;28(11):1447-1453.

52. U.S. Preventive Services Task Force. Screening for osteoporosis: U.S. preventive services task force recommendation statement. Ann Intern Med. 2011;154(5):356-364. doi: 10.7326/0003-4819-154-5-201103010-00307 [doi].

53. Rosenblatt RA, Hart LG, Baldwin L, Chan L, Schneeweiss R. The generalist role of specialty physicians: Is there a hidden system of primary care? JAMA. 1998;279(17):1364-1370. 
54. Bartman BA, WEISS KB. Women's primary care in the united states: A study of practice variation among physician specialties. Journal of Women's Health. 1993;2(3):261-268.

55. Franks P, Bertakis KD. Physician gender, patient gender, and primary care. Journal of Women's Health. 2003;12(1):73-80.

56. Nadel MR, Shapiro JA, Klabunde CN, et al. A national survey of primary care physicians' methods for screening for fecal occult blood. Ann Intern Med. 2005;142(2):86-94.

57. Earle CC, Neville BA. Under use of necessary care among cancer survivors. Cancer. 2004;101(8):1712-1719.

58. Snyder CF, Frick KD, Herbert RJ, et al. Quality of care for comorbid conditions during the transition to survivorship: Differences between cancer survivors and noncancer controls. J Clin Oncol. 2013;31(9):1140-1148. doi: 10.1200/JCO.2012.43.0272 [doi].

59. Dimaggio C. Introduction. In: SAS for epidemiologists. Springer; 2013:1-5.

60. Lafata JE, Salloum RG, Fishman PA, Ritzwoller DP, O’Keeffe-Rosetti MC, Hornbrook MC. Preventive care receipt and office visit use among breast and colorectal cancer survivors relative to age-and gender-matched cancer-free controls. Journal of Cancer Survivorship. 2015;9(2):201207.

61. Smitten AL, Simon TA, Hochberg MC, Suissa S. A meta-analysis of the incidence of malignancy in adult patients with rheumatoid arthritis. Arthritis research \& therapy. 2008;10(2):1. 
62. Wolfe F, Michaud K. Biologic treatment of rheumatoid arthritis and the risk of malignancy: Analyses from a large US observational study. Arthritis \& Rheumatism. 2007;56(9):2886-2895.

63. Takkouche B, Regueira-Mendez C, Etminan M. Breast cancer and use of nonsteroidal antiinflammatory drugs: A meta-analysis. J Natl Cancer Inst. 2008;100(20):1439-1447. doi: 10.1093/jnci/djn324 [doi].

64. Mellemkjaer L, Linet M, Gridley G, Frisch M, Møller H, Olsen J. Rheumatoid arthritis and cancer risk. Eur J Cancer. 1996;32(10):1753-1757.

65. Mandelblatt J, Saha S, Teutsch S, et al. The cost-effectiveness of screening mammography beyond age 65 years: A systematic review for the US preventive services task force. Ann Intern Med. 2003;139(10):835-842.

66. Kerlikowske K, Salzmann P, Phillips KA, Cauley JA, Cummings SR. Continuing screening mammography in women aged 70 to 79 years: Impact on life expectancy and cost-effectiveness. JAMA. 1999;282(22):2156-2163.

67. Schousboe JT, Kerlikowske K, Loh A, Cummings SR. Personalizing mammography by breast density and other risk factors for breast cancer: Analysis of health benefits and costeffectiveness. Ann Intern Med. 2011;155(1):10-20.

68. Black DM. Why elderly women should be screened and treated to prevent osteoporosis. Am J Med. 1995;98(2):67S-75S.

69. Wilkins $\mathrm{CH}$, Goldfeder JS. Osteoporosis screening is unjustifiably low in older africanamerican women. J Natl Med Assoc. 2004;96(4):461-467. 
70. Hillier TA, Stone KL, Bauer DC, et al. Evaluating the value of repeat bone mineral density measurement and prediction of fractures in older women: The study of osteoporotic fractures. Arch Intern Med. 2007;167(2):155-160.

71. Snyder CF, Frick KD, Herbert RJ, et al. Quality of care for comorbid conditions during the transition to survivorship: Differences between cancer survivors and noncancer controls. J Clin Oncol. 2013;31(9):1140-1148. doi: 10.1200/JCO.2012.43.0272 [doi].

72. Baldwin LM, Adamache W, Klabunde CN, Kenward K, Dahlman C, L Warren J. Linking physician characteristics and medicare claims data: Issues in data availability, quality, and measurement. Med Care. 2002;40(8 Suppl):IV-82-95. doi:

10.1097/01.MLR.0000020933.36849.20 [doi]. 
Table 3.1 Description of Selected Characteristics of Female Medicare Beneficiaries above 65 Years of Age with Diffuse Large B-Cell Lymphoma (DLBCL) and No Cancer before and after Inverse Probability Treatment Weights. Surveillance Epidemiology and End Results Program (SEER) Medicare 2003-2011.

\begin{tabular}{|c|c|c|c|c|c|c|c|c|}
\hline & \multicolumn{2}{|c|}{ DLBCL } & \multicolumn{2}{|c|}{ No Cancer } & \multirow[b]{2}{*}{$\operatorname{sig}$} & \multirow{2}{*}{$\begin{array}{c}\text { DLBCL } \\
\text { IPTW col\% }\end{array}$} & \multirow{2}{*}{$\begin{array}{l}\text { No Cancer } \\
\text { IPTW col\% }\end{array}$} \\
\hline & & $\mathrm{n}$ & $\mathrm{col} \%$ & $\mathrm{n}$ & $\mathrm{col} \%$ & & & \\
\hline & Total & 3,029 & 100.0 & 11,956 & 100.0 & & & \\
\hline \multirow[t]{3}{*}{ Age } & & & & & & $* * *$ & & \\
\hline & $66-69 \mathrm{yrs}$. & 535 & 17.7 & 2,914 & 24.4 & & 23.0 & 23.0 \\
\hline & $\geq 70$ yrs. & 2,494 & 82.3 & 9,042 & 75.6 & & 77.0 & 77.0 \\
\hline \multirow[t]{5}{*}{ Race } & & & & & & $* * *$ & & \\
\hline & White & 2,645 & 87.3 & 9,877 & 82.6 & & 83.4 & 83.6 \\
\hline & African American & 121 & 4.0 & 940 & 7.9 & & 7.3 & 7.1 \\
\hline & Hispanic & 78 & 2.6 & 272 & 2.3 & & 2.3 & 2.3 \\
\hline & Others & 185 & 6.1 & 867 & 7.3 & & 7.0 & 7.0 \\
\hline \multirow[t]{5}{*}{ Regior } & & & & & & $* * *$ & & \\
\hline & Northeast & 667 & 22.0 & 2,371 & 19.8 & & 20.5 & 20.3 \\
\hline & South & 705 & 23.3 & 3,207 & 26.8 & & 25.8 & 26.1 \\
\hline & North-central & 401 & 13.2 & 1,448 & 12.1 & & 12.3 & 12.3 \\
\hline & West & 1,256 & 41.5 & 4,930 & 41.2 & & 41.4 & 41.3 \\
\hline \multicolumn{9}{|c|}{ Rural Urban } \\
\hline & Metro & 2,514 & 83.0 & 9,926 & 83.0 & & 83.1 & 83.1 \\
\hline & Urban & 455 & 15.0 & 1,791 & 15.0 & & 15.0 & 14.9 \\
\hline & Rural & 60 & 2.0 & 239 & 2.0 & & 2.0 & 2.0 \\
\hline \multicolumn{2}{|c|}{ Index year } & & & & & ** & & \\
\hline & 2003 & 341 & 11.3 & 1,409 & 11.8 & & 11.7 & 11.7 \\
\hline & 2004 & 349 & 11.5 & 1,325 & 11.1 & & 11.5 & 11.2 \\
\hline & 2005 & 334 & 11.0 & 1,277 & 10.7 & & 10.9 & 10.8 \\
\hline & 2006 & 326 & 10.8 & 1,158 & 9.7 & & 10.1 & 9.9 \\
\hline & 2007 & 336 & 11.1 & 1,207 & 10.1 & & 10.2 & 10.3 \\
\hline & 2008 & 357 & 11.8 & 1,245 & 10.4 & & 10.6 & 10.7 \\
\hline & 2009 & 331 & 10.9 & 1,320 & 11.0 & & 11.0 & 11.0 \\
\hline & 2010 & 323 & 10.7 & 1,403 & 11.7 & & 11.4 & 11.5 \\
\hline & 2011 & 332 & 11.0 & 1,612 & 13.5 & & 12.5 & 13.0 \\
\hline \multicolumn{2}{|c|}{ Arthritis } & & & & & $* * *$ & & \\
\hline & Yes & 1,125 & 37.1 & 3,895 & 32.6 & & 33.3 & 33.5 \\
\hline & No & 1,904 & 62.9 & 8,061 & 67.4 & & 66.7 & 66.5 \\
\hline \multicolumn{2}{|c|}{ Any Heart Condition } & & & & & $* * *$ & & \\
\hline & Yes & 1,227 & 40.5 & 4,422 & 37.0 & & 38.2 & 37.7 \\
\hline & No & 1,802 & 59.5 & 7,534 & 63.0 & & 61.8 & 62.3 \\
\hline \multicolumn{2}{|c|}{ Asthma/COPD } & & & & & $* * *$ & & \\
\hline & Yes & 643 & 21.2 & 2,202 & 18.4 & & 19.2 & 19.0 \\
\hline & No & 2,386 & 78.8 & 9,754 & 81.6 & & 80.8 & 81.0 \\
\hline \multicolumn{2}{|c|}{ Depression/Anxiety } & & & & & $* * *$ & & \\
\hline & Yes & 417 & 13.8 & 1,741 & 14.6 & & 14.8 & 14.4 \\
\hline & No & 2,612 & 86.2 & 10,215 & 85.4 & & 85.2 & 85.6 \\
\hline \multicolumn{2}{|c|}{ Diabetes } & & & & & $* * *$ & & \\
\hline & Yes & 892 & 29.4 & 3,443 & 28.8 & & 29.7 & 28.8 \\
\hline
\end{tabular}




\section{No}

$2,137 \quad 70.6 \quad 8,513 \quad 71.2$

70.3

71.2

Note. Based on 3,029 female Medicare beneficiaries with Diffuse Large B-Cell Lymphoma and a random sample of 11,956 female beneficiaries without any cancer who resided in SEER areas. Weighted percentages were derived with using inverse probability treatment weights. COPD: Chronic Obstructive Pulmonary Disease; Sig. significance level.

$* * * \mathrm{p}<.001 * * .001 \leq \mathrm{p}<.01$ 
Table 3.2 Unadjusted Differences and Adjusted Odds Ratios for Screening Mammography by Selected Characteristics of Female Medicare Beneficiaries between 66-74 years of age after Inverse Probability Treatment Weights. Surveillance Epidemiology and End Results Program (SEER) - Medicare 2003-2011.

Screening Mammography

\begin{tabular}{|c|c|c|c|c|c|c|c|c|c|c|c|}
\hline & & & Yes & No & & & Model 1 & & & Model 2 & \\
\hline & & $\mathrm{n}$ & IPTV & ow\% & Sig. & AOR & $95 \% \mathrm{CI}$ & Sig. & AOR & $95 \% \mathrm{CI}$ & Sig. \\
\hline & Total & & 4,103 & 2,720 & & & & & & & \\
\hline DLBCL & & & & & & & & & & & \\
\hline & Yes & 1,137 & 59.8 & 40.2 & & 0.98 & {$[0.86,1.13]$} & & 0.82 & {$[0.71,0.94]$} & $* *$ \\
\hline & No Cancer & 5,686 & 60.2 & 39.8 & & Ref. & & & Ref. & & \\
\hline Mean M & nthly PCP Visits & 0.43 & 0.80 & 0.54 & $* * *$ & & NA & & 1.62 & {$[1.48,1.77]$} & $* * *$ \\
\hline Age & & & & & $* * *$ & & & & & & \\
\hline & $70-74$ yrs. & 3,374 & 57.5 & 42.5 & & 0.80 & {$[0.72,0.89]$} & $* * *$ & 0.80 & {$[0.72,0.89]$} & $* * *$ \\
\hline & $66-69 \mathrm{yrs}$. & 3,449 & 62.8 & 37.2 & & Ref. & & & Ref. & & \\
\hline Race & & & & & $* * *$ & & & & & & \\
\hline & African American & 541 & 58.7 & 41.3 & & 0.97 & {$[0.79,1.18]$} & & 0.97 & {$[0.79,1.18]$} & \\
\hline & Hispanic & 149 & 60.3 & 39.7 & & 1.07 & {$[0.75,1.53]$} & & 1.10 & {$[0.76,1.58]$} & \\
\hline & Others & 512 & 49.4 & 50.6 & & 0.59 & {$[0.48,0.72]$} & $* * *$ & 0.57 & {$[0.47,0.70]$} & $* * *$ \\
\hline & White & 5,621 & 61.3 & 38.7 & & Ref. & & & Ref. & & \\
\hline Region & & & & & & & & & & & \\
\hline & South & 1,903 & 59.5 & 40.5 & & 1.17 & {$[0.98,1.41]$} & & 1.12 & {$[0.93,1.35]$} & \\
\hline & North-central & 803 & 59.7 & 40.3 & & 0.97 & {$[0.80,1.19]$} & & 0.92 & {$[0.75,1.12]$} & \\
\hline & West & 2,893 & 60.5 & 39.5 & & 1.13 & {$[0.95,1.34]$} & & 1.10 & {$[0.92,1.31]$} & \\
\hline & Northeast & 1,224 & 60.4 & 39.6 & & Ref. & & & Ref. & & \\
\hline Rurality & & & & & & & & & & & \\
\hline & Metro & 5,612 & 60.5 & 39.5 & & 1.62 & {$[1.09,2.40]$} & $*$ & 1.57 & {$[1.05,2.35]$} & $*$ \\
\hline & Urban & 1,080 & 59.2 & 40.8 & & 1.42 & {$[0.96,2.09]$} & & 1.35 & {$[0.91,2.01]$} & \\
\hline & Rural & 131 & 51.9 & 48.1 & & Ref. & & & Ref. & & \\
\hline Arthritis & & & & & & & & & & & \\
\hline & Yes & 1,964 & 61.4 & 38.6 & & 1.19 & {$[1.06,1.34]$} & $* *$ & 1.15 & {$[1.02,1.29]$} & $*$ \\
\hline & No & 4,859 & 59.6 & 40.4 & & Ref. & & & Ref. & & \\
\hline Any Hec & t Condition & & & & $*$ & & & & & & \\
\hline & Yes & 1,974 & 58.0 & 42.0 & & 1.00 & {$[0.88,1.12]$} & & 0.92 & {$[0.82,1.04]$} & \\
\hline & No & 4,849 & 61.0 & 39.0 & & Ref. & & & Ref. & & \\
\hline Asthma/ & COPD & & & & $* * *$ & & & & & & \\
\hline & Yes & 1,236 & 54.5 & 45.5 & & 0.82 & {$[0.71,0.93]$} & $* *$ & 0.78 & {$[0.68,0.90]$} & $* * *$ \\
\hline & No & 5,587 & 61.4 & 38.6 & & Ref. & & & Ref. & & \\
\hline Depress & n/Anxiety & & & & $* * *$ & & & & & & \\
\hline & Yes & 1,000 & 54.9 & 45.1 & & 0.78 & {$[0.67,0.90]$} & $* * *$ & 0.71 & {$[0.61,0.82]$} & $* * *$ \\
\hline & No & 5,823 & 61.0 & 39.0 & & Ref. & & & Ref. & & \\
\hline Diabetes & & & & & $* * *$ & & & & & & \\
\hline & Yes & 2,012 & 56.5 & 43.5 & & 0.86 & {$[0.77,0.97]$} & $*$ & 0.80 & {$[0.71,0.90]$} & $* * *$ \\
\hline & No & 4,811 & 61.7 & 38.3 & & Ref. & & & Ref. & & \\
\hline Tobacco & Use & & & & $* * *$ & & & & & & \\
\hline & Yes & 214 & 41.3 & 58.7 & & 0.48 & {$[0.36,0.65]$} & $* * *$ & 0.46 & {$[0.34,0.62]$} & $* * *$ \\
\hline & No & 6,609 & 60.7 & 39.3 & & Ref. & & & Ref. & & \\
\hline
\end{tabular}

Index Year 
Table 3.2 Unadjusted Differences and Adjusted Odds Ratios for Screening Mammography by Selected Characteristics of Female Medicare Beneficiaries between 66-74 years of age after Inverse Probability Treatment Weights. Surveillance Epidemiology and End Results Program (SEER) - Medicare 2003-2011.

\begin{tabular}{|c|c|c|c|c|c|c|c|c|c|c|}
\hline After 2009 & 1,990 & 59.7 & 40.3 & & 0.97 & {$[0.86,1.08]$} & & 0.96 & {$[0.86,1.08]$} & \\
\hline Before 2009 & 4,833 & 60.3 & 39.7 & & Ref. & & & Ref. & & \\
\hline County\% Blacks & & & & $* *$ & & & & & & \\
\hline 4.45 & 1,686 & 60.8 & 39.2 & & 0.87 & {$[0.74,1.02]$} & & 0.85 & {$[0.72,1.00]$} & \\
\hline 10.09 & 1,701 & 57.2 & 42.8 & & 0.79 & {$[0.66,0.95]$} & $*$ & 0.78 & {$[0.65,0.93]$} & $* *$ \\
\hline 31.12 & 1,710 & 58.9 & 41.1 & & 0.80 & {$[0.65,0.97]$} & $*$ & 0.79 & {$[0.64,0.97]$} & * \\
\hline 1.22 & 1,726 & 63.7 & 36.3 & & Ref. & & & Ref. & & \\
\hline $\begin{array}{l}\text { County\% Less than High } \\
\text { School Education }\end{array}$ & & & & $* * *$ & & & & & & \\
\hline 12.48 & 1,697 & 63.3 & 36.7 & & 0.98 & {$[0.84,1.14]$} & & 0.98 & {$[0.84,1.15]$} & \\
\hline 16.71 & 1,731 & 59.0 & 41.0 & & 0.80 & {$[0.69,0.94]$} & $* *$ & 0.82 & {$[0.70,0.96]$} & $*$ \\
\hline 25.37 & 1,698 & 54.6 & 45.4 & & 0.68 & {$[0.57,0.82]$} & $* * *$ & 0.67 & {$[0.56,0.80]$} & $* * *$ \\
\hline 8.48 & 1,697 & 63.7 & 36.3 & & Ref. & & & Ref. & & \\
\hline
\end{tabular}

Note. Based on 1,137 female Medicare beneficiaries with Diffuse Large B-Cell Lymphoma and a random sample of 5,686 female beneficiaries without any cancer between 66-74 years of age who resided in SEER areas. Weighted percentages were derived with using inverse probability treatment weights. COPD: Chronic Obstructive Pulmonary Disease; PCP: Primary care physician; Sig. significance level.

$* * * \mathrm{p}<.001 * * .001 \leq \mathrm{p}<.01 * .01 \leq \mathrm{p}<.05$ 
Table 3.3 Unadjusted Differences and Adjusted Odds Ratios for Bone Density Testing by Selected Characteristics of Female Medicare Beneficiaries above 65 years of Age after Inverse Probability Treatment Weights. Surveillance Epidemiology and End Results Program (SEER) - Medicare 2003-2011.

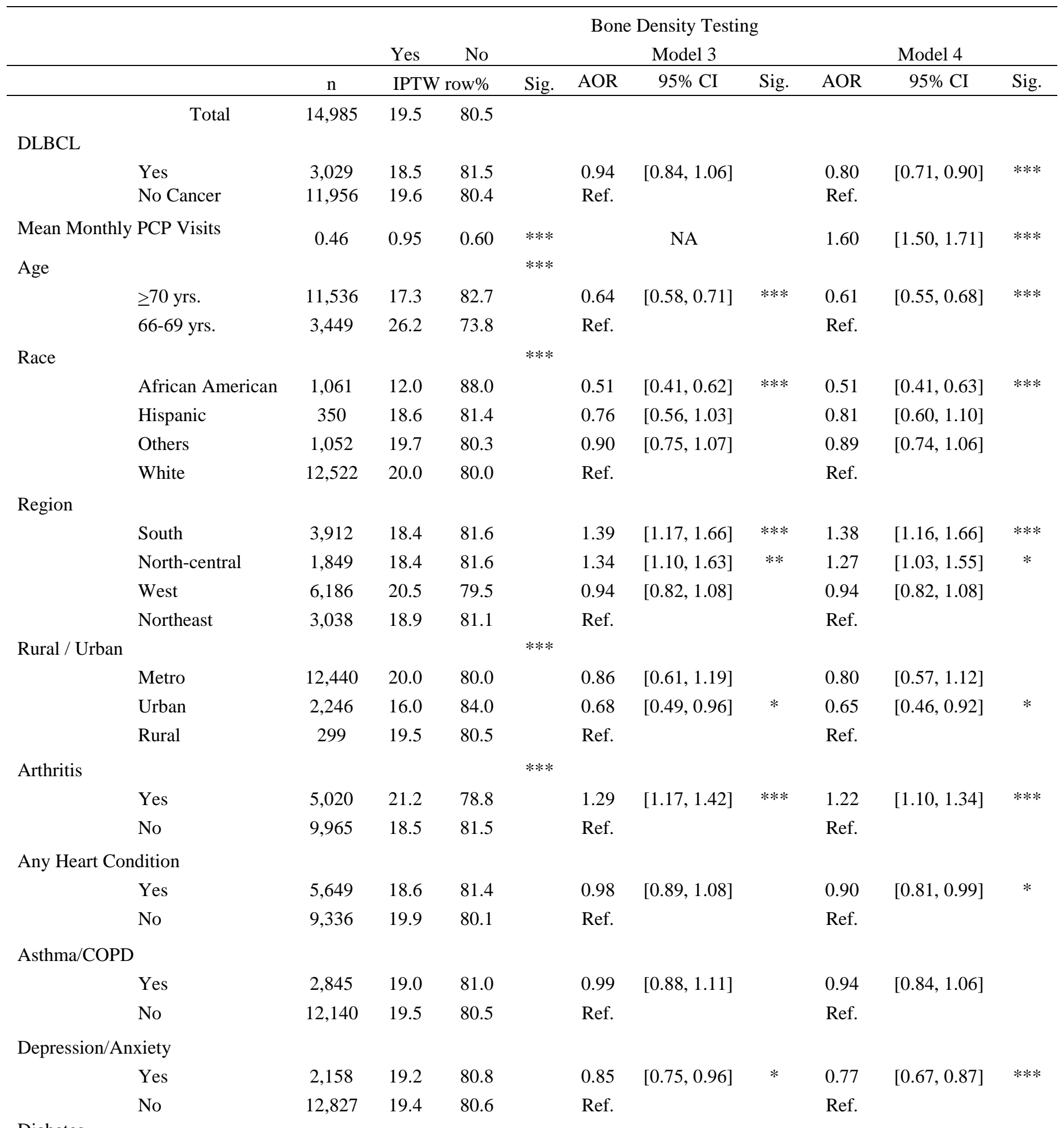


Table 3.3 Unadjusted Differences and Adjusted Odds Ratios for Bone Density Testing by Selected Characteristics of Female Medicare Beneficiaries above 65 years of Age after Inverse Probability Treatment Weights. Surveillance Epidemiology and End Results Program (SEER) - Medicare 2003-2011.

\begin{tabular}{|c|c|c|c|c|c|c|c|c|c|c|c|}
\hline & Yes & 4,335 & 19.0 & 81.0 & & 0.87 & {$[0.79,0.97]$} & $* *$ & 0.81 & {$[0.73,0.90]$} & $* * *$ \\
\hline & No & 10,650 & 19.5 & 80.5 & & Ref. & & & Ref. & & \\
\hline \multirow[t]{7}{*}{ Index Year } & & & & & $* * *$ & & & & & & \\
\hline & 2007 & 1,543 & 28.6 & 71.4 & & 4.84 & {$[4.15,5.63]$} & $* * *$ & 4.79 & {$[4.10,5.59]$} & $* * *$ \\
\hline & 2008 & 1,602 & 31.2 & 68.8 & & 5.45 & {$[4.69,6.33]$} & $* * *$ & 5.44 & {$[4.68,6.33]$} & $* * *$ \\
\hline & 2009 & 1,651 & 27.3 & 72.7 & & 4.52 & {$[3.88,5.26]$} & $* * *$ & 4.49 & {$[3.85,5.23]$} & $* * *$ \\
\hline & 2010 & 1,726 & 28.3 & 71.7 & & 4.63 & {$[3.99,5.37]$} & $* * *$ & 4.50 & {$[3.87,5.23]$} & $* * *$ \\
\hline & 2011 & 1,944 & 28.0 & 72.0 & & 4.47 & {$[3.86,5.17]$} & $* * *$ & 4.38 & {$[3.78,5.08]$} & $* * *$ \\
\hline & $\begin{array}{l}2003,2004,2005, \\
2006\end{array}$ & 6,519 & 7.5 & 92.5 & & Ref. & & & Ref. & & \\
\hline \multicolumn{5}{|c|}{ County\% Hispanics } & $* * *$ & & & & & & \\
\hline & 6.81 & 3,772 & 19.9 & 80.1 & & 1.29 & {$[1.10,1.51]$} & $* *$ & 1.27 & {$[1.08,1.49]$} & $* *$ \\
\hline & 17.00 & 3,656 & 19.9 & 80.1 & & 1.42 & {$[1.17,1.71]$} & $* * *$ & 1.43 & {$[1.18,1.74]$} & $* * *$ \\
\hline & 42.99 & 3,791 & 22.9 & 77.1 & & 2.05 & {$[1.62,2.59]$} & $* * *$ & 2.09 & {$[1.65,2.65]$} & $* * *$ \\
\hline & 2.23 & 3,766 & 14.7 & 85.3 & & Ref. & & & Ref. & & \\
\hline \multicolumn{12}{|c|}{ County\% Less Than High School } \\
\hline & 12.43 & 3,829 & 19.5 & 80.5 & & 0.96 & {$[0.83,1.10]$} & & 0.94 & {$[0.82,1.08]$} & \\
\hline & 16.71 & 3,691 & 19.0 & 81.0 & & 0.85 & {$[0.73,0.99]$} & $*$ & 0.84 & {$[0.72,0.98]$} & $*$ \\
\hline & 25.20 & 3,721 & 19.3 & 80.7 & & 0.78 & {$[0.65,0.94]$} & $* *$ & 0.75 & {$[0.62,0.90]$} & $* *$ \\
\hline & 8.46 & 3,744 & 19.7 & 80.3 & & Ref. & & & Ref. & & \\
\hline
\end{tabular}

Note. Based on 3,029 female Medicare beneficiaries with Diffuse Large B-Cell Lymphoma and a random sample of 11,956 female beneficiaries without any cancer who resided in SEER areas. Weighted percentages were derived with using inverse probability treatment weights. COPD: Chronic Obstructive Pulmonary Disease; PCP: Primary care physician; Sig. significance level. $* * * \mathrm{p}<.001 * * .001<\mathrm{p}<.01 * .01<\mathrm{p}<.05$ 
Appendix 3.1 Flowchart of Sample Selection for Female Medicare Beneficiaries with Diffuse Large B-Cell Lymphoma.

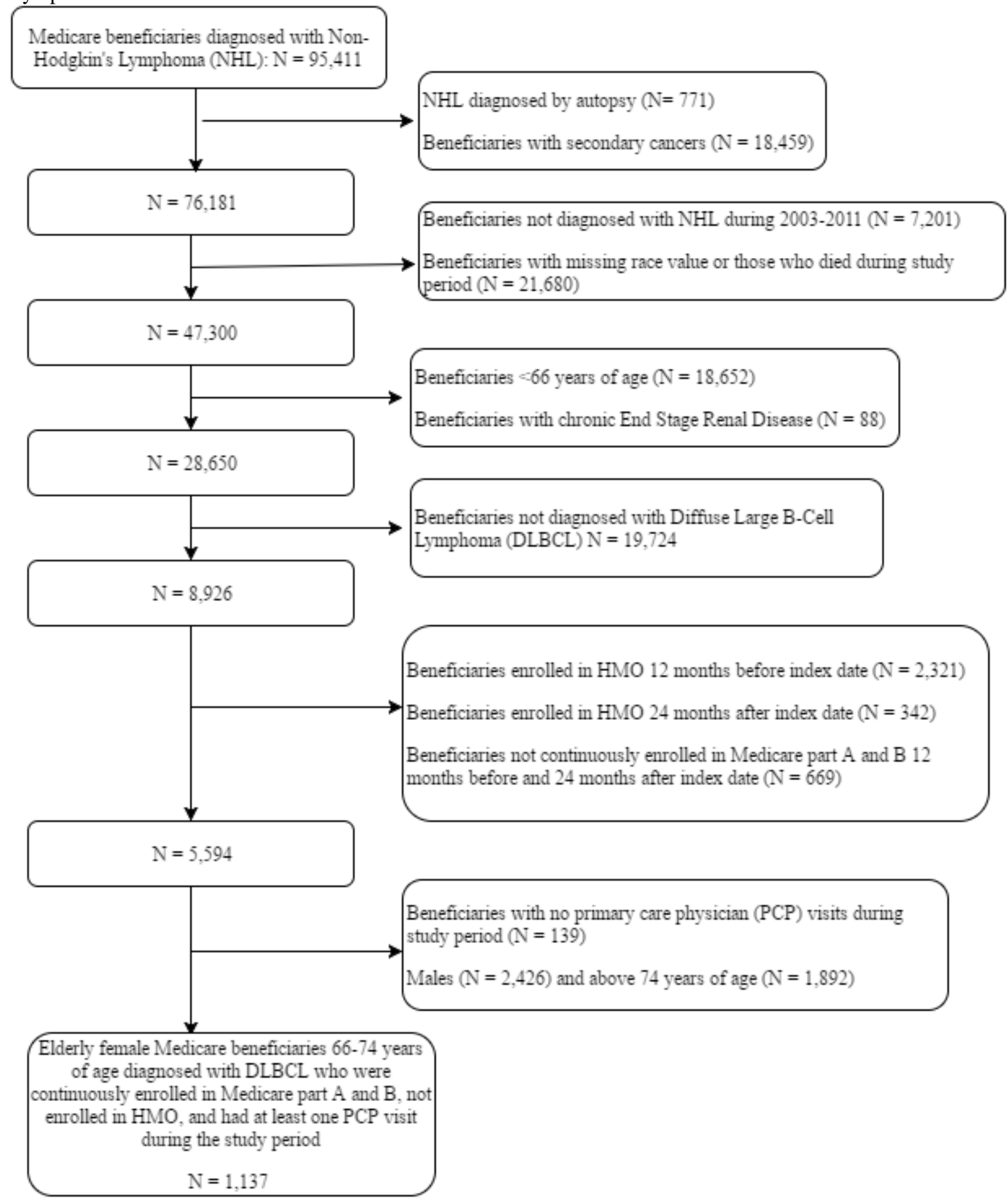


Appendix 3.2 Flowchart of Sample Selection for Female Medicare Beneficiaries with No Cancer.

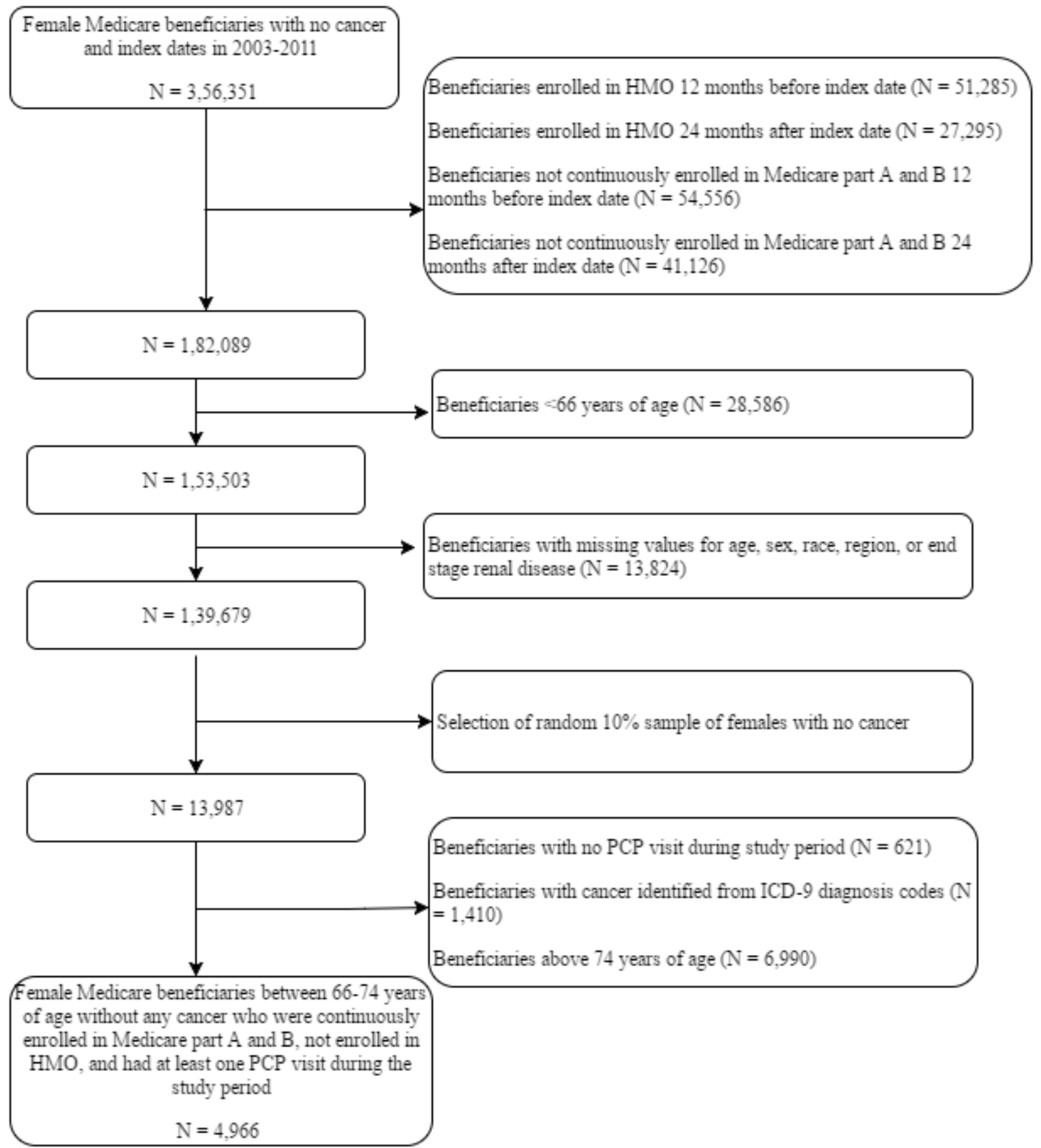




\section{Chapter 4: Impact of Diffuse Large B-Cell Lymphoma on the Costs of Chronic Conditions in Elderly Medicare Beneficiaries}

\subsection{Abstract}

Background. Newly diagnosed Diffuse Large B-Cell Lymphoma (DLBCL) can increase the cost burden of chronic conditions in elderly individuals. However, there is a lack of research on change in costs of chronic conditions during DLBCL diagnosis, treatment, and follow-up as compared to those without cancer. Objective. We examined the cost of common chronic conditions and total cost among 5,455 DLBCL patients $>65$ years of age as compared to 14,770 individuals without cancer during a 3-year period of DLBCL diagnosis, treatment, and followup. Methods. We used a retrospective longitudinal study design with Surveillance, Epidemiology, and End Results (SEER)-Medicare 2002-2013 data to estimate the costs of care during 6 months' intervals (pre-diagnosis: $\mathrm{t} 1$, t2 and post-diagnosis: $\mathrm{t} 3, \mathrm{t} 4, \mathrm{t}$, t6). All costs were adjusted to 2013 constant dollars. Results. The difference in total cost between DLBCL and noncancer patients increased substantially from $\mathrm{t} 1(\$ 468.8)$ to $\mathrm{t} 3$ (treatment period: $\$ 60,746.1)$ and t6 $(\$ 6,614.8)$. DLBCL patients had a higher cost of heart conditions; however, they had significantly lower costs of hypertension, asthma/chronic obstructive pulmonary disease, any mental illness, and diabetes than non-cancer patients (all $\mathrm{p}<.001)$. Conclusions. DLBCL patients incurred high total cost of care during the treatment period. The cardiotoxicity of DLBCL treatment may have increased the cost of heart conditions. DLBCL patients might be receiving less healthcare services for other conditions leading to lower short term costs of other common chronic conditions. Future studies are recommended to investigate the cost-effectiveness of increasing the quality of care for chronic conditions among DLBCL patients. 


\subsection{Introduction}

Advances in early detection and treatment of cancer among elderly individuals have led to a substantial cost burden to Medicare, which is projected to further increase in the next decade. ${ }^{1,2}$ The cancer specific and total costs of care vary widely according to the tumor site and phase of care. ${ }^{1}$ Brain, pancreatic, gastric, esophageal, ovarian, and liver cancers account for highest costs (> \$40,000), as compared to breast, prostate, urinary bladder, and skin cancers. ${ }^{1}$ Non-Hodgkin's Lymphoma is the most common blood cancer in the United States and is commonly diagnosed in an aggressive form. ${ }^{3}$ The total annual cost of care for patients with lymphoma has been found to be highest during the first 12 months after diagnosis (men: $\$ 27,686$, women: $\$ 28,882)$ and last year of life $(\$ 45,760, \$ 51,763)$ as compared to annual cost in between these phases $(\$ 3,993, \$ 4,536) .{ }^{1}$ To date, no studies have compared the costs of care for patients with lymphoma to non-cancer controls.

Medicare spending is further compounded for beneficiaries who have chronic conditions in addition to cancer, ${ }^{4}$ which is ten times more common among elderly as compared to younger individuals. ${ }^{5-7}$ For example, elderly renal cell cancer patients had higher one year Medicare costs due to hyperlipidemia (\$2745) and anemia (\$2167) in 2005 as compared to cancer patients without hyperlipidemia and anemia. ${ }^{8}$ Further, the additional 6-month cost of chronic conditions among cancer survivors included $\$ 3418$-\$4385 for heart conditions; $\$ 5040-\$ 8155$ for respiratory conditions; \$7483-\$7714 for diabetes; and \$8004-\$11,009 for mental conditions in Medicaid enrollees in three states (Georgia, Maine, or Illinois) in 2003. Existing studies have examined the additional cost burden of chronic conditions in patients with cancers such as colon ${ }^{9}$, renal cell ${ }^{8}$, oral $^{10}$, ovarian ${ }^{11}$, and thyroid ${ }^{12}$ cancers as compared to those without any chronic condition. However, there is a dearth of evidence for the impact of cancer on the costs of chronic conditions 
before cancer diagnosis, during cancer treatment, and at follow-up periods, as compared to those without cancer. Aggressive cancers such as Diffuse Large B-Cell Lymphoma (DLBCL) can have varying effects on the costs of different chronic conditions, particularly in light of treatment toxicities, which has not been previously explored.

DLBCL is the most common subtype of Non-Hodgkin's lymphoma ${ }^{13}$ and requires intensive treatment regimens such as chemo-immunotherapy and stem cell transplant. ${ }^{14,15}$ Chemotherapy with Doxorubicin is associated with cardiotoxicity ${ }^{16}$ while stem cell transplant increases the risk of osteoporosis and fractures ${ }^{17,18}$ in DLBCL patients. These treatments can specifically increase the cost of heart conditions, arthritis, and osteoporosis in DLBCL patients. However, previous studies have found that patients with colorectal cancer were less likely to receive care for heart conditions, diabetes, and COPD, ${ }^{19,20}$ which can decrease the short term cost but increase the long term cost of these chronic conditions. Hence, the diagnosis and treatment of DLBCL can selectively increase or decrease the cost of some chronic conditions, which has implications for resource allocation and bundled payments for DLBCL.

The Centers for Medicare and Medicaid Services (CMS) launched a new bundled payment model for cancer care called the 'Oncology Care Model' in 2016. ${ }^{21}$ This model will be implemented over next five years and will reward participating physician group practices for reducing the costs of care while meeting the benchmark quality measures. It is important to examine the total costs and the costs of common chronic conditions among DLBCL patients to inform the target costs for performance-based payments under this model. The study findings will also highlight the potential benefits of early prevention, detection, and chronic disease management efforts for DLBCL patients. 


\subsection{Theoretical Framework}

To date, most existing studies dealing with costs of care have examined the individual characteristics including gender, race, age, education, and income, while less attention has been paid to the societal or contextual factors. ${ }^{22-2627}$ Societal and environmental factors such as county level racial/ethnic composition, availability of healthcare facilities, and transportation have a significant impact on healthcare utilization, thereby affecting the costs of care. ${ }^{28-31}$ For example, blacks had higher healthcare utilization when they lived in a county with a higher percentage of blacks. ${ }^{29}$ Higher availability of primary care physicians and non-rural area of residence were associated with higher use of preventive services. ${ }^{32}$ Per-capita spending by Medicare varies significantly across the different states as well. ${ }^{33}$

Since the costs of care are a result of decisions made at individual, societal, and organizational levels, ${ }^{34}$ we used a multilevel Socio Ecological Model (SEM) as the theoretical framework to analyze the cost of chronic conditions and total cost among DLBCL patients..$^{35,36}$ Previous studies have used the SEM to examine the healthcare utilization of patients with or without cancer. ${ }^{37-41}$ According to the SEM, the utilization of healthcare services is determined by following individual and contextual factors ${ }^{35,36,42}:$ 1) Intra-personal factors: include unique socio-demographic characteristics of individuals such as age, sex, race, stage of DLBCL, and DLBCL treatments; 2) Inter-personal factors: consist of racial/ethnic composition of county measured by percentage of Blacks and Hispanics in the county; 3) Healthcare system factors: include the availability of hospitals and physicians in the county which facilitate the use of healthcare services; and 4) Community factors: consist of the surrounding geographical area including SEER region, urban/rural region, and county level poverty, education, and average travel time. ${ }^{36,37,43}$ Therefore, the purpose of this study is to examine the costs of care for common 
chronic conditions and total costs among elderly Medicare beneficiaries with DLBCL over a 3year study period as compared to beneficiaries without any cancer.

\subsection{Methods}

\subsubsection{Study Design}

This study used a retrospective longitudinal study design with 12 month pre-index and 24 month post-index phases. For DLBCL patients, we defined the pre-index and post-index phases using the DLBCL diagnosis as the index date. For non-cancer patients, we used a random inpatient or outpatient Medicare claim service date to identify the pre-index and post-index phases. We divided the pre-index and post-index phases into six months' intervals (t1-t6). For DLBCL patients, the pre-index phase consisted of baseline (t1) and pre-diagnosis ( $\mathrm{t} 2$ ) and postindex phase comprised of treatment (t3), post-treatment (t4), short follow-up (t5), and long follow-up (t6) periods.

\subsubsection{Data Sources}

We utilized the following data sources for this study: 1) Surveillance, Epidemiology and End Results Program (SEER) data: SEER is an epidemiologic cancer surveillance system which collects information on patients with incident cancers residing in 20 cancer registry areas (Alaska Native Tumor Registry, Arizona Indians, Cherokee Nation-Oklahoma, Connecticut, Detroit, Atlanta-Georgia, Greater California, Greater Georgia, Hawaii, Iowa, Kentucky, Los Angeles, Louisiana, New Jersey, New Mexico, Rural Georgia, San Francisco-Oakland, San JoseMonterey, Seattle-Puget Sound, and Utah). ${ }^{44}$ SEER contains data on cancer patient's demographic characteristics, site and date of cancer diagnosis, stage and grade of cancer (e.g., Ann Arbor DLBCL stage, and region and rurality of resident area. 2) Random sample of 5\% Medicare beneficiaries: We used this data to derive a comparison group of Medicare 
beneficiaries without any cancer (except basal cell carcinoma) who resided in SEER areas. 3) Medicare claims data: We linked the Medicare claims data with SEER registry data to obtain detailed information on use of healthcare services and their costs. 4) Area Health Resource File (AHRF): We used the publicly available AHRF dat $\mathrm{a}^{45}$ to obtain information on the county level inter-personal, healthcare system, and community factors.

\subsubsection{Study Sample}

We included 5,455 DLBCL patients who were aged $\geq 66$ years with a primary diagnosis of DLBCL (International Classification of Diseases for Oncology - Third Revision (ICD-O3)/World Health Organization 2008 codes: 13, 14, 15, 16) during 2003-2011. We included patients who had only one primary cancer (except basal cell carcinoma) and whose cancer was not diagnosed from autopsy. For the comparison group, we selected a 10\% random sample of Medicare beneficiaries with $\geq 66$ years of age from the non-cancer patient dataset who resided in SEER areas and did not have any cancer (except basal cell carcinoma).

We applied the following exclusion criteria to both DLBCL and non-cancer patients: 1) those with End Stage Renal Disease (ESRD); 2) not alive during the study period; 3) enrolled in managed care plans during study period; 4) not continuously enrolled in Medicare parts A and B; 5) not having any Primary Care Physician (PCP) visit during the study period; and 6) having missing values for age, sex, race, region, or ESRD.

\subsubsection{Measures}

Dependent variables. We analyzed the following direct medical costs of care as dependent variables: 1) disease specific and overall cost of the following chronic conditions arthritis, asthma/COPD, any heart condition, any mental illness, diabetes, hypertension, hyperlipidemia, and osteoporosis. We used the payments made by Medicare for inpatient (Part 
A), outpatient and physician services (Part B), and home health agency (HHA) services for these chronic conditions to estimate these costs; 2) total cost of care including all payments made by Medicare for part A, part B, HHA, and Durable Medical Equipment (DME) claims for any health condition. ${ }^{46}$ Similar to previous studies,,${ }^{1,47}$ we used payments made by Medicare, instead of billed charges, to measure the true cost of care. All costs were adjusted to 2013 dollars by using the consumer price index for medical care..$^{48}$

Cancer Status. The key independent variable for this study was the diagnosis of DLBCL as compared to having no cancer. The DLBCL diagnosis belonged to the domain of intrapersonal factors from the SEM.

\section{SEM Independent Variables}

Our study included both time varying and time invariant factors. The independent variables of tobacco use and chronic conditions (arthritis, diabetes, any heart condition, depression/anxiety, and asthma/COPD) were time varying and were measured during each time interval from $\mathrm{t} 1$ to $\mathrm{t} 6$. The intra-personal factors of cancer treatments (chemo-immunotherapy, radiotherapy, and stem cell transplant) for DLBCL patients were measured during the post-index phase of two years. All other intra-personal, inter-personal, healthcare system, and community factors were measured during the one year pre-index phase.

Intra-personal factors consisted of: 1) age at index date; 2) sex; 3) race; 4) arthritis (osteoarthritis or rheumatoid arthritis); 5) diabetes; 6) any heart condition (cardiac arrhythmia, coronary artery disease, or congestive heart failure); 7) depression or anxiety; and 8) respiratory condition (Asthma or COPD). The following factors were measured for DLBCL patients only: 1) Ann Arbor DLBCL stage (stage I, II, III or IV); 2) chemo-immunotherapy with Rituximab, 
Cyclophosphamide, Doxorubicin, Vincristine, and Prednisolone (R-CHOP); 3) radiotherapy; and 4) stem cell transplantation.

Inter-personal factors included 1) racial/ethnic isolation measured by percentage of Blacks and Hispanics in the county; and 2) social/cultural cohesion estimated by the percentage of non-English speaking individuals above 18 years of age in the county.

Healthcare system factors consisted of county level: 1) primary care physician shortage area (Whole County, part of county, or no shortage); 2) number of hospitals per 10,000 individuals above 65 years of age; and 3) number of Federal Qualified Health Centers (FQHC) per 10,000 individuals above 65 years of age.

Community factors included county level: 1) geographic region (Northeast, South, North-Central, or West); 2) rurality: We used urban/rural recode to classify region into metro (counties in metro areas with 250,000 to $1,000,000$ population), urban (counties with urban population of 2,500 to 20,000 population), and rural (counties with completely rural or $<2,500$ urban population $)^{44}$; 3) percentage of individuals between 18 and 64 years of age without health insurance; 4) percentage of individuals with below high school education; and 5) average travel time to work. In addition to the SEM variables, we included time and index year as independent variables.

\subsubsection{Statistical Analyses}

We conducted unadjusted analyses of non-normal cost data by using non-parametric tests. ${ }^{49}$ Kruskal-Wallis rank tests analyzed the unadjusted differences in total cost and cost of all chronic conditions among DLBCL and non-cancer patients. ${ }^{50}$ Further, we utilized repeated measures Friedman test to analyze the unadjusted differences in cost between DLBCL and noncancer patients during t $1-\mathrm{t} 6 .{ }^{51}$ For adjusted analyses, the population-averaged Generalized 
Estimating Equations (GEE) with gamma distribution and log link analyzed the skewed cost data. ${ }^{52}$ We used an unstructured correlation structure with GEE to account for the repeated measures of costs among patients during t $1-\mathrm{t} 6 .{ }^{52}$ Also, to reduce the observed selection bias between DLBCL and non-cancer patients, we utilized Inverse Probability Treatment Weights (IPTW) in all the adjusted analyses with GEE. We also analyzed the interaction between patients' race/ethnicity and racial/ethnic composition of county to elucidate its impact on the cost of chronic conditions in this study. All analyses were conducted using SAS version 9.4. ${ }^{53}$

\subsection{Results}

\subsubsection{Costs of Care by Characteristics of DLBCL Patients}

The description of cost of chronic conditions and total overall cost during 12 months after cancer diagnosis in DLBCL patients is presented in Table 4.1. The DLBCL patients had substantial total annual cost $(\$ 80,220.9)$ after diagnosis. Those having depression/anxiety (\$97,098.7), asthma/COPD $(\$ 92,341.2)$, any heart condition $(\$ 88,840.2)$, diabetes $(\$ 88,311.7)$, and arthritis $(\$ 87,501.7)$ had higher average total cost as compared to those with no depression/anxiety $(\$ 75,766.9)$, no asthma/COPD $(\$ 74,910.2)$, no heart condition $(\$ 64,326.2)$, no diabetes $(\$ 75,748.4)$, and no arthritis $(\$ 76,782.0)$. The total annual cost of common chronic conditions was $\$ 3,099.7$ after cancer diagnosis. Tobacco users had a significantly higher cost of chronic conditions $(\$ 4,424.5)$ than non-tobacco users $(\$ 3,017.7)$. Further, beneficiaries between 75-79 years of age as compared to 66-69 years, those living in North-East as compared to South, those living in metro as compared to rural area, and those with a chronic condition as compared to those without chronic condition had higher cost of chronic conditions and total costs of care.

\subsubsection{Total Costs for DLBCL Patients}


Mean net costs of care (i.e., the difference in total cost between DLBCL and individuals without cancer) are presented in Table 4.2. DLBCL patients had significantly higher costs than non-cancer patients from t1 to t6. The 6-month cost difference between DLBCL and non-cancer patients increased sharply from baseline, t1 $(\$ 468.8)$ to treatment period, t3 $(\$ 60,746.1)$ and remained higher during long follow-up period, t6 $(\$ 6,614.8)$.

\subsubsection{Costs of Chronic Conditions for DLBCL Patients}

The change in cost of heart conditions and cost of all chronic conditions among beneficiaries with DLBCL and those without cancer are presented in Figure 4.1. The change in cost of heart conditions had the most impact on the cost of all chronic conditions, as both significantly increased during the treatment period and decreased after the treatment was over. The cost of all chronic conditions of DLBCL patients remained greater than baseline during the follow-up periods. For beneficiaries without cancer, the cost of chronic conditions showed a random increase during $\mathrm{t} 2$ and then constantly increased from $\mathrm{t} 3$ to $\mathrm{t} 6$. One explanation is the increasing age of Medicare beneficiaries, and hence, an increase in the diagnosis and treatment of chronic conditions.

The cost of chronic conditions was moderately higher among DLBCL patients as compared to those without cancer (Table 4.2). The largest difference in total cost of all chronic conditions was during t3 (\$768.3). The cost of heart conditions accounted for the majority of cost of chronic care among DLBCL patients (about 60\%) (Table 4.3). The net cost of heart conditions among DLBCL patients increased from t1 (\$148.3) to t3 (\$663.9) and then decreased during t6 (\$231.3). The cost of arthritis was lower among DLBCL patients as compared to patients without cancer from $\mathrm{t} 2$ to $\mathrm{t} 6$. Also, the cost of hypertension and diabetes was lower among DLBCL patients as compared to non-cancer patients during t1, t2, and t6 (Table 4.3). 


\subsubsection{Impact of DLBCL on Cost of Chronic Conditions}

From adjusted analysis, DLBCL patients had $\$ 586.8$ higher adjusted cost of all chronic conditions than patients without cancer (Table 4.4). The cost of chronic conditions was significantly higher during $\mathrm{t} 2, \mathrm{t} 3, \mathrm{t} 4, \mathrm{t} 5$ and $\mathrm{t} 6$ as compared to $\mathrm{t} 1$. Among DLBCL patients, those receiving radiotherapy had lower cost of chronic conditions.

With regard to the intra-personal factors, beneficiaries with age 70-74, 75-79, or $\geq 80$ years as compared to 66-69 years, Blacks as compared to Whites, and tobacco users as compared to non-tobacco users had significantly higher cost of chronic conditions. Further, females as compared to males and those living in West or South as compared to North-East had significantly lower costs of chronic conditions.

For county level factors, those living in counties with shortage of PCPs as compared to counties with no shortage, counties with higher average travel time to work as compared to counties with lower travel time, and counties with lower education level as compared to counties with higher education level had higher cost of chronic conditions. There was a significant interaction between patient's race and the racial composition of the county. Black Medicare beneficiaries living in a county with higher prevalence of Blacks had higher costs of chronic conditions.

\subsection{Discussion}

In this study, we used SEER-Medicare data to examine the costs of common chronic conditions and total cost of care among elderly Medicare beneficiaries with DLBCL as compared to those without cancer. The net total costs of care increased substantially during the treatment period among DLBCL patients, which was comparable to brain and pancreatic cancers. ${ }^{1}$ High cost of care for DLBCL patients may be attributed to stem cell transplantation which was 
received by $64 \%$ of DLBCL patients and costs about $\$ 99,899$ (autologous) to $\$ 203,026$ (allogeneic) for 100 days of treatment. ${ }^{54,50}$ With an aging US population and increased life expectancy, the cost burden of DLBCL to the Medicare program may increase further in the future.

Outpatient costs constituted the largest component of the total cost of care for DLBCL. This result is contrary to other cancers such as colorectal, cervical, and renal cancers for which hospitalizations account for the largest share of cost estimates. ${ }^{1}$ The reason for high proportion of outpatient costs is that chemo-immunotherapy or radiotherapy are the main treatments for DLBCL which are provided in hospital outpatient or office/clinic settings. ${ }^{55-57}$ Further exploration of the other components of costs such as prescription drugs for DLBCL patients is warranted.

The impact of DLBCL on the costs of chronic conditions varied by the specific chronic disease reflecting differences in the impact of DLBCL and its treatment on prognosis and care of different chronic conditions. DLBCL patients had significantly higher cost of heart conditions than non-cancer patients. The cost of heart conditions doubled during the treatment period and accounted for the majority of cost of chronic conditions. One explanation is the use of Doxorubicin based chemotherapy which causes cardiotoxicity such as development of congestive heart failure and cardiomyopathy in lymphoma patients. ${ }^{58,59}$ Treatment related cardiotoxicity can cause significant morbidity and mortality in lymphoma patients, ${ }^{60,61}$ which can lead to higher long term costs. The bundled payment for cancer care under the CMS's Oncology Care Model should include the cost of heart conditions in DLBCL patients. Appropriate management of heart conditions in DLBCL patients is critical and can reduce the long term costs of care. Some primary prevention measures for high-risk patients include the use of dexrazoxane 
and the administration of doxorubicin in liposomal form or as continuous infusion. ${ }^{62}$ Also, biomarkers and imaging studies can be used for early detection and treatment of heart conditions in DLBCL patients. ${ }^{62}$

We found that among DLBCL patients, the cost of arthritis decreased over time from DLBCL diagnosis to treatment and follow-up periods. Further, DLBCL patients had lower costs of common conditions such as hypertension, asthma/COPD, mental illness, and diabetes during the baseline and follow-up periods. There was no significant difference in the cost of arthritis, hyperlipidemia, and osteoporosis in DLBCL patients as compared to non-cancer patients. These results may reflect the lower receipt of care for these chronic conditions as found in previous studies. ${ }^{19,20}$ This is concerning because DLBCL treatment increases the risk of osteoporosis, fractures, and mental illness. ${ }^{18,63}$ Further research is required to investigate the impact of DLBCL on the quality of care of these chronic conditions and their association with overall survival. The inclusion of quality measures for chronic conditions in cancer care models might improve chronic care and reduce long term costs of DLBCL patients.

Our findings suggest that costs of chronic care among cancer patients are influenced by both individual and community level factors. We identified county level factors such as racial composition, shortage of primary care, education level, and travel time were associated with cost of chronic care. Blacks living in community with higher prevalence of blacks had higher cost of chronic conditions. The efforts to reduce the costs of chronic conditions for cancer patients should move beyond individual level factors and focus on the community level factors as well.

Our study has some limitations. We included Medicare beneficiaries with index date in 2003-2011. The Medicare Part D data, which provides prescription drug coverage, was available from 2007. Hence, the majority of our study population was not enrolled in Part D, and we could 
not include the cost of medications in our cost estimates. Future studies with cost of prescription drugs may further elucidate the impact of cancer on cost of chronic conditions. We also did not include the out-of-pocket cost or co-payments by Medicare enrollees, which have been estimated to be approximately $7 \%$ for Medicare Part A and 20\% for Part B. ${ }^{1}$ Our study results may be applicable to fee-for-service Medicare enrollees only.

The strengths of this study include the use of a large population-based data for patients with newly diagnosed cancer. Since Medicare is the primary insurance payer for individuals above 65 years of age, SEER-Medicare dataset provides the most complete information on the use and cost of health services by beneficiaries with cancer. The direct medical cost estimates of specific chronic conditions and DLBCL from our study can be used for resource allocation and health policy design. The phase specific costs of care over 3 years for DLBCL patients can also be used in cost-effectiveness analyses of interventions for disease prevention.

\subsection{Conclusions}

DLBCL patients had substantially higher total costs of care than Medicare beneficiaries without cancer, which was primarily due to the treatments of chemo-immunotherapy and stem cell transplant. However, the cost of all chronic conditions was only moderately higher among DLBCL patients, and it varied depending on the specific chronic condition. The cost of heart conditions was higher while the cost of other chronic conditions was either lower or similar to non-cancer patients. Cardiotoxicity of DLBCL treatment may have increased the cost of heart conditions among DLBCL patients. It is important to adjust the bundled payments of DLBCL care for the cost of heart conditions. Even though risks for other conditions were increased in DLBCL patients, the cost was lower, indicating they might be receiving suboptimal care for other common chronic conditions. The quality of care for chronic conditions might need to be 
improved for DLBCL patients. Future studies are suggested to investigate the impact of other common cancers such as breast, colorectal, and prostate cancer on the costs and quality of care for chronic conditions. Further, the long-term cost effectiveness of increasing chronic disease management among cancer patients needs to be examined. 


\subsection{References}

1. Yabroff KR, Lamont EB, Mariotto A, et al. Cost of care for elderly cancer patients in the united states. J Natl Cancer Inst. 2008;100(9):630-641. doi: 10.1093/jnci/djn103 [doi].

2. Mariotto AB, Yabroff KR, Shao Y, Feuer EJ, Brown ML. Projections of the cost of cancer care in the united states: 2010-2020. J Natl Cancer Inst. 2011;103(2):117-128. doi: 10.1093/jnci/djq495 [doi].

3. National cancer institute. surveillance, epidemiology, and end results program. SEER stat fact sheets: Non-hodgkin lymphoma. http://seer.cancer.gov/statfacts/html/nhl.html. Updated 2016. Accessed 05/09, 2016.

4. Rim SH, Guy Jr GP, Yabroff KR, McGraw KA, Ekwueme DU. The impact of chronic conditions on the economic burden of cancer survivorship: A systematic review. Expert review of pharmacoeconomics \& outcomes research. 2016;16(5):579-589.

5. Potetz L, DeWilde L. Cancer and medicare: A chartbook. Washington, DC: American Cancer Society Cancer Action Network. 2009.

6. Lochner KA. Prevalence of multiple chronic conditions among medicare beneficiaries, united states, 2010. Preventing chronic disease. 2013;10.

7. Edwards BK, Noone A, Mariotto AB, et al. Annual report to the nation on the status of cancer, 1975-2010, featuring prevalence of comorbidity and impact on survival among persons with lung, colorectal, breast, or prostate cancer. Cancer. 2014;120(9):1290-1314. 
8. Hollenbeak CS, Nikkel LE, Schaefer EW, Alemao E, Ghahramani N, Raman JD.

Determinants of medicare all-cause costs among elderly patients with renal cell carcinoma. Journal of Managed Care Pharmacy. 2011;17(8):610-620.

9. Luo Z, Bradley CJ, Dahman BA, Gardiner JC. Colon cancer treatment costs for medicare and dually eligible beneficiaries. Health Care Financ Rev. 2010;31(1):35-50.

10. Hollenbeak CS, Kulaylat AN, Mackley H, Koch W, Schaefer EW, Goldenberg D.

Determinants of medicare costs for elderly patients with oral cavity and pharyngeal cancers. JAMA Otolaryngology-Head \& Neck Surgery. 2015;141(7):628-635.

11. Forde G, Chang J, Ziogas A, Tewari K, Bristow R. Costs of treatment for elderly women with advanced ovarian cancer in a medicare population. Gynecol Oncol. 2015;137(3):479-484.

12. Boltz MM, Hollenbeak CS, Schaefer E, Goldenberg D, Saunders BD. Attributable costs of differentiated thyroid cancer in the elderly medicare population. Surgery. 2013;154(6):13631370.

13. Shankland KR, Armitage JO, Hancock BW. Non-hodgkin lymphoma. The Lancet. 2012;380(9844):848-857.

14. Hamlin PA, Satram-Hoang S, Reyes C, Hoang KQ, Guduru SR, Skettino S. Treatment patterns and comparative effectiveness in elderly diffuse large B-cell lymphoma patients: A surveillance, epidemiology, and end results-medicare analysis. Oncologist. 2014;19(12):12491257. doi: 10.1634/theoncologist.2014-0113 [doi]. 
15. Zelenetz AD, Abramson JS, Advani RH, et al. NCCN clinical practice guidelines in oncology: Non-hodgkin's lymphomas. J Natl Compr Canc Netw. 2010;8(3):288-334.

16. Hershman DL, McBride RB, Eisenberger A, Tsai WY, Grann VR, Jacobson JS.

Doxorubicin, cardiac risk factors, and cardiac toxicity in elderly patients with diffuse B-cell nonhodgkin's lymphoma. J Clin Oncol. 2008;26(19):3159-3165. doi: 10.1200/JCO.2007.14.1242 [doi].

17. Majhail NS, Ness KK, Burns LJ, et al. Late effects in survivors of hodgkin and non-hodgkin lymphoma treated with autologous hematopoietic cell transplantation: A report from the bone marrow transplant survivor study. Biology of Blood and Marrow Transplantation. 2007;13(10):1153-1159.

18. Cabanillas ME, Lu H, Fang S, Du XL. Elderly patients with non-hodgkin lymphoma who receive chemotherapy are at higher risk for osteoporosis and fractures. Leuk Lymphoma. 2007;48(8):1514-1521.

19. Snyder CF, Frick KD, Herbert RJ, et al. Quality of care for comorbid conditions during the transition to survivorship: Differences between cancer survivors and noncancer controls. J Clin Oncol. 2013;31(9):1140-1148. doi: 10.1200/JCO.2012.43.0272 [doi].

20. Earle CC, Neville BA. Under use of necessary care among cancer survivors. Cancer. 2004;101(8):1712-1719.

21. Mortimer L, Strawbridge L, Lukens E, et al. CMS'oncology care model: Delivering higher value cancer care. Clinical Pharmacology \& Therapeutics. 2017. 
22. Allaire BT, Ekwueme DU, Guy GP, et al. Medical care costs of breast cancer in privately insured women aged 18-44 years. Am J Prev Med. 2016;50(2):270-277.

23. Krahn M, Bremner K, Luo J, Tomlinson G, Alibhai S. Long-term health care costs for prostate cancer patients on androgen deprivation therapy. Current Oncology. 2016;23(5):e443.

24. Krahn M, Bremner K, Luo J, Alibhai S. Health care costs for prostate cancer patients receiving androgen deprivation therapy: Treatment and adverse events. Current Oncology. 2014;21(3):457-465.

25. Fisher MD, Punekar R, Yim YM, et al. Differences in health care use and costs among patients with cancer receiving intravenous chemotherapy in physician offices versus in hospital outpatient settings. Journal of Oncology Practice. 2016:JOP. 2016.012930.

26. Davis KL, Goyal RK, Able SL, Brown J, Li L, Kaye JA. Real-world treatment patterns and costs in a US medicare population with metastatic squamous non-small cell lung cancer. Lung Cancer. 2015;87(2):176-185.

27. Andersen R, Newman JF. Societal and individual determinants of medical care utilization in the united states. Milbank Q. 2005;83(4):Online-only-Online-only.

28. Gaskin DJ, Dinwiddie GY, Chan KS, McCleary R. Residential segregation and disparities in health care services utilization. Medical Care Research and Review. 2012;69(2):158-175.

29. Haas JS, Phillips KA, Sonneborn D, et al. Variation in access to health care for different racial/ethnic groups by the racial/ethnic composition of an individual's county of residence. Med Care. 2004;42(7):707-714. doi: 00005650-200407000-00012 [pii]. 
30. Casey MM, Call KT, Klingner JM. Are rural residents less likely to obtain recommended preventive healthcare services? Am J Prev Med. 2001;21(3):182-188.

31. Benjamins MR, Kirby JB, Huie SAB. County characteristics and racial and ethnic disparities in the use of preventive services. Prev Med. 2004;39(4):704-712.

32. Coughlin SS, Leadbetter S, Richards T, Sabatino SA. Contextual analysis of breast and cervical cancer screening and factors associated with health care access among united states women, 2002. Soc Sci Med. 2008;66(2):260-275.

33. Lochner KA, Goodman RA, Posner S, Parekh A. Multiple chronic conditions among medicare beneficiaries: State-level variations in prevalence, utilization, and cost, 2011. Medicare \& medicaid research review. 2013;3(3).

34. Getzen TE. Health care is an individual necessity and a national luxury: Applying multilevel decision models to the analysis of health care expenditures. J Health Econ. 2000;19(2):259-270.

35. Stokols D. Translating social ecological theory into guidelines for community health promotion. American journal of health promotion. 1996;10(4):282-298.

36. McLeroy KR, Bibeau D, Steckler A, Glanz K. An ecological perspective on health promotion programs. Health Education \& Behavior. 1988;15(4):351-377.

37. Mobley L, Kuo T, Urato M, Boos J, Lozano-Gracia N, Anselin L. Predictors of endoscopic colorectal cancer screening over time in 11 states. Cancer Causes \& Control. 2010;21(3):445461. 
38. Mobley LR, Driscoll D, Clayton L, Anselin L. Heterogeneity in mammography use across the nation: Separating evidence of disparities from the disproportionate effects of geography. International journal of health geographics. 2008;7(1):1.

39. Mobley LR, Clayton LJ, Evans WD. Mammography facilities are accessible, so why is utilization so low? Cancer Causes \& Control. 2009;20(6):1017-1028.

40. Hoerster KD, Mayer JA, Gabbard S, et al. Impact of individual-, environmental-, and policylevel factors on health care utilization among US farmworkers. Am J Public Health.

2011;101(4):685-692.

41. Revenson TA, Pranikoff JR. A contextual approach to treatment decision making among breast cancer survivors. Health Psychology. 2005;24(4S):S93.

42. Sallis JF, Owen N, Fisher EB. Ecological models of health behavior. Health behavior and health education: Theory, research, and practice. 2008;4:465-486.

43. Levit L, Balogh E, Nass S, Ganz PA. Delivering high-quality cancer care:: Charting a new course for a system in crisis. National Academies Press; 2013.

44. SEER-medicare linked database. https://healthcaredelivery.cancer.gov/seermedicare/. Accessed 11/09, 2016.

45. US Department of Health and Human Services. Area health resource file (AHRF). Rockville, MD: Health Resources and Services Administration. .

http://ahrf.hrsa.gov/ALLVARs_search.asp. 
46. Brown ML, Riley GF, Schussler N, Etzioni R. Estimating health care costs related to cancer treatment from SEER-medicare data. Med Care. 2002;40(8 Suppl):IV-104-17. doi:

10.1097/01.MLR.0000020939.20666.47 [doi].

47. Erdem E, Prada SI, Haffer SC. Medicare payments: How much do chronic conditions matter. Medicare Medicaid Res Rev. 2013;3(2):E1-15.

48. U.S. bureau of labor statistics. consumer price index: CPI databases. https://www.bls.gov/.

49. Cleophas TJ, Zwinderman AH. Non-parametric tests. Springer; 2011.

50. McKight PE, Najab J. Kruskal-Wallis test. Corsini Encyclopedia of Psychology. 2010.

51. Zimmerman DW, Zumbo BD. Relative power of the wilcoxon test, the friedman test, and repeated-measures ANOVA on ranks. The Journal of Experimental Education. 1993;62(1):7586.

52. Ballinger GA. Using generalized estimating equations for longitudinal data analysis. Organ Res Methods. 2004;7(2):127-150.

53. Dimaggio C. Introduction. In: SAS for epidemiologists. Springer; 2013:1-5.

54. Majhail NS, Mau L, Denzen EM, Arneson TJ. Costs of autologous and allogeneic hematopoietic cell transplantation in the united states: A study using a large national private claims database. Bone Marrow Transplant. 2013;48(2):294-300. 
55. Byfield SD, Becker LK, Small A. Differences in treatment patterns and costs among diffuse large B-cell lymphoma patients treated in the clinic vs. the hospital outpatient setting. Blood. 2013;122(21):1751-1751.

56. Casebeer AW, Hopson S, Jankus DAD, et al. Are there differences in treatment patterns, cost, and quality indicators by site of care for first line treatment for non-hodgkin's lymphoma and chronic lymphocytic leukemia (NHL/CLL)? Blood. 2015;126(23):3298-3298.

57. Byfield SD, Becker LK, Small A. Differences in treatment patterns and costs among diffuse large B-cell lymphoma patients treated in the clinic vs. the hospital outpatient setting. Blood. 2013;122(21):1751-1751.

58. Hershman DL, McBride RB, Eisenberger A, Tsai WY, Grann VR, Jacobson JS.

Doxorubicin, cardiac risk factors, and cardiac toxicity in elderly patients with diffuse B-cell nonhodgkin's lymphoma. J Clin Oncol. 2008;26(19):3159-3165. doi: 10.1200/JCO.2007.14.1242 [doi].

59. Vejpongsa P, Yeh ET. Prevention of anthracycline-induced cardiotoxicity: Challenges and opportunities. J Am Coll Cardiol. 2014;64(9):938-945.

60. Myrehaug S, Pintilie M, Tsang R, et al. Cardiac morbidity following modern treatment for hodgkin lymphoma: Supra-additive cardiotoxicity of doxorubicin and radiation therapy. Leuk Lymphoma. 2008;49(8):1486-1493. 
61. Myrehaug S, Pintilie M, Yun L, et al. A population-based study of cardiac morbidity among hodgkin lymphoma patients with preexisting heart disease. Blood. 2010;116(13):2237-2240. doi: 10.1182/blood-2010-01-263764 [doi].

62. Vejpongsa P, Yeh ET. Prevention of anthracycline-induced cardiotoxicity: Challenges and opportunities. J Am Coll Cardiol. 2014;64(9):938-945.

63. Devlen J, Maguire P, Phillips P, Crowther D. Psychological problems associated with diagnosis and treatment of lymphomas. II: Prospective study. Br Med J (Clin Res Ed). 1987;295(6604):955-957. 
Figure 4.1 Change in Cost of Heart Conditions and Cost of All Chronic Conditions among Medicare Beneficiaries with Diffuse Large B-Cell Lymphoma (DLBCL) and Beneficiaries without Cancer (2002-2013).

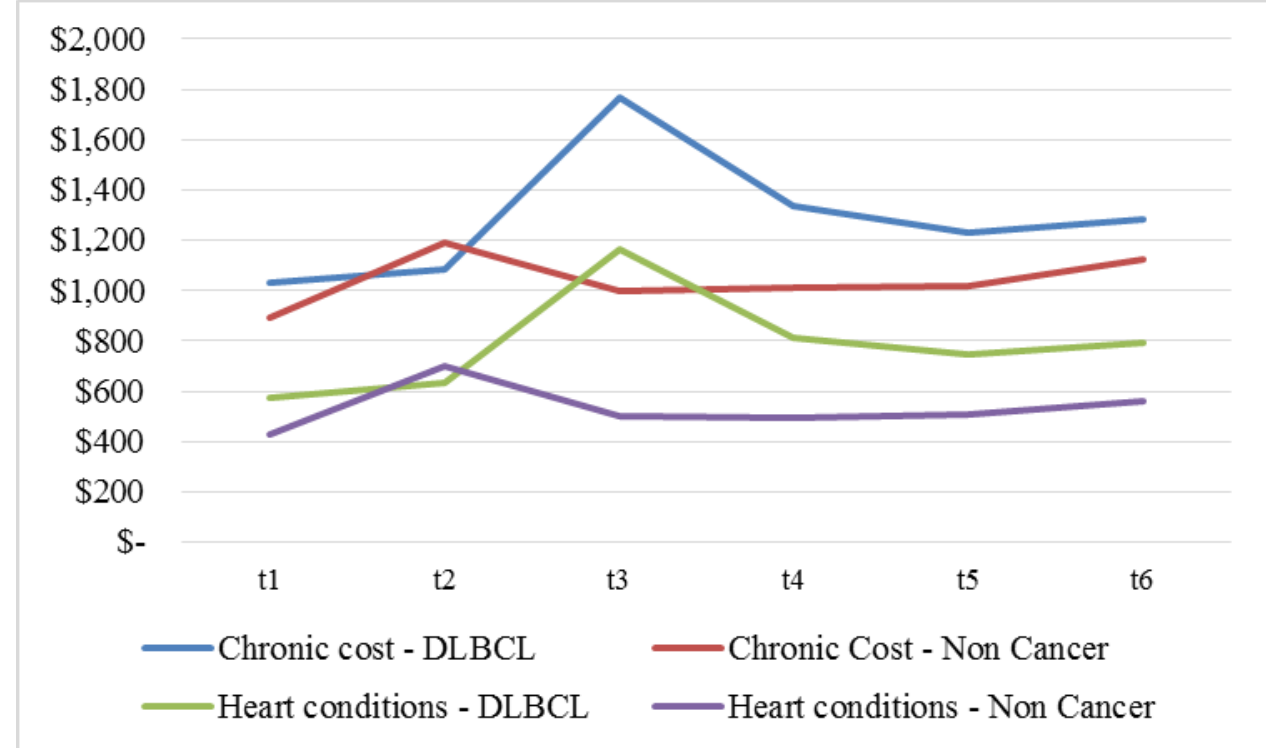

Cost of all chronic conditions included inpatient, outpatient, and home health costs for arthritis, asthma/chronic obstructive pulmonary disease, any heart condition, any mental illness, diabetes, hypertension, hyperlipidemia, and osteoporosis. The study period of 3 years was categorized in 6 months' intervals ( $\mathrm{t} 1-\mathrm{t} 6)$. The pre-index phase ( $\mathrm{t} 1$, $\mathrm{t} 2$ ) was 12 months before DLBCL diagnosis and post-index phase (t3, t4, t5, t6) was 24 months after diagnosis. 
Table 4.1 Description of Mean Total Cost and Cost of Chronic Conditions among Medicare Beneficiaries with Diffuse Large B-Cell Lymphoma (DLBCL) during 12 Months after Cancer Diagnosis (2002-2013).

\begin{tabular}{|c|c|c|c|c|c|}
\hline & $\mathrm{n}$ & Total Cost, $\$$ & Sig. & Chronic Cost, \$ & Sig. \\
\hline Total & 5,455 & $80,220.9$ & & $3,099.7$ & \\
\hline Sex & & & $*$ & & + \\
\hline Female & 3,029 & $79,598.4$ & & $2,839.3$ & \\
\hline Male & 2,426 & $80,998.2$ & & $3,424.9$ & \\
\hline Age (years) & & & $* * *$ & & $* * *$ \\
\hline 66-69 & 1,071 & $81,471.2$ & & $2,640.7$ & \\
\hline $70-74$ & 1,374 & $83,406.9$ & & $2,392.9$ & \\
\hline $75-79$ & 1,373 & $84,834.4$ & & $3,772.4$ & \\
\hline$\geq 80$ & 1,637 & $72,859.5$ & & $3,429.1$ & \\
\hline Race & & & & & + \\
\hline White & 4,796 & $80,041.0$ & & $3,056.8$ & \\
\hline African American & 190 & $80,109.6$ & & $4,677.5$ & \\
\hline Hispanic & 120 & $88,400.9$ & & $3,477.5$ & \\
\hline Others & 349 & $79,942.3$ & & $2,699.5$ & \\
\hline Marital status & & & $* * *$ & & \\
\hline Married & 3,123 & $81,655.5$ & & $3,000.8$ & \\
\hline $\begin{array}{l}\text { Separated/Divorced/ } \\
\text { Widowed }\end{array}$ & 1,660 & $78,622.8$ & & $3,361.7$ & \\
\hline Unmarried & 372 & $85,446.4$ & & $3,483.6$ & \\
\hline Region & & & $* * *$ & & $* * *$ \\
\hline North Central & 720 & $77,346.3$ & & $3,306.8$ & \\
\hline Northeast & 1,113 & $87,656.8$ & & $4,134.9$ & \\
\hline South & 1,267 & $75,401.1$ & & $2,825.0$ & \\
\hline West & 2,355 & $80,178.7$ & & $2,694.9$ & \\
\hline Rurality & & & $* * *$ & & $* * *$ \\
\hline Rural & 115 & $68,590.1$ & & $2,658.9$ & \\
\hline Urban & 815 & $74,707.2$ & & $2,657.0$ & \\
\hline Metro & 4,525 & $81,509.6$ & & $3,190.6$ & \\
\hline Dual eligibility & & & + & & $* * *$ \\
\hline Yes & 294 & $86,246.1$ & & $5,056.7$ & \\
\hline No & 5,161 & $79,877.7$ & & $2,988.2$ & \\
\hline Any heart condition & & & $* * *$ & & $* * *$ \\
\hline Yes & 3,537 & $88,840.2$ & & $4,395.3$ & \\
\hline No & 1,918 & $64,326.2$ & & 710.4 & \\
\hline Asthma/COPD & & & $* * *$ & & $* * *$ \\
\hline Yes & 1,662 & $92,341.2$ & & $4,421.3$ & \\
\hline No & 3,793 & $74,910.2$ & & $2,520.6$ & \\
\hline Depression/Anxiety & & & $* * *$ & & $* * *$ \\
\hline Yes & 1,139 & $97,098.7$ & & $4,458.4$ & \\
\hline No & 4,316 & $75,766.9$ & & $2,741.1$ & \\
\hline Arthritis & & & $* * *$ & & $* * *$ \\
\hline
\end{tabular}




\begin{tabular}{|c|c|c|c|c|c|}
\hline Yes & 1,750 & $87,501.7$ & & $4,208.0$ & \\
\hline No & 3,705 & $76,782.0$ & & $2,576.2$ & \\
\hline Diabetes & & & $* * *$ & & $* * *$ \\
\hline Yes & 1,942 & $88,311.7$ & & $4,626.8$ & \\
\hline No & 3,513 & $75,748.4$ & & $2,255.5$ & \\
\hline Tobacco use & & & & & $* * *$ \\
\hline Yes & 318 & $84,874.1$ & & $4,424.5$ & \\
\hline No & 5,137 & $79,932.9$ & & $3,017.7$ & \\
\hline DLBCL stage & & & $* * *$ & & \\
\hline Stage I & 1,813 & $72,724.4$ & & $2,964.0$ & \\
\hline Stage II & 1,066 & $82,795.0$ & & $3,249.3$ & \\
\hline Stage III & 812 & $83,118.8$ & & $3,033.1$ & \\
\hline Stage IV & 1,391 & $89,974.9$ & & $3,123.6$ & \\
\hline Chemo-immuno therapy & & & $* * *$ & & $* *$ \\
\hline Yes & 5,007 & $84,677.5$ & & $3,099.1$ & \\
\hline No & 448 & $30,412.9$ & & $3,106.2$ & \\
\hline Radiotherapy & & & $* * *$ & & \\
\hline Yes & 1,629 & $77,184.5$ & & $2,810.7$ & \\
\hline No & 3,826 & $81,513.8$ & & $3,222.8$ & \\
\hline Stem cell transplant & & & $* * *$ & & \\
\hline Yes & 3,479 & $82,594.2$ & & $3,090.2$ & \\
\hline No & 1,976 & $76,042.6$ & & $3,116.4$ & \\
\hline Primary care shortage & & & & & \\
\hline Part county & 2,748 & $81,028.2$ & & $3,130.3$ & \\
\hline Whole county & 1,848 & $80,122.6$ & & $2,949.1$ & \\
\hline No shortage & 859 & $77,850.3$ & & $3,325.6$ & \\
\hline
\end{tabular}

Note. Based on 5,455 Medicare beneficiaries with Diffuse Large B-Cell Lymphoma (DLBCL) $\geq 66$ years of age who resided in Surveillance, Epidemiology, and End Results program (SEER) areas. Total cost included all inpatient, outpatient, home health agency, and durable medical equipment costs. Cost of chronic conditions included inpatient, outpatient, and home health agency costs for arthritis, asthma/COPD, any heart condition, any mental illness, diabetes, hypertension, hyperlipidemia, and osteoporosis. All costs were adjusted to 2013 constant dollars. Significance values (Sig.) were derived from Kruskal-Wallis tests.

COPD: Chronic Obstructive Pulmonary Disease.

$* * * \mathrm{p}<.001 * * .001 \leq \mathrm{p}<.01 * .01 \leq \mathrm{p}<.05+.05 \leq \mathrm{p}<.1$ 
Table 4.2 Differences in Total Cost and Cost of Chronic Conditions between Medicare Beneficiaries with Diffuse Large B-Cell Lymphoma (DLBCL) and Beneficiaries without Cancer (2002-2013).

\begin{tabular}{|c|c|c|c|c|}
\hline \multicolumn{5}{|c|}{ Total cost, \$ } \\
\hline Time & DLBCL & No Cancer & Net Cost & Sig. \\
\hline $\mathrm{t} 1$ & $3,406.6$ & $2,937.8$ & 468.8 & $* * *$ \\
\hline $\mathrm{t} 2$ & $5,123.4$ & $3,701.5$ & $1,421.9$ & \\
\hline $\mathrm{t} 3$ & $64,228.9$ & $3,482.8$ & $60,746.1$ & \\
\hline $\mathrm{t} 4$ & $15,992.1$ & $3,236.1$ & $12,756.0$ & \\
\hline t5 & $10,586.1$ & $3,519.7$ & $7,066.4$ & \\
\hline t6 & $10,543.6$ & $3,928.8$ & $6,614.8$ & \\
\hline \multicolumn{4}{|c|}{ Cost of chronic conditions, $\$$} & Sig. \\
\hline & DLBCL & No Cancer & Net Cost & $* * *$ \\
\hline $\mathrm{t} 1$ & $1,029.2$ & 894.2 & 135.0 & \\
\hline $\mathrm{t} 2$ & $1,084.7$ & $1,187.3$ & -102.7 & \\
\hline $\mathrm{t} 3$ & $1,765.7$ & 997.4 & 768.3 & \\
\hline $\mathrm{t} 4$ & $1,334.0$ & $1,012.9$ & 321.1 & \\
\hline t5 & $1,232.8$ & $1,018.8$ & 214.1 & \\
\hline t6 & $1,286.5$ & $1,123.3$ & 163.1 & \\
\hline
\end{tabular}

Note. Based on 5,455 Medicare beneficiaries with Diffuse Large B-Cell Lymphoma and 14,770 beneficiaries without cancer who were $\geq 66$ years of age and resided in Surveillance, Epidemiology, and End Results program (SEER) areas. Total cost included all inpatient, outpatient, home health agency, and durable medical equipment costs. Cost of chronic conditions included inpatient, outpatient, and home health agency costs for arthritis, asthma/COPD, any heart condition, any mental illness, diabetes, hypertension, hyperlipidemia, and osteoporosis. All costs were adjusted to 2013 constant dollars. The study period of 3 years was categorized in 6 months' intervals (pre-index: $\mathrm{t} 1, \mathrm{t} 2$ and post-index: $\mathrm{t} 3, \mathrm{t} 4, \mathrm{t} 5, \mathrm{t} 6)$. Significance values (Sig.) were derived from Friedman's tests. $* * * \mathrm{p}<.001$ 
Table 4.3 Description of Cost of Common Chronic Conditions among Medicare Beneficiaries with Diffuse Large B-Cell Lymphoma (DLBCL) and Beneficiaries without Cancer (2002-2013).

\begin{tabular}{|c|c|c|c|c|}
\hline Time & DLBCL & No Cancer & Net Cost, \$ & Sig. \\
\hline \multicolumn{4}{|c|}{ Heart conditions, $\$$} & \multirow[t]{7}{*}{$* * *$} \\
\hline $\mathrm{t} 1$ & 576.7 & 428.4 & 148.3 & \\
\hline $\mathrm{t} 2$ & 635.1 & 698.8 & -63.7 & \\
\hline $\mathrm{t} 3$ & $1,164.8$ & 500.9 & 663.9 & \\
\hline $\mathrm{t} 4$ & 814.7 & 496.0 & 318.7 & \\
\hline t5 & 743.5 & 504.7 & 238.8 & \\
\hline \multirow[t]{2}{*}{ t6 } & 794.0 & 562.6 & 231.3 & \\
\hline & Diabetes, \$ & & & $* * *$ \\
\hline $\mathrm{t} 1$ & 71.2 & 79.6 & -8.3 & \\
\hline $\mathrm{t} 2$ & 67.0 & 73.0 & -5.9 & \\
\hline $\mathrm{t} 3$ & 190.9 & 92.2 & 98.7 & \\
\hline $\mathrm{t} 4$ & 123.1 & 86.8 & 36.3 & \\
\hline $\mathrm{t} 5$ & 91.1 & 86.7 & 4.4 & \\
\hline \multirow[t]{2}{*}{ t6 } & 92.6 & 97.6 & -5.0 & \\
\hline & Arthritis, \$ & & & \\
\hline $\mathrm{t} 1$ & 205.9 & 177.7 & 28.3 & \\
\hline $\mathrm{t} 2$ & 192.8 & 196.8 & -4.0 & \\
\hline $\mathrm{t} 3$ & 45.6 & 158.0 & -112.3 & \\
\hline $\mathrm{t} 4$ & 140.4 & 181.0 & -40.5 & \\
\hline $\mathrm{t} 5$ & 157.4 & 161.0 & -3.6 & \\
\hline \multirow[t]{2}{*}{ t6 } & 147.0 & 176.4 & -29.5 & \\
\hline & Hypertension, \$ & & & $* * *$ \\
\hline $\mathrm{t} 1$ & 67.3 & 85.1 & -17.8 & \\
\hline $\mathrm{t} 2$ & 81.6 & 87.4 & -5.8 & \\
\hline $\mathrm{t} 3$ & 149.6 & 106.0 & 43.7 & \\
\hline $\mathrm{t} 4$ & 95.2 & 95.2 & 0.1 & \\
\hline $\mathrm{t} 5$ & 76.7 & 91.4 & -14.7 & \\
\hline \multirow[t]{2}{*}{ t6 } & 96.2 & 105.0 & -8.8 & \\
\hline & Asthma/COPD, \$ & & & $* * *$ \\
\hline $\mathrm{t} 1$ & 28.77 & 38.54 & -9.77 & \\
\hline $\mathrm{t} 2$ & 43.23 & 37.22 & 6.01 & \\
\hline $\mathrm{t} 3$ & 116.27 & 51.88 & 64.39 & \\
\hline $\mathrm{t} 4$ & 56.16 & 60.73 & -4.57 & \\
\hline $\mathrm{t} 5$ & 57.43 & 59.96 & -2.53 & \\
\hline \multirow[t]{2}{*}{ t6 } & 62.10 & 63.88 & -1.78 & \\
\hline & Mental Illness, \$ & & & $* * *$ \\
\hline $\mathrm{t} 1$ & 46.25 & 55.24 & -8.99 & \\
\hline $\mathrm{t} 2$ & 28.64 & 65.52 & -36.88 & \\
\hline $\mathrm{t} 3$ & 66.68 & 56.88 & 9.80 & \\
\hline $\mathrm{t} 4$ & 74.62 & 62.81 & 11.81 & \\
\hline
\end{tabular}




\begin{tabular}{cccc} 
t5 & 71.94 & 82.52 & -10.58 \\
t6 & 61.45 & 81.31 & -19.86 \\
\multicolumn{4}{c}{ Hyperlipidemia, \$ } \\
t1 & 26.00 & 23.57 & 2.43 \\
t2 & 27.35 & 22.25 & 5.10 \\
t3 & 15.70 & 24.24 & -8.54 \\
t4 & 19.69 & 23.81 & -4.12 \\
t5 & 22.74 & 23.88 & -1.14 \\
t6 & 23.23 & 25.70 & -2.47 \\
& Osteoporosis, \$ & & \\
t1 & 7.08 & 6.24 & 0.84 \\
t2 & 9.00 & 6.43 & 2.57 \\
t3 & 16.03 & 7.34 & 8.69 \\
t4 & 10.13 & 6.65 & 3.48 \\
t5 & 12.11 & 8.67 & 3.44 \\
t6 & 9.98 & 10.85 & -0.87 \\
\hline
\end{tabular}

Note. Based on 5,455 Medicare beneficiaries with Diffuse Large B-Cell Lymphoma and 14,770 beneficiaries with no cancer who were $\geq 66$ years of age and resided in SEER areas. The cost of chronic conditions included inpatient, outpatient, and home health agency costs. All costs were adjusted to 2013 constant dollars. The study period of 3 years was categorized in 6 months' intervals (pre-index: $\mathrm{t} 1, \mathrm{t} 2$ and post-index: $\mathrm{t} 3, \mathrm{t} 4, \mathrm{t} 5, \mathrm{t} 6$ ). Significance values (Sig.) were derived from Friedman's tests. COPD: Chronic Obstructive Pulmonary Disease $* * * \mathrm{p}<.001$. 
Table 4.4 Parameter Estimates from Generalized Estimating Equations on Cost of Chronic Conditions among Medicare Beneficiaries with Diffuse Large B-Cell Lymphoma (DLBCL) as compared to Beneficiaries without Cancer (2002-2013).

\begin{tabular}{|c|c|c|c|c|c|}
\hline & & $\beta$ & SE & Sig. & $\begin{array}{c}\text { Adjusted } \\
\text { cost, } \$\end{array}$ \\
\hline Intercept & & 6.190 & 0.130 & $* * *$ & 489.4 \\
\hline \multicolumn{6}{|l|}{ DLBCL } \\
\hline & Yes & 0.182 & 0.035 & $* * *$ & 586.8 \\
\hline & No Cancer & Ref. & & & \\
\hline \multicolumn{6}{|l|}{ Time } \\
\hline & Pre-Diagnosis & 0.233 & 0.046 & $* * *$ & 617.7 \\
\hline & Treatment & 0.217 & 0.043 & $* * *$ & 608.0 \\
\hline & Post-Treatment & 0.178 & 0.046 & $* * *$ & 584.5 \\
\hline & Short Follow-up & 0.151 & 0.045 & $* * *$ & 569.1 \\
\hline & Long Follow-up & 0.233 & 0.044 & $* * *$ & 617.7 \\
\hline & Baseline & Ref. & & & \\
\hline \multicolumn{6}{|c|}{ Age (Years) } \\
\hline & $70-74$ & 0.253 & 0.048 & $* * *$ & 630.5 \\
\hline & $75-79$ & 0.424 & 0.049 & $* * *$ & 747.7 \\
\hline & $\geq 80$ & 0.582 & 0.045 & $* * *$ & 875.9 \\
\hline & $66-69$ & Ref. & & & \\
\hline \multicolumn{6}{|l|}{ Sex } \\
\hline & Female & -0.160 & 0.033 & $* * *$ & 418.6 \\
\hline & Male & Ref. & & & \\
\hline \multicolumn{6}{|l|}{ Race } \\
\hline & Black & 0.275 & 0.062 & $* * *$ & 644.5 \\
\hline & Hispanic & 0.204 & 0.109 & & 600.0 \\
\hline & Others & 0.014 & 0.064 & & 496.3 \\
\hline & White & Ref. & & & \\
\hline \multicolumn{6}{|l|}{ Region } \\
\hline & North-Central & -0.070 & 0.064 & & 456.7 \\
\hline & West & -0.290 & 0.053 & $* * *$ & 367.3 \\
\hline & South & -0.300 & 0.063 & $* * *$ & 364.1 \\
\hline & Northeast & Ref. & & & \\
\hline \multicolumn{6}{|l|}{ Rurality } \\
\hline & Urban & 0.142 & 0.099 & & 564.2 \\
\hline & Metro & 0.190 & 0.102 & & 591.8 \\
\hline & Rural & Ref. & & & \\
\hline \multicolumn{6}{|c|}{ Tobacco use } \\
\hline & Yes & 1.180 & 0.069 & $* * *$ & $1,590.7$ \\
\hline & No & Ref. & & & \\
\hline \multicolumn{6}{|c|}{ County\% Blacks } \\
\hline & 4.43 & 0.017 & 0.053 & & 497.8 \\
\hline & 9.88 & 0.167 & 0.061 & $* *$ & 578.1 \\
\hline
\end{tabular}


1.21

County\% FQHC

0.36

0.94

3.84

0.01

Primary care shortage area

Part county

Whole county

No shortage

County average travel time

24.09

27.42

30.95

19.62

County\% Less Than High

School Education

12.23

16.24

24.98

8.41
$0.108 \quad 0.067$

Ref.

$\begin{array}{llll}-0.130 & 0.057 & * & 429.7 \\ -0.080 & 0.058 & & 449.8 \\ -0.100 & 0.055 & & 444.0\end{array}$

Ref.

$\begin{array}{lll}0.071 & 0.052 & 525.6\end{array}$

$\begin{array}{llll}0.128 & 0.057 & * & 556.3\end{array}$

Ref.

$\begin{array}{cccc}0.027 & 0.049 & & 502.6 \\ 0.054 & 0.051 & & 516.4 \\ 0.138 & 0.055 & * & 561.9 \\ \text { Ref. } & & & \end{array}$

Ref.

$\begin{array}{ll}0.086 & 0.050\end{array}$

533.3

$\begin{array}{lll}0.287 & 0.050 & * * *\end{array}$

652.1

$0.284 \quad 0.055 \quad * * * \quad 649.9$

Ref.

Note. Based on 5,455 Medicare beneficiaries with Diffuse Large B-Cell Lymphoma and 14,770 beneficiaries without any cancer $\geq 66$ years of age who resided in SEER areas. FQHC: Federal Qualified Health Center; SE: standard errors; Sig: significance level. The adjusted cost of chronic conditions was derived from Generalized Estimating Equations with gamma distribution and log link. All costs were adjusted to 2013 constant dollars. $* * * \mathrm{p}<.001 * * .001 \leq \mathrm{p}<.01 * .01 \leq \mathrm{p}<.05$ 
Appendix 4.1 Description of One-Year Total Cost and Cost of Chronic Conditions among Medicare Beneficiaries $\geq 66$ Years of Age without Cancer (2002-2013).

\begin{tabular}{|c|c|c|c|c|c|}
\hline & $\mathrm{n}$ & Total Cost, \$ & sig & $\begin{array}{l}\text { otal Chron } \\
\text { Cost, } \$\end{array}$ & sig \\
\hline Total & 14,770 & $6,718.8$ & & $2,010.3$ & \\
\hline Sex & & & $* * *$ & & $* * *$ \\
\hline Female & 9,479 & $6,939.5$ & & $2,018.9$ & \\
\hline Male & 5,291 & $6,323.5$ & & $1,994.8$ & \\
\hline Age (years) & & & $* * *$ & & $* * *$ \\
\hline $66-69$ & 4,452 & $5,078.1$ & & $1,523.0$ & \\
\hline $70-74$ & 3,914 & $6,110.7$ & & $1,985.1$ & \\
\hline $75-79$ & 2,786 & $7,396.4$ & & $2,140.1$ & \\
\hline$\geq 80$ & 3,618 & $8,873.9$ & & $2,537.1$ & \\
\hline Race & & & + & & $* * *$ \\
\hline White & 11,885 & $6,577.0$ & & $1,908.1$ & \\
\hline African American & 1,217 & $8,643.5$ & & $2,987.5$ & \\
\hline Hispanic & 379 & $8,211.9$ & & $2,841.0$ & \\
\hline Others & 1,289 & $5,769.9$ & & $1,785.5$ & \\
\hline Region & & & $* * *$ & & $* * *$ \\
\hline North Central & 1,752 & $7,095.8$ & & $2,127.7$ & \\
\hline Northeast & 2,885 & $7,091.6$ & & $2,358.9$ & \\
\hline South & 3,779 & $6,189.2$ & & $1,919.6$ & \\
\hline West & 6,354 & $6,760.6$ & & $1,873.5$ & \\
\hline Rurality & & & $* * *$ & & $* * *$ \\
\hline Rural & 320 & $6,391.9$ & & $1,541.0$ & \\
\hline Urban & 2,278 & $6,324.7$ & & $1,887.1$ & \\
\hline Metro & 12,172 & $6,801.2$ & & $2,045.7$ & \\
\hline Any heart condition & & & $* * *$ & & $* * *$ \\
\hline Yes & 5,749 & $12,027.2$ & & $4,067.9$ & \\
\hline No & 9,021 & $3,335.8$ & & 699.0 & \\
\hline Asthma/COPD & & & $* * *$ & & $* * *$ \\
\hline Yes & 2,734 & $12,476.6$ & & $3,965.8$ & \\
\hline No & 12,036 & $5,410.9$ & & $1,566.1$ & \\
\hline Depression/Anxiety & & & $* * *$ & & $* * *$ \\
\hline Yes & 1,913 & $14,617.1$ & & $3,814.5$ & \\
\hline No & 12,857 & $5,543.6$ & & $1,741.8$ & \\
\hline Arthritis & & & $* * *$ & & $* * *$ \\
\hline Yes & 4,372 & $10,874.3$ & & $3,497.9$ & \\
\hline No & 10,398 & $4,971.6$ & & $1,384.8$ & \\
\hline Diabetes & & & $* * *$ & & $* * *$ \\
\hline Yes & 4,845 & $9,443.0$ & & $2,959.6$ & \\
\hline No & 9,925 & $5,389.0$ & & $1,546.8$ & \\
\hline Tobacco use & & & $* * *$ & & $* * *$ \\
\hline Yes & 464 & $13,312.3$ & & $4,812.4$ & \\
\hline
\end{tabular}


Primary care shortage

$\begin{array}{llll}\text { Part county } & 7,094 & 6,514.0 & 1,997.9 \\ \text { Whole county } & 5,511 & 7,185.0 & 2,115.3 \\ \text { No shortage } & 2,165 & 6,203.2 & 1,783.5\end{array}$

Note. Based on 14,770 Medicare beneficiaries with no cancer $\geq 66$ years of age who resided in Surveillance, Epidemiology, and End Results program (SEER) areas. Total cost included all inpatient, outpatient, home health agency, and durable medical equipment costs. Cost of chronic conditions included inpatient, outpatient, and home health agency costs for arthritis, asthma/COPD, any heart condition, any mental illness, diabetes, hypertension, hyperlipidemia, and osteoporosis. All costs were adjusted to 2013 constant dollars. Significance values (Sig.) were derived from Kruskal-Wallis tests.

COPD: Chronic Obstructive Pulmonary Disease.

$* * * p<.001 * * .001 \leq p<.01 * .01 \leq p<.05+.05 \leq p<.1$ 
Appendix 4.2 Parameter Estimates from Generalized Estimating Equations on Cost of Chronic Conditions among Medicare Beneficiaries with Diffuse Large B-Cell Lymphoma $\geq 66$ Years of Age (2002-2013).

\begin{tabular}{llcccc}
\hline & & & & & $\begin{array}{c}\text { Adjusted } \\
\text { cost, \$ }\end{array}$ \\
\hline Intercept & & $\beta$ & SE & Sig. & \\
Time & & 6.650 & 0.234 & $* * *$ & 772.3 \\
& & & & & \\
& Pre-Diagnosis & 0.094 & 0.085 & & 848.5 \\
& Treatment & 0.545 & 0.078 & $* * *$ & $1,331.8$ \\
& Post-Treatment & 0.340 & 0.085 & $* * *$ & $1,084.7$ \\
& Short Follow-up & 0.261 & 0.086 & $* *$ & $1,002.5$ \\
& Long Follow-up & 0.295 & 0.084 & $* * *$ & $1,037.6$ \\
$\quad$ Baseline & Ref. & & & \\
Age (Years) & & & & \\
$\quad 70-74$ & 0.193 & 0.088 & $*$ & 936.8 \\
$75-79$ & 0.377 & 0.086 & $* * *$ & $1,125.7$ \\
& & 0.391 & 0.081 & $* * *$ & $1,142.1$ \\
& R6-69 & Ref. & & &
\end{tabular}

Sex

$\begin{array}{lcccc}\text { Female } & -0.280 & 0.055 & * * * & 585.2 \\ \text { Male } & \text { Ref. } & & & \end{array}$

Race

$\begin{array}{lcccc}\text { African American } & 0.389 & 0.135 & * * & 1,139.0 \\ \text { Hispanic } & -0.060 & 0.191 & & 730.5 \\ \text { Others } & 0.072 & 0.122 & & 830.3 \\ \text { White } & \text { Ref. } & & & \end{array}$

Region

$\begin{array}{lccll}\text { North-Central } & -0.090 & 0.103 & & 706.7 \\ \text { West } & -0.360 & 0.080 & * * * & 537.9 \\ \text { South } & -0.270 & 0.085 & * * & 591.9 \\ \text { Northeast } & \text { Ref. } & & & \end{array}$

Rurality

$\begin{array}{lccc}\text { Urban } & 0.218 & 0.191 & 960.7 \\ \text { Metro } & 0.318 & 0.185 & 1,061.2 \\ \text { Rural } & \text { Ref. } & & \end{array}$

Medicaid Dual Eligible

$\begin{array}{lcccc}\text { Yes } & 0.579 & 0.109 & * * * & 1,377.3 \\ \text { No } & \text { Ref. } & & & \end{array}$

DLBCL stage

$\begin{array}{lccc}\text { Stage II } & -0.100 & 0.076 & 696.0 \\ \text { Stage III } & -0.060 & 0.082 & 726.6 \\ \text { Stage IV } & 0.047 & 0.073 & 809.4 \\ \text { Stage I } & \text { Ref. } & & \end{array}$

Tobacco use

$\begin{array}{lcccc}\text { Yes } & 0.884 & 0.119 & * * * & 1,870.2 \\ \text { No } & \text { Ref. } & & & \end{array}$

Chemo-immuno therapy
Yes
0.032
0.110
797.3 


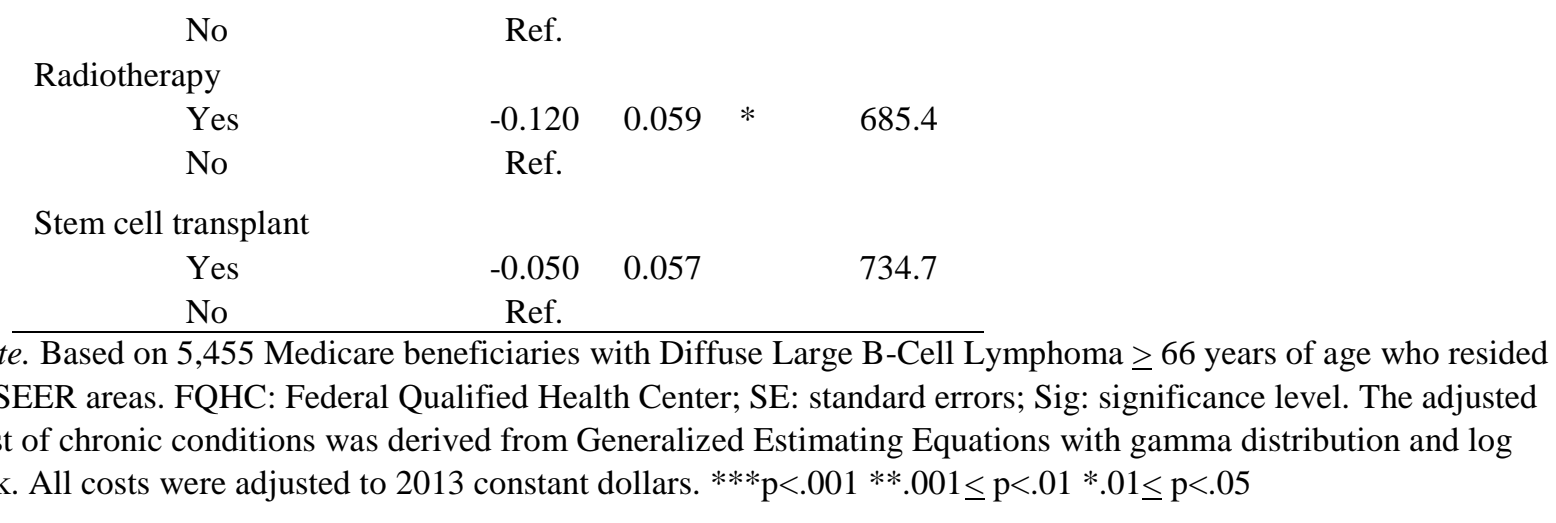




\section{Chapter 5: Discussion}

\subsection{Results Summary and Discussion}

The current study investigated the impact of newly diagnosed DLBCL on primary care and costs of care among elderly patients with DLBCL as compared to Medicare beneficiaries without cancer. Owing to the dearth of research on the impact of DLBCL on primary care and costs, we conducted this study to fill a critical knowledge gap and inform interventions for early disease prevention and chronic disease management among elderly patients with DLBCL. Specifically, our study examined the impact of newly diagnosed DLBCL on visits to PCPs and other medical specialists and costs of common chronic conditions before DLBCL diagnosis, during DLBCL treatment, and at follow-up periods as compared to Medicare beneficiaries without cancer. The study also analyzed the receipt of mammography and bone mineral density testing (BDT) by women with DLBCL during two years after DLBCL diagnosis as compared to women without cancer. We used a comprehensive Social Ecological Model (SEM) to examine individual as well as societal factors that may play a role in the care of DLBCL patients. ${ }^{1,2}$

One of the main goals of the study was to understand how having a DLBCL diagnosis influences a patient's utilization of primary care services in comparison to patients without cancer. DLBCL patients had more visits to PCPs and some specialists as compared to those without any cancer, even after adjusting for intra-personal, inter-personal, healthcare system, and community factors. Surprisingly, even though DLBCL patients had more PCP visits, the rates of mammography and BDT were similar between female DLBCL and non-cancer patients. After controlling for PCP visits, female DLBCL patients were less likely to receive either mammography or BDT as compared to women without cancer, which is concerning as female DLBCL patients are at a greater risk of breast cancer and osteoporosis. The prioritization of 
acute cancer care might have resulted in suboptimal preventive screenings in DLBCL patients. Another important reason for the less-than-ideal receipt of preventive services among DLBCL patients is limited provider and patient time. The providers face the difficulty of integrating many screenings recommended by the USPSTF along with the competing demands of intensive DLBCL treatment. ${ }^{3}$ The patients are also engaged with the tremendous increase in number of diagnostic and therapeutic approaches for DLBCL. Further, 80-100\% of cancer patients report cancer-related fatigue in addition to the treatment side effects. ${ }^{4}$ Amid the burden of DLBCL treatment and its effects, patients may not adhere to guidelines for preventive services. The providers and patients must choose which preventive services will deliver the largest improvement in quality of life and overall survival. Some previous studies have ranked the USPSTF recommended preventive services with regard to their health impact and costeffectiveness. ${ }^{5}$ Although all preventive services are important and should be provided, giving such information on the relative importance of preventive services to providers and patients can assist in deciding where to focus their prevention efforts.

There is also a need for individualized risk-based preventive care of patient based on the treatment received, age of patient, and risk of developing a disease. We did not find a significant relationship of the type of DLBCL treatment such as radiotherapy and stem cell transplant with mammography and BDT. Increasing mammography screening of patients receiving chemotherapy and more BDT of those receiving stem cell transplant can increase the early detection of breast cancer and osteoporosis and hence, reduce the morbidity and mortality from these conditions. Further, women between 70-74 years of age were less likely to have mammography and women above 70 years of age were less likely to receive BDT than women between 66-74 years of age. Continued mammography screening for women aged 70-74 years 
and BDT among women above 70 years of age is also needed, as recommended by the US Preventive Services Task Force (USPSTF) guidelines. Currently, there is a lack of clinical guidelines for preventive care of patients with different types of cancers and treatments. Future development and refinement of such guidelines can further assist in prioritization of specific preventive services depending on the risk of a particular cancer patient.

Our second goal was to examine the differences in visits to provider type and utilization of care for different types of chronic diseases among DLBCL patients over the cancer care trajectory. Although DLBCL diagnosis resulted in more visits to PCPs and some specialists and increased the total cost of chronic conditions, the impact of DLBCL varied as a function of the type of provider specialty and the type of chronic disease. For instance, visits to cardiologists, pulmonologists, and endocrinologists and cost of cardiac conditions increased during the treatment period. The significant increase in visits to endocrinologists and cost of cardiac conditions may be due to chemotherapy with Doxorubicin among DLBCL patients, which can cause significant cardiotoxicity including the development of congestive heart failure and cardiomyopathy in lymphoma patients. ${ }^{6,7}$ Interventions to reduce the long terms costs of DLBCL can be more effective by increasing the preventive care for heart conditions before and during treatment, especially for patients with pre-existing cardiac illnesses. Some primary prevention measures for cardiac illnesses include the use of biomarkers and imaging studies for early detection and administration of dexrazoxane for preventive treatment. ${ }^{62}$ Further, for the 'Oncology Care Model' with bundled payments for cancer patients, ${ }^{8}$ policy makers and researchers should consider the cost of heart conditions while setting benchmarks for the reimbursements of care for DLBCL. 
Although the utilization of care for cardiac conditions increased, the visits to rheumatologists and mental health specialists decreased during treatment and follow-up periods. Further, the cost of arthritis decreased from DLBCL diagnosis to treatment and follow-up periods. DLBCL patients also had lower costs of other conditions such as hypertension, asthma/COPD, mental illness, and diabetes during the baseline and follow-up periods. There was no significant difference in the cost of hyperlipidemia and osteoporosis as compared to noncancer patients. These findings may reflect lower quality of care for these chronic conditions as found in some previous studies. ${ }^{9,10}$ One possible explanation is that patients might be engaged with the sudden increase in treatments for DLBCL and may not have enough time or energy to visit providers for chronic conditions. Currently there is a lack of studies examining this phenomenon among patients with newly diagnosed cancer. Future studies might shed further light on the reasons for poorer quality of care for chronic conditions among cancer patients. Also, the diagnosis and treatment of DLBCL can lead to an increase in mental health conditions such as anxiety, depression, post-traumatic stress disorder, and poorer health status. ${ }^{11-13}$ Even though DLBCL patients in our study had an increased diagnosis of mental health conditions over treatment and follow-up periods, their visits to mental health providers did not change. It is critical to screen elderly DLBCL patients for mental health conditions during and after DLBCL treatment and to refer suitable patients to mental health providers when necessary. Similarly, DLBCL patients are at a greater risk of osteoporosis and fractures. Given the low rate of BDT among elderly women, clinicians and other healthcare providers may consider using an osteoporosis risk assessment too ${ }^{14}$ to analyze the absolute fracture risk of women with DLBCL and to provide BDT and appropriate osteoporosis treatments. Further research on the impact of 
DLBCL on quality of care of these chronic conditions and their association with overall survival is warranted.

In addition to our two main study goals, we also explored the functionality of an ecological model to help us understand the impact of DLBCL over the cancer care trajectory. The use of an ecological model helped us identify additional environmental factors, which were significantly related to the care of DLBCL patients. The racial composition of county was a significant determinant of the visits to PCPs, as DLBCL patients living in counties with a higher percentage of African Americans had less PCP visits. Further, the racial composition of county had a significant interaction with the patient's race on the total costs of chronic conditions. African Americans living in counties with higher prevalence of African Americans had higher total cost of chronic conditions. Those living in the South or West regions as compared to Northeast had more PCP visits but less total cost of chronic conditions. Other significant societal factors included the level of education and health insurance in the county. Medicare beneficiaries with DLBCL living in counties with a lower education level had more PCP visits and higher total cost of chronic conditions. Further, DLBCL patients living in counties with less health insurance had fewer PCP visits. With respect to preventive care, DLBCL patients living in counties with more travel time were less likely to have mammography and those living in counties with higher prevalence of Hispanics were more likely to have BDT. These findings indicate the importance of policy changes aimed at environmental and organizational factors in addition to individual level factors for improving care and reducing costs among DLBCL patients. Given the lack of environmental and organizational variables in many existing studies, it would be valuable for more studies to analyze the contribution of environmental factors to the understanding of primary care and costs among cancer patients. 


\subsection{Study Limitations}

Our study findings should be interpreted in the context of some limitations. First, the study sample included elderly individuals enrolled in fee-for-service Medicare and without Health Maintenance Organization (HMO) enrollment. Hence, the study findings may not be applicable to younger patients, those enrolled in managed care or commercial insurance plans, and those residing in non- Surveillance, Epidemiology, and End Results Program (SEER) regions. In addition, for the second aim, our study was restricted to elderly women with DLBCL between 65-74 years of age for mammography screening and above 65 years of age for BDT. Therefore, the findings from aim 2 cannot be generalized to men and younger women. We used the Health Care Financing Administration (HCFA) codes to determine the physician specialty in this study which might underestimate the provider specialties in the Medicare claims. Further, due to non-enrollment in Medicare Part D by most of our study sample, we could not include the costs of prescription drugs in the costs of chronic conditions in our study.

\subsection{Study Strengths}

Despite some limitations, the current study contributed to the nascent literature on the impact of DLBCL on visits to different provider specialties, preventive care, and the costs of chronic conditions among elderly individuals with newly diagnosed DLBCL as compared to Medicare beneficiaries without cancer. Our study examined the visits to other medical specialists over a three-year time period spanning the cancer diagnosis, treatment, and follow-up periods, which had not been examined in the literature previously. We used the SEER-Medicare database, which is a nationally representative data to examine the care of elderly patients with newly diagnosed cancer. Since Medicare is the primary insurance payer for individuals above 65 years of age, SEER-Medicare dataset provides the most complete information on the use and cost of 
health services by beneficiaries with cancer. Also, a comprehensive SEM framework analyzed the association of various personal and contextual factors with primary care and costs among elderly DLBCL patients. Other strengths of this study include a robust study design with Inverse Probability Treatment Weights (IPTW) adjusted analyses to reduce observed selection bias, a non-cancer comparison group, and time varying diagnosis of chronic conditions. The direct medical cost estimates of specific chronic conditions and DLBCL from our study can be used for resource allocation and health policy design. The phase specific costs of care over 3 years for DLBCL patients can also be used in cost-effectiveness analyses of interventions for disease prevention.

\subsection{Conclusions and Research Implications}

Elderly Medicare beneficiaries with DLBCL were more likely to visit PCPs, cardiologists, pulmonologists, and endocrinologists than non-cancer patients. Treatment adverse effects and more frequent contact with the healthcare system may have led to an increased diagnosis of other chronic conditions, which partially explained more visits to PCPs and some specialists. Interventions to improve care-coordination among PCPs and specialists may need to target the treatment period when coordination is most vulnerable. However, an increased diagnosis of mental health conditions and other chronic conditions did not result in increased visits to mental health specialists and other corresponding provider specialties. Elderly DLBCL patients should be screened for mental health conditions and referred to mental health specialists when necessary. Patients with pre-existing conditions and those receiving chemoimmunotherapy and stem cell transplant need extra attention for the care of chronic conditions. Further research and interventions to improve the quality of care for these conditions among patients with DLBCL are warranted. 
Even though DLBCL patients had more PCP visits, female DLBCL patients were less likely to receive mammography and BDT than women without cancer. Interventions to increase the recommendations for mammography screening and BDT among women with DLBCL are needed. Rates of mammography should especially be increased for elderly women receiving chemo-immunotherapy and BDT for those receiving stem cell transplant. Risk assessment tools for osteoporosis can further help in targeting the use of BDT and treatment of osteoporosis in DLBCL patients. Further, due to the low rate of preventive care among Medicare beneficiaries, future studies should investigate the impact of newly diagnosed cancer on the receipt of other preventive services recommended by the USPSTF. With respect to the cost of care, DLBCL patients had markedly higher total costs due to cancer treatment than Medicare beneficiaries without cancer. The cost of all chronic conditions was only moderately higher among DLBCL patients, and it varied for different types of chronic conditions. The cost of heart conditions was higher while the cost of other common chronic conditions was lower among DLBCL patients than those without cancer. Personalized medicine, through use of biomarkers and imaging studies, for early detection and preventive drug therapies for treatment of cardiac illnesses may reduce the cost of DLBCL patients. It is also critical to examine the long-term cost-effectiveness of increasing chronic disease management in patients with cancer. 


\subsection{References}

1. Sallis JF, Owen N, Fisher EB. Ecological models of health behavior. Health behavior and health education: Theory, research, and practice. 2008;4:465-486.

2. Stokols D. Translating social ecological theory into guidelines for community health promotion. American journal of health promotion. 1996;10(4):282-298.

3. Lowenstein LM, Ouellet JA, Dale W, Fan L, Mohile SG. Preventive care in older cancer survivors. Journal of geriatric oncology. 2015;6(2):85-92.

4. Meneses-Echávez JF, Gonzalez-Jimenez E, Ramírez-Vélez R. Supervised exercise reduces cancer-related fatigue: A systematic review. Journal of physiotherapy. 2015;61(1):3-9.

5. Maciosek MV, Coffield AB, Edwards NM, Flottemesch TJ, Goodman MJ, Solberg LI. Priorities among effective clinical preventive services: Results of a systematic review and analysis. Am J Prev Med. 2006;31(1):52-61.

6. Hershman DL, McBride RB, Eisenberger A, Tsai WY, Grann VR, Jacobson JS. Doxorubicin, cardiac risk factors, and cardiac toxicity in elderly patients with diffuse B-cell non-hodgkin's lymphoma. J Clin Oncol. 2008;26(19):3159-3165. doi: 10.1200/JCO.2007.14.1242 [doi].

7. Vejpongsa P, Yeh ET. Prevention of anthracycline-induced cardiotoxicity: Challenges and opportunities. J Am Coll Cardiol. 2014;64(9):938-945.

8. Mortimer L, Strawbridge L, Lukens E, et al. CMS'oncology care model: Delivering higher value cancer care. Clinical Pharmacology \& Therapeutics. 2017. 
9. Snyder CF, Frick KD, Herbert RJ, et al. Quality of care for comorbid conditions during the transition to survivorship: Differences between cancer survivors and noncancer controls. J Clin Oncol. 2013;31(9):1140-1148. doi: 10.1200/JCO.2012.43.0272 [doi].

10. Earle CC, Neville BA. Under use of necessary care among cancer survivors. Cancer. 2004;101(8):1712-1719.

11. Oerlemans S, Mols F, Nijziel MR, Zijlstra WP, Coebergh JWW, van de Poll-Franse, Lonneke V. The course of anxiety and depression for patients with Hodgkin's lymphoma or diffuse large B cell lymphoma: A longitudinal study of the PROFILES registry. Journal of Cancer Survivorship. 2014;8(4):555-564.

12. Smith SK, Zimmerman S, Williams CS, Preisser JS, Clipp EC. Post-traumatic stress outcomes in non-hodgkin's lymphoma survivors. J Clin Oncol. 2008;26(6):934-941. doi: 10.1200/JCO.2007.12.3414 [doi].

13. Andrykowski MA, Lykins E, Floyd A. Psychological health in cancer survivors. . 2008;24(3):193-201.

14. Lim LS, Hoeksema LJ, Sherin K, ACPM Prevention Practice Committee. Screening for osteoporosis in the adult US population: ACPM position statement on preventive practice. Am J Prev Med. 2009;36(4):366-375. 